\title{
WestVirginiaUniversity
}

THE RESEARCH REPOSITORY @ WVU

Graduate Theses, Dissertations, and Problem Reports

1999

\section{Dual fuel conversion of a direct-injection diesel engine}

Talus Park

West Virginia University

Follow this and additional works at: https://researchrepository.wvu.edu/etd

\section{Recommended Citation}

Park, Talus, "Dual fuel conversion of a direct-injection diesel engine" (1999). Graduate Theses,

Dissertations, and Problem Reports. 953.

https://researchrepository.wvu.edu/etd/953

This Thesis is protected by copyright and/or related rights. It has been brought to you by the The Research Repository @ WVU with permission from the rights-holder(s). You are free to use this Thesis in any way that is permitted by the copyright and related rights legislation that applies to your use. For other uses you must obtain permission from the rights-holder(s) directly, unless additional rights are indicated by a Creative Commons license in the record and/ or on the work itself. This Thesis has been accepted for inclusion in WVU Graduate Theses, Dissertations, and Problem Reports collection by an authorized administrator of The Research Repository @ WVU. For more information, please contact researchrepository@mail.wvu.edu. 


\title{
DUAL FUEL CONVERSION OF A DIRECT INJECTION DIESEL ENGINE
}

by

Talus Park

THESIS

Submitted to the College of Engineering and Mineral Resources at

West Virginia University

in partial fulfillment of the requirements for the degree of

\author{
Master of Science \\ in \\ Mechanical Engineering \\ Nigel N. Clark, Ph. D., Chair \\ Christopher M. Atkinson, Sc. D. \\ Thomas R. Long, Ph. D. \\ Department of Mechanical and Aerospace Engineering \\ Morgantown, West Virginia \\ 1999
}

Keywords: Dual Fuel, Pilot Injection, Diesel, Natural Gas, CNG

Copyright 1999 Talus Park 


\section{Acknowledgements}

First and foremost, I thank Richard Atkinson, the resident electronics guru, for his invaluable guidance and assistance throughout this project. I also extend thanks (excuse the wart) to Dr. Nigel Clark for this research opportunity and for quality advising over the course of this project, and to Dr. Chris Atkinson and Dr. Tom Long for serving on my committee. Many thanks go to Mike Traver who provided much data acquisition assistance, to Tom McDaniel who keeps the Engine Research Center running like a well

oiled machine, and to Wayne Hildebrand for performing the gas chromatograph analysis. I also thank IMPCO Technologies, Inc. for donating the natural gas control valve and the pressure regulator used in this project. Finally, immeasurable gratitude to my wife, Natalie, for supporting me both financially and emotionally, even while pursuing a Master's degree of her own, and to my son, whose imminent arrival provided the kick in the pants I needed to complete this thesis. 


\section{Abstract}

Dual fuel pilot-injected diesel natural gas engines offer significant potential to reduce oxides of nitrogen $\left(\mathrm{NO}_{\mathrm{x}}\right)$ and particulate matter $(\mathrm{PM})$ emissions while maintaining diesel-like efficiency. A 1994 Navistar T444E turbocharger V-8 diesel engine was converted to dual fuel diesel and compressed natural gas (CNG). In an attempt to reduce the overall cost and complexity of conversion, the engine was left completely original, including the diesel fuel injection system. Also, for the sake of simplicity, the method of intake manifold fumigation through an IMPCO, Inc. electronic natural gas control valve was chosen to deliver the CNG. A microprocessor-based electronic control unit was developed to manage the hydraulically-actuated, electronically-controlled unit injectors (HEUI). Pilot injection parameters (start of injection, injection duration, and injection pressure) were varied along with the $\mathrm{CNG}$ flowrate to minimize $\mathrm{NO}_{\mathrm{x}}$ production while still considering hydrocarbon $(\mathrm{HC})$, carbon dioxide $\left(\mathrm{CO}_{2}\right)$, carbon monoxide $(\mathrm{CO})$, and PM limits. Thermal efficiency and diesel fuel replacement ratio were noted as well. Incylinder pressure data was collected and used to calculate run-time combustion parameters such as indicated mean effective pressure (IMEP), heat release rate (HRR) and to observe the ignition delay period. Comparative diesel and dual fuel tests were completed at intermediate load (1500 rpm, $335 \mathrm{~N}-\mathrm{m})$ and high load (1500 rpm, $580 \mathrm{~N}-\mathrm{m})$ operating conditions to determine the emissions benefits of the dual fuel conversion. Compared to diesel operation, optimized dual fuel operation at intermediate load produced a $32 \%$ decrease in $\mathrm{NO}_{\mathrm{x}}$ and a $57 \%$ decrease in PM. Dual fuel operation at high load produced a $19 \%$ decrease in $\mathrm{NO}_{\mathrm{x}}$ and a $72 \%$ decrease in PM. However, these reductions came with an increase in $\mathrm{HC}$ and $\mathrm{CO}$ emissions over standard diesel operation. 


\section{Table of Contents}

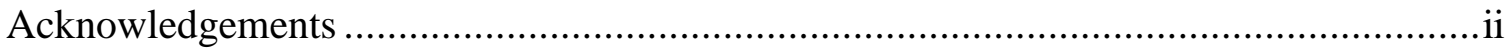

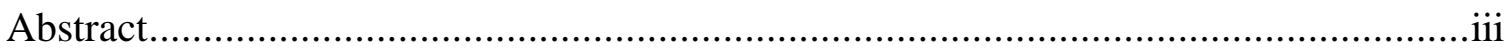

Table of Contents ...........................................................................................

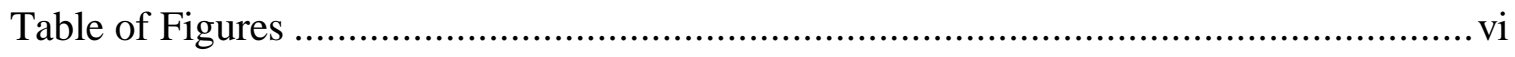

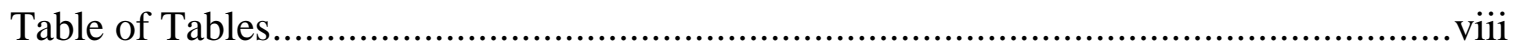

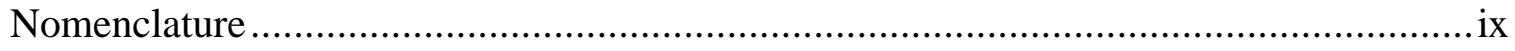

1 INTRODUCTION \& OBJECTIVES ..................................................... 1

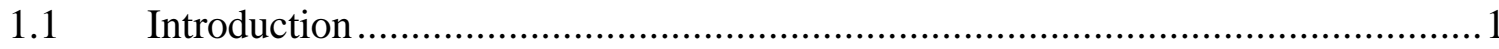

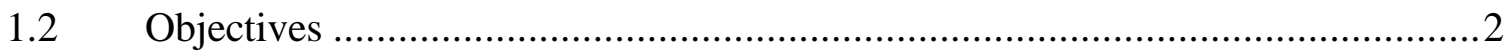

2 LITERATURE REVIEW .......................................................................

3 EXPERIMENTAL SETUP ...................................................................

3.1 Engine, Conversion \& Instrumentation .................................................. 9

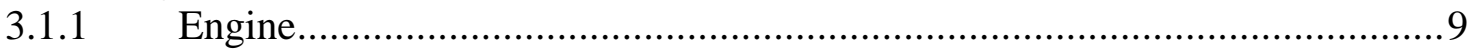

3.1.2 Natural Gas Delivery ................................................................ 10

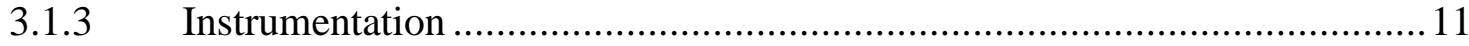

3.1.4 Electronic Control Unit ................................................................. 16

3.2 Testing Facility \& Equipment ................................................................ 19

3.2.1 Analyzers \& Dilution Tunnel .......................................................... 19

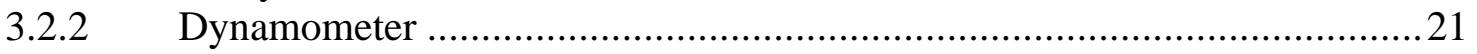

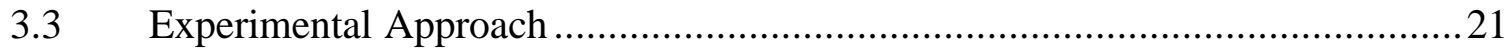

3.3.1 Analysis of In-Cylinder Pressure Data................................................... 23

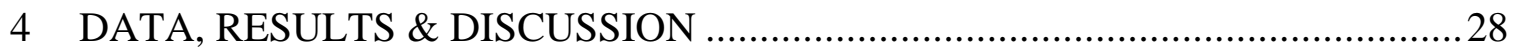

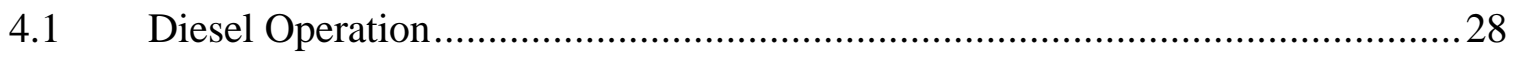

4.1.1 Diesel Steady State Test Data Using EEC-IV .........................................28

4.1.2 Diesel Sweep Data Using WVU-ECU ............................................ 34

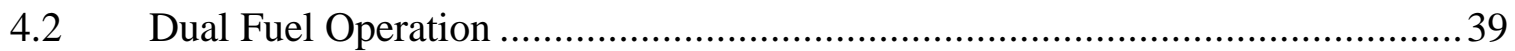

4.2.1 Dual Fuel Sweep Data Using WVU-ECU.......................................... 39 
4.2.2 Dual Fuel Steady State Test Data Using WVU-ECU

4.3 Comparison of Diesel and Dual Fuel Operation .........................................52

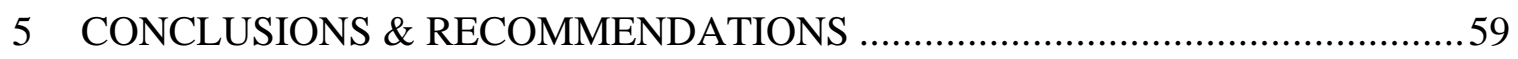

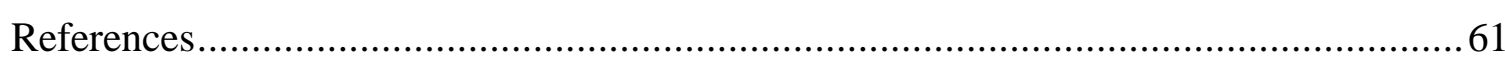

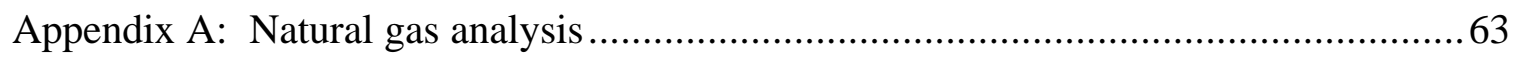

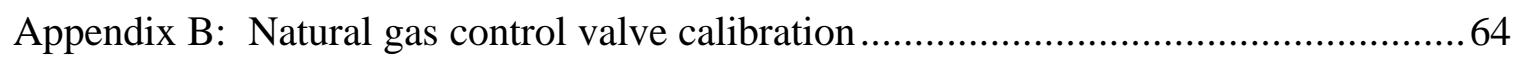

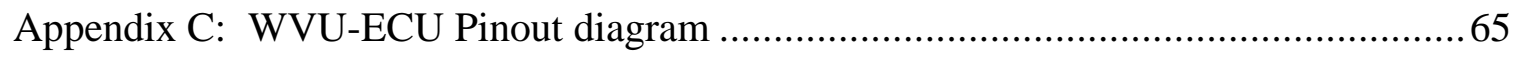

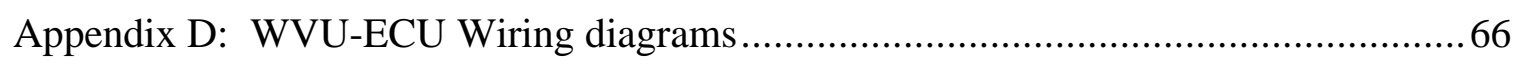

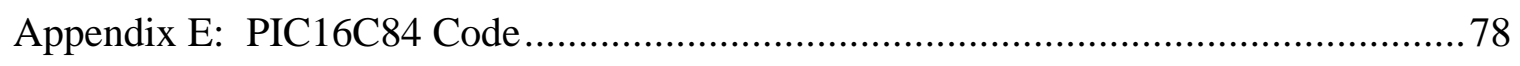

Appendix F: BASIC Stamp II code................................................................ 90 


\section{Table of Figures}

Figure 1: Schematic of the natural gas delivery system ...................................... 11

Figure 2: Calibration of Navistar temperature and pressure sensors ........................... 13

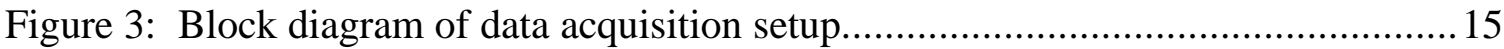

Figure 4: Experimental electronic control system setup ............................................. 17

Figure 5: Simplified block diagram of WVU-ECU ................................................... 19

Figure 6: $\log \mathrm{P}$ vs Log $\mathrm{V}$ diagram for 2 consecutive motoring cycles to verify proper phasing

Figure 7: Example diesel-only heat release rate diagram with combustion stages labeled

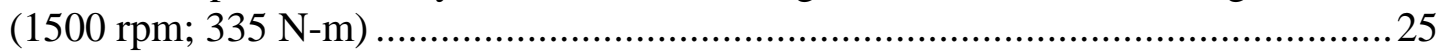

Figure 8: In-cylinder pressure vs. CA for diesel EEC-IV (1500 rpm; $335 \mathrm{~N}-\mathrm{m})$............30

Figure 9: In-cylinder pressure vs. CA for diesel EEC-IV (1500 rpm; $580 \mathrm{~N}-\mathrm{m})$............30

Figure 10: P-V diagram for diesel EEC-IV (1500 rpm; $335 \mathrm{~N}-\mathrm{m})$.............................. 31

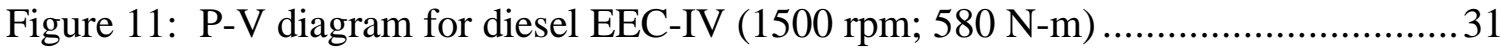

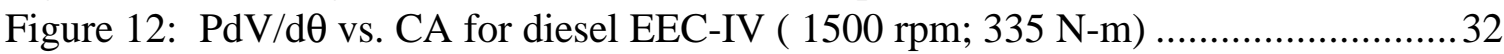

Figure 13: PdV/d $\theta$ vs. CA for diesel EEC-IV (1500 rpm; $580 \mathrm{~N}-\mathrm{m})$........................... 32

Figure 14: HRR \& in-cylinder pressure for diesel EEC-IV (1500 rpm; $335 \mathrm{~N}-\mathrm{m})$........33

Figure 15: HRR \& in-cylinder pressure for diesel EEC-IV $(1500 \mathrm{rpm} ; 580 \mathrm{~N}-\mathrm{m})$.........33

Figure 16: Torque vs. FIPW for diesel WVU-ECU (1500 rpm; 6.5 ADV; 10-10.5 MPa

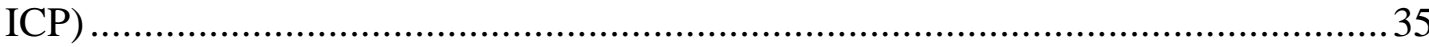

Figure 17: Emissions vs. FIPW for diesel WVU-ECU (1500 rpm; 6.5 ADV; 10-10.5

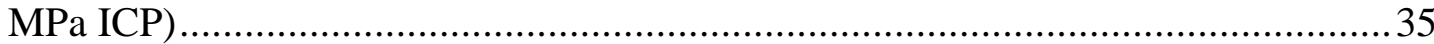

Figure 18: Thermal efficiency vs. FIPW for diesel WVU-ECU (1500 rpm; $6.5^{\circ}$ ADV;

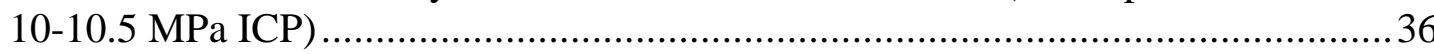

Figure 19: Emissions vs. ADV for diesel WVU-ECU (1500 rpm; $900 \mu$ s FIPW; 10-10.5

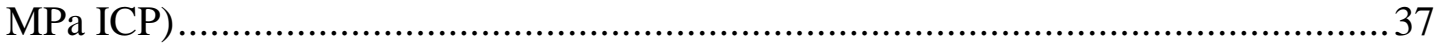

Figure 20: Emissions vs. ADV for diesel WVU-ECU (1500 rpm; $2373 \mu$ s FIPW; 10-10.5

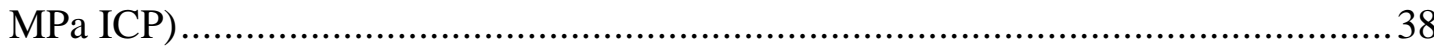

Figure 21: Thermal Efficiency vs. ADV for diesel WVU-ECU (1500 rpm; 10-10.5 MPa

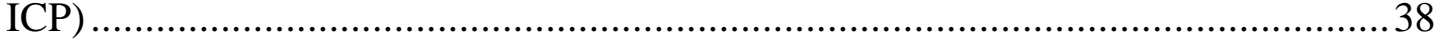

Figure 22: Dual fuel emissions vs. FIPW (1500 rpm; $335 \mathrm{~N}-\mathrm{m} ; 6.5^{\circ} \mathrm{BTDC} ; 11 \mathrm{MPa}$

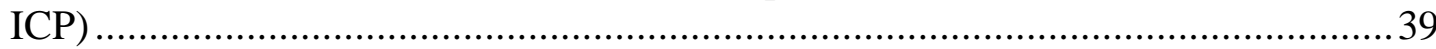

Figure 23: Dual fuel emissions vs. FIPW (1500 rpm; $580 \mathrm{~N}-\mathrm{m} ; 6.5^{\circ} \mathrm{BTDC} ; 11 \mathrm{MPa}$

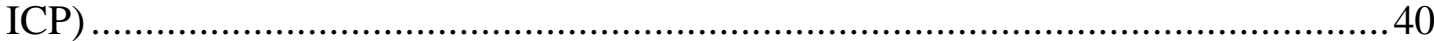

Figure 24: Dual fuel efficiency vs. FIPW (1500 rpm; 335 N-m \& 580 N-m) ............... 40

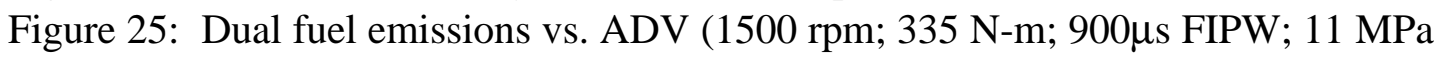

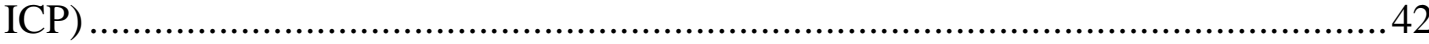

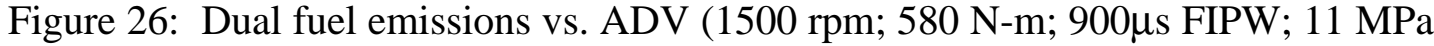

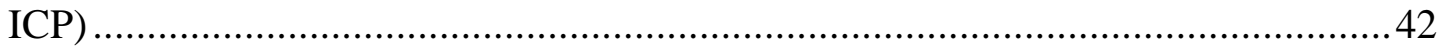

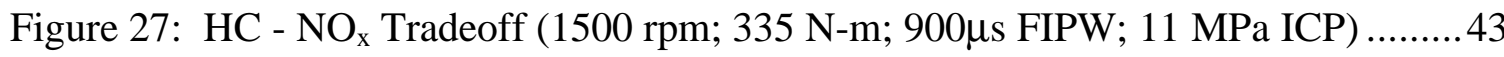

Figure 28: $\mathrm{HC}-\mathrm{NO}_{\mathrm{x}}$ Tradeoff (1500 rpm; $580 \mathrm{~N}-\mathrm{m}$; $900 \mu \mathrm{s}$ FIPW; $11 \mathrm{MPa}$ ICP) .........43

Figure 29: Dual fuel efficiency vs. ADV (1500 rpm; $335 \mathrm{~N}-\mathrm{m} \& 580 \mathrm{~N}-\mathrm{m}) \ldots \ldots \ldots \ldots \ldots . . . . . .44$

Figure 30: Dual fuel emissions vs. ICP (1500 rpm; $\left.335 \mathrm{~N}-\mathrm{m} ; 4.75^{\circ} \mathrm{BTDC}\right)$................45

Figure 31: Dual fuel emissions vs. ICP (1500 rpm; $\left.580 \mathrm{~N}-\mathrm{m} ; 2.5^{\circ} \mathrm{BTDC}\right)$..................45 
Figure 32: Dual fuel efficiency vs. ICP (1500 rpm; 335 N-m \& 580 N-m) ..................46

Figure 33: Dual fuel in-cylinder pressure vs. CA (1500 rpm; $335 \mathrm{~N}-\mathrm{m})$........................48

Figure 34: Dual fuel in-cylinder pressure vs. CA (1500 rpm; $580 \mathrm{~N}-\mathrm{m})$.......................49

Figure 35: Dual fuel P-V diagram (1500 rpm; $335 \mathrm{~N}-\mathrm{m})$........................................49

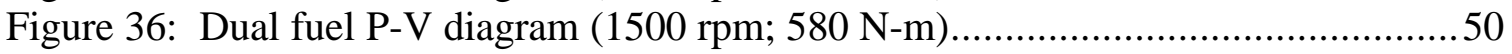

Figure 37: Dual fuel PdV/d $\theta$ vs. CA (1500 rpm; $335 \mathrm{~N}-\mathrm{m})$.........................................50

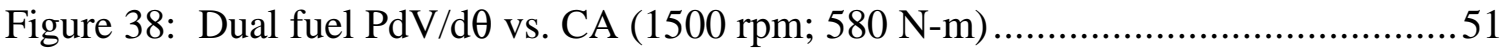

Figure 39: Dual fuel in-cylinder pressure \& HRR vs. CA (1500 rpm; $335 \mathrm{~N}-\mathrm{m})$..........51

Figure 40: Dual fuel in-cylinder pressure \& HRR vs. CA (1500 rpm; $580 \mathrm{~N}-\mathrm{m})$...........52

Figure 41: Dual fuel and diesel heat release rate comparison $(1500 \mathrm{rpm} ; 335 \mathrm{~N}-\mathrm{m})$......55

Figure 42: Dual fuel and diesel heat release rate comparison $(1500 \mathrm{rpm} ; 580 \mathrm{~N}-\mathrm{m})$......55

Figure 43: Dual fuel and diesel in-cylinder pressure and IMEPg comparison (1500 rpm; $335 \mathrm{~N}-\mathrm{m})$

Figure 44: Dual fuel and diesel in-cylinder pressure and IMEPg comparison (1500 rpm; $580 \mathrm{~N}-\mathrm{m})$ .57

Figure 45: Dual fuel and diesel $\mathrm{PdV} / \mathrm{d} \theta$ comparison $(1500 \mathrm{rpm} ; 335 \mathrm{~N}-\mathrm{m})$..................58

Figure 46: Dual fuel and diesel PdV/d $\theta$ comparison $(1500 \mathrm{rpm} ; 580 \mathrm{~N}-\mathrm{m})$...................58

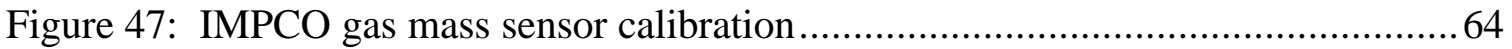

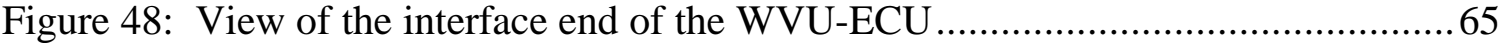




\section{Table of Tables}

Table 1: Engine Specifications for 1994 Navistar T444E model A190F.........................9

Table 2: Pressure measurement hardware specifications ...................................... 12

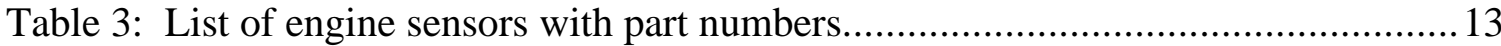

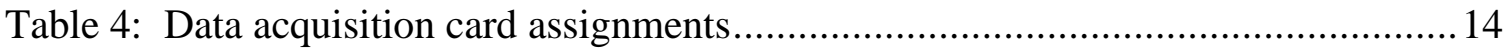

Table 5: Diesel and dual fuel test table................................................................ 23

Table 6: Averaged diesel emissions with EEC-IV (335 N-m \& $580 \mathrm{~N}-\mathrm{m}$ at $1500 \mathrm{rpm}$ ) .28

Table 7: COV(IMEPg) \& ignition delay for diesel with EEC-IV ...............................29

Table 8: Peak in-cylinder pressure for different ICP (335 N-m \& $580 \mathrm{~N}-\mathrm{m})$................46

Table 9: Dual fuel optimized FIPW, ADV, ICP (335 N-m \& 580 N-m) ......................46

Table 10: Averaged DF emissions (335 N-m \& 580 N-m) .....................................47

Table 11: Gas chromatograph data showing \%MHC .................................................47

Table 12: Dual fuel COV(IMEPg) \& ignition delay (335 N-m \& $580 \mathrm{~N}-\mathrm{m})$.................48

Table 13: CNG/Diesel ratios $(335 \mathrm{~N}-\mathrm{m} \& 580 \mathrm{~N}-\mathrm{m})$.................................................52

Table 14: Emissions comparison of DF \& diesel (335 N-m \& $580 \mathrm{~N}-\mathrm{m})$......................53

Table 15: DF \& diesel operation diesel fuel usage (335 N-m \& $580 \mathrm{~N}-\mathrm{m}$ ) ...................53

Table 16: Comparison of diesel and dual fuel thermal efficiency .............................54

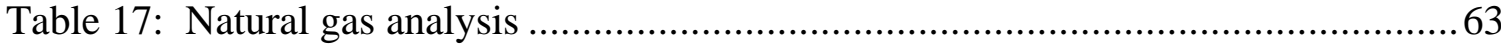

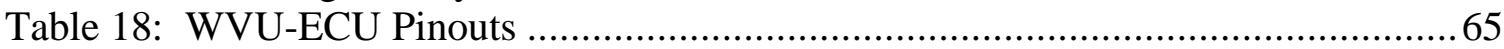




\section{Nomenclature}

\section{Abbreviations and Symbols}

\begin{tabular}{|c|c|}
\hline $\mathrm{ADC}$ & Analog to Digital Converter \\
\hline ADV & Injection Advance \\
\hline APS & Accelerator Pedal Sensor \\
\hline ATDC & After Top Dead Center \\
\hline ATS & Air Temperature Sensor \\
\hline BSFC & Brake Specific Fuel Consumption \\
\hline BTDC & Before Top Dead Center \\
\hline BTU & British Thermal Unit \\
\hline CA & Crank Angle \\
\hline CMP & Camshaft Position \\
\hline $\mathrm{CNG}$ & Compressed Natural Gas \\
\hline $\mathrm{CO}$ & Carbon Monoxide \\
\hline $\mathrm{CO}_{2}$ & Carbon Dioxide \\
\hline $\mathrm{COV}$ & Coefficient of Variation \\
\hline D2 & Number 2 Diesel (light diesel) \\
\hline DAS & Data Acquisition System \\
\hline DF & Dual Fuel \\
\hline DI & Direct Injected \\
\hline ECT & Engine Coolant Temperature \\
\hline ECU & Electronic Control Unit \\
\hline EEC-IV & Ford Motor Company electronic control unit \\
\hline EGR & Exhaust Gas Recirculation \\
\hline EOI & End Of Injection \\
\hline EOP & Engine Oil Pressure \\
\hline EOT & Engine Oil Temperature \\
\hline FID & Flame Ionization Detector \\
\hline FIPW & Fuel Injection Pulse Width \\
\hline GC & Gas Chromatograph \\
\hline $\mathrm{HC}$ & Hydrocarbon \\
\hline HEUI & Hydraulically-Actuated Electronically-Controlled Unit Injection \\
\hline HRR & Heat Release Rate \\
\hline $\mathrm{Hz}$ & Hertz \\
\hline ICP & Injection Control Pressure \\
\hline ICPR & Injection Control Pressure Regulator \\
\hline IDM & Injector Drive Module \\
\hline IMEP & Indicated Mean Effective Pressure \\
\hline IMEPg & Gross Indicated Mean Effective Pressure \\
\hline $\log$ & Logarithm \\
\hline LPG & Liquefied Petroleum Gas \\
\hline MAP & Manifold Absolute Pressure \\
\hline NMHC & Non Methane Hydrocarbons \\
\hline
\end{tabular}




$\begin{array}{ll}\mathrm{NO}_{x} & \text { Oxides of Nitrogen } \\ \mathrm{P} & \text { Pressure } \\ \text { PID } & \text { Proportional Integral Differential } \\ \text { PING } & \text { Pilot-Injected Natural Gas } \\ \text { PM } & \text { Particulate Matter } \\ \text { PWM } & \text { Pulse Width Modulation } \\ \text { R } & \text { Universal Gas Constant } \\ \text { RPM } & \text { Revolutions Per Minute } \\ \text { SCFM } & \text { Standard Cubic Feet Per Minute } \\ \text { SI } & \text { Spark-Ignited } \\ \text { SOI } & \text { Start Of Injection } \\ \text { TDC } & \text { Top Dead Center } \\ \text { THC } & \text { Total Hydrocarbons } \\ \text { V } & \text { Volume } \\ \text { VPM } & \text { Vehicle Personality Module } \\ \text { WVU } & \text { West Virginia University }\end{array}$




\section{Introduction \& Objectives}

\subsection{Introduction}

With increasing government restriction of tailpipe emissions from vehicles powered by internal combustion engines and a growing concern over the use of imported oil, alternative fuels have gained popularity. Natural gas has become a widely used alternative fuel for a variety of reasons including ready availability and its low emissions potential. Spark-ignited natural gas engines are common but suffer lowered efficiency due to pumping losses from intake throttling and therefore, cannot match the thermal efficiency of a diesel engine. Existing diesel engines may be converted readily to operate primarily on natural gas, using pilot injection of diesel to achieve ignition. However, many initial attempts to implement this technology were crude, leading to excessive diesel usage, over fueling to achieve acceptable power levels, and unacceptably high emissions. Pilot-injected natural gas (PING) engines show significant potential to rival diesel engines in their part and full load efficiency. While diesel engines have significant advantages over spark-ignited (SI) natural gas engines in terms of fuel efficiency, they cannot presently match the low emissions benefits of dedicated SI engines, particularly in their emissions of particulate matter $(\mathrm{PM})$ and oxides of nitrogen $\left(\mathrm{NO}_{\mathrm{x}}\right)$. This research is aimed at reducing the emissions from diesel engines through dual fuel conversion and the adoption of advanced engine control strategies, while maintaining diesel-like thermal efficiency and minimizing diesel fuel consumption. 


\subsection{Objectives}

The overall objective of this project was to produce an engine control strategy to facilitate engine operation that was efficient, reduced exhaust emissions, and minimized diesel fuel usage. In order to fulfill this goal three steps were taken: First, complete control of all engine parameters had to be obtained to allow maximum flexibility in developing an engine control strategy. This required replacing the stock engine control unit with one that offered the advanced control needed. Since no such engine controller was commercially available, one was built. Secondly, a natural gas delivery system was designed and fitted to the engine. An attempt was made to keep the conversion as simple and inexpensive as possible in order to make this technology more appealing to industry. Low cost, off-the-shelf products were used wherever possible with minimal modification to the engine's stock configuration. Finally, the engine was comparison tested while operating in both diesel-only and dual fuel mode to verify completion of the overall objective. 


\section{Literature Review}

Pilot-injected dual fuel engines are internal combustion engines designed or converted to run primarily on a gaseous air-fuel mixture. This homogeneous mixture is drawn into the cylinder on the intake stroke and deliberately ignited slightly before top dead center on the compression stroke by a small amount of diesel fuel injected into the cylinder. Because there is premixing of the primary fuel with air before it enters the cylinder, the combustion process in dual fuel engines is similar to SI engines. However, since dual fuel engines rely on the autoignition of the pilot diesel fuel, then they also have some of the properties of compression ignition engines [1]*.

Dual fuel engines can use nearly any type of gaseous fuel such as propane, compressed natural gas (CNG), low BTU wood gas, and hydrogen gas as well as liquefied petroleum gas (LPG). The use of these fuels is desirable because they provide a means to increase domestic energy use, have the potential to reduce emissions, and in some cases offer significant fuel cost savings $[2,3,4,5,6]$. A study found that dual fuel engine conversions cost less than $\$ 1000$ per ton of $\mathrm{NO}_{\mathrm{x}}$ eliminated, which is much less than the cost of some existing measures such as exotic alternative compression ignition fuels and catalyst exhaust after-treatment [1]. Of all the options available, CNG is the most widely used in dual fuel applications. This is mainly because, of the fuels listed above, only CNG offers a fuel cost savings that can justify the increased cost of operation and the initial cost of conversion [7]. Compressed natural gas is highly knock resistant with a research octane number of 120 to 130 which makes it ideal for use as the homogeneous charge fuel in high compression diesel engines [1]. In addition, many

\footnotetext{
* Numbers in brackets denote references listed at the end of the document.
} 
years of proven use in reciprocating engines makes CNG the preferred choice for a dual fuel engine [8].

There are many advantages that dual fuel engines have over their dedicated diesel and spark-ignited counterparts. Most dual fuel engines can operate on gaseous fuel with diesel pilot or on diesel fuel alone. This makes dual fuel engines particularly attractive in vehicular applications where range is a concern because of a lack of CNG refueling facilities. Another advantage is that an existing diesel engine can be converted to dual fuel with relative ease as opposed to converting a diesel engine to spark-ignited CNG operation. The original cylinder head can be used and the compression ratio can be retained because of CNG's good antiknock characteristics.

Under certain operating conditions, dual fuel engines are capable of achieving thermal efficiencies equal to that of dedicated diesel engines and greater than that of spark-ignited engines. Two factors make dual fuel engine efficiency superior to sparkignited. First, since dual fuel engines are almost never throttled, pumping losses are reduced to a minimum [1]. Second, when the pilot fuel is sprayed into the combustion chamber and autoignition occurs, many individual ignition sources are created, allowing for more complete and rapid combustion of the CNG-air mixture than with a single spark plug [9]. One efficiency problem with dual fuel engine conversions is the valve overlap in many diesel engines. In most diesel engines, the intake valves are opened before the exhaust valves have closed, allowing some of the intake air to escape out through the exhaust which promotes good exhaust scavenging [1]. This is perfectly acceptable in a diesel engine because the fuel does not enter the cylinder with the intake air, but in a dual fuel engine the intake stroke draws in a fuel-air mix and therefore, some fuel escapes out 
the exhaust before it ever has a chance to be burned which compromises thermal efficiency. However, reducing the valve overlap requires a new camshaft profile which would greatly increase the cost of a dual fuel conversion.

The main advantage of dual fuel engines is reduced exhaust emissions, namely oxides of nitrogen $\left(\mathrm{NO}_{\mathrm{x}}\right)$ and particulate matter $(\mathrm{PM})$. However, these emissions reductions are only realized during moderate to high load operating conditions, leaving emissions reduction at light load an area for increased research [1].

Poor combustion at light load brings about losses in thermal efficiency as well as increased emissions. Dual fuel engines are seldom throttled which causes very lean fuelair mixtures at light load. At these light load operating conditions the bulk of the energy released comes from the pilot fuel combustion and any gaseous fuel-air mixture that is entrained in the pilot zone at the time of ignition. The remaining gaseous fuel-air mixture is very lean which slows propagation of the flame front and makes combustion difficult, if not impossible. In order to ensure complete combustion of the gaseous fuel-air mixture, it then becomes necessary to increase the pilot quantity to a greater amount than would be required at high load conditions [10]. Methods have been investigated to improve dual fuel engine performance and emissions at light load. Gebert et al. [11] have tried several methods, including injection timing optimization, skip firing, and turbocharger air bypass. They found that advancing injection timing increased $\mathrm{NO}_{\mathrm{x}}$ production, while retarding the injection timing resulted in reduced $\mathrm{NO}_{\mathrm{x}}$ but increased hydrocarbon (HC), carbon monoxide (CO), and smoke emissions as well as reduced thermal efficiency. Skip firing requires the engine to run on a reduced number of cylinders at light load to bring the fuel-air ratio closer to stoichiometric in the cylinders 
that are used. This was determined to be a very effective method to improve light load operation and even allowed idle operation with a 95\% diesel substitution which would otherwise be impossible. An observed problem with skip firing was rough operation that caused visible shaking of the engine on the dynamometer. At some engine speed and load points it is desirable to redirect the turbocharger boost to decrease the mass of air filling the combustion chamber and therefore increase the equivalence ratio of the mixture. Turbocharger boost bypassing was tried and shown to reduce $\mathrm{HC}$ and $\mathrm{CO}$ emissions. Daisho et al. [3] used hot and cooled exhaust gas recirculation (EGR) to increase the fuel-air ratio and thus improve combustion at light loads. They found that hot EGR at light loads improved the thermal efficiency due to the charge temperature increase. Hot EGR also reduced $\mathrm{NO}_{\mathrm{x}}$ and smoke formation. Cooled EGR gave slightly lower thermal efficiency but provided an even greater $\mathrm{NO}_{\mathrm{x}}$ reduction than hot EGR. Along similar lines, Poonia et al. [6] found that intake air heating improved thermal efficiency at light load. Karim's [12] research of light load dual fuel operation produces some more suggestions for improving performance and emissions. He suggests fuel charge stratification to produce a slightly richer gaseous mixture in the areas surrounding the pilot zone. This would allow a greater percentage of the gaseous mixture to be burned before the lean limit is reached. The use of auxiliary fuels such as hydrogen or gasoline vapor to improve the combustion characteristics of the natural gas is recommended. This, however, adds great complexity to a dual fuel engine. Finally, reducing the engine operational speed is suggested to increase the time that the piston remains near top dead center and therefore increase the time for ignition and flame propagation through the lean fuel-air charge. It has been shown that ignition delay 
increases as the fuel-air mixture becomes leaner and reduced engine speed would minimize the detrimental effects of this delay increase [13].

Dual fuel engine emissions and efficiency can also be improved by modifying the pilot fuel properties. Li et al. [14] found that in a diesel engine, nitrate and peroxide type cetane enhancing additives produced a reduction in $\mathrm{CO}$ at all load ranges and a $\mathrm{NO}_{\mathrm{x}}$ reduction at low load. This information is pertinent to dual fuel operation because, during dual fuel operation at low load, the primary energy source is the pilot fuel. Another investigation of pilot fuel cetane number in dual fuel engines by Gunea et al. [15] also found that the use of pilot fuels with a higher cetane rating led to improved dual fuel engine performance and allowed lower pilot fuel quantities to be used.

Pilot fuel delivery systems for dual fuel engines have been another focus. With research being done to reduce pilot quantities, the limitation of emissions reduction becomes the ability to reduce the flow of the diesel injectors to the miniscule amounts that the new fueling parameters require. Most diesel fuel injection systems have a turndown ratio of about 10 , which means that the injector's minimum flow per injection can only be about $10 \%$ of the maximum flow per injection. For this reason BKM, Inc. has developed the Servojet electro-hydraulic, accumulator type unit fuel injection system that is capable of delivering down to $2 \mathrm{~mm}^{3}$ per injection which represents $2 \%$ of the total energy required to run a 7.6 liter Navistar DT-466 at full load [16]. FEV Motortechnik GmbH \& Company has developed a piezoelectric fuel injection system that allows precise time controlled fuel injection of very small amounts of diesel with minimal cycleto-cycle variations [9]. 
Other research being done in the area of dual fuel engines is computer modeling of the dual fuel combustion process. Liu and Karim [17] developed a multi-zone thermodynamic dual fuel model that can be used to predict autoignition characteristics, the onset of knock, and exhaust emissions as well as the overall performance of a dual fuel engine at both high and low load. Catalyst development is also an area of research that can assist in the progress of dual fuel engines. Since an unthrottled dual fuel engine runs very lean at light load, there are large quantities of excess oxygen in the exhaust. This excess oxygen reduces the ability of a conventional catalyst to reduce the $\mathrm{NO}_{\mathrm{x}}$ emissions. A new type of catalyst has been developed that stores $\mathrm{NO}_{\mathrm{x}}$ during lean burn operation for reduction when the engine is running near stoichiometric. This type of technology may be applicable to a vehicular dual fuel engine that operates alternately at light load and full load [18]. A plasma-assisted catalyst is another method with which $\mathrm{NO}_{\mathrm{x}}$ from a dual fuel engine operating at light load can be reduced. This catalyst uses plasma to oxidize $\mathrm{NO}$ into $\mathrm{NO}_{2}$, which is then reacted with the hydrocarbons with another catalyst. By using the plasma to first oxidize the $\mathrm{NO}$ into $\mathrm{NO}_{2}$, new more durable and more active catalysts can be used to reduce the remaining $\mathrm{NO}_{2}$. Since this technology involves complex exhaust plumbing, it would be feasible only for stationary dual fuel engines [19]. 


\section{Experimental Setup}

\subsection{Engine, Conversion \& Instrumentation}

\subsubsection{Engine}

A 1994 Navistar T444E diesel engine was selected for this project. It is a direct injected medium duty diesel engine that utilizes the Hydraulically-Actuated Electronically-Controlled Unit Injection (HEUI) fuel delivery system. This system is ideal for use in a dual fuel conversion because of its flexibility. Since this system is electronically actuated rather than mechanically, the rate of injection can be controlled independently of engine speed. The start of injection (SOI) and end of injection (EOI) can be controlled regardless of engine speed as well. Another advantage of this system is the ability to readily change the injection pressure by changing the hydraulic oil injection control pressure (ICP) which allows injection pressures between 3,000 and 21,000 psi at any engine speed, including idle.

\begin{tabular}{|l|l|}
\hline Stock Engine Specifications: & \\
\hline Type & Diesel, 4 stroke \\
\hline Cooling System & Water cooled \\
\hline Intake System & Turbocharged, intercooled \\
\hline Fuel System & HEUI \\
\hline Engine Control System & Ford EEC-IV electronic control unit \\
\hline Cylinder Configuration & V8 \\
\hline Displacement & 7.3 liter $(444$ c.i.) \\
\hline Bore and Stroke & $104.39 \mathrm{~mm}$ x 106.20 mm (4.11 in x 4.18 in) \\
\hline Compression Ratio & $17.5: 1$ \\
\hline Valve Train & 2 valves/cylinder, pushrod \\
\hline Firing Order & $1-2-7-3-4-5-6-8$ \\
\hline Rated Power & $142 \mathrm{~kW} @$ @ 2600 rpm (190 hp) \\
\hline Peak Torque & $650 \mathrm{~N}-\mathrm{m} @ 1500 \mathrm{rpm}(485 \mathrm{ft}-\mathrm{lb})$ \\
\hline
\end{tabular}

Table 1: Engine Specifications for 1994 Navistar T444E model A190F 


\subsubsection{Natural Gas Delivery}

One of the goals of this project was to develop a dual fuel conversion that was simple but effective. Intake manifold fumigation was the chosen method to deliver CNG to the engine because of simplicity. The CNG flow was controlled by a simple valve and entered the intake stream at a single point between the intercooler and the intake manifold. No costly gaseous fuel injectors or extensive intake manifold porting were required for this setup. IMPCO Technologies, Inc. is an established manufacturer of CNG delivery systems including regulators and CNG control valves. An IMPCO natural gas control valve (model number GMSZ30) and a low pressure regulator (PEV-1-7) were procured for this project. Both of these parts are used on the Chevrolet $\mathrm{C} / \mathrm{K} \mathrm{Bi}$-Fuel pickup truck.

The IMPCO natural gas control valve is of the servo-actuated throttle plate type that operates at $1.5 \mathrm{kPa}$ over the intake manifold pressure. It is equipped with a hot-wire flow meter with built in temperature correction. This valve makes it possible to set the desired CNG flow by simply supplying a $1000 \mathrm{~Hz}$ to $1600 \mathrm{~Hz}$ signal and read back the actual CNG flow by recording a $508 \mathrm{~Hz}$ to $2724 \mathrm{~Hz}$ signal. Calibration curves provided by IMPCO allowed conversion of the signal from frequency to CNG flow in grams per second.

The IMPCO low pressure regulator is a diaphragm-type, capable of reducing CNG pressures of as high as $1170 \mathrm{kPa}$ down to $1.5 \mathrm{kPa}$, a range which is more than adequate for the $345 \mathrm{kPa}$ house gas supply that was used. The regulator was referenced to the intake manifold pressure to maintain a constant $1.5 \mathrm{kPa}$ pressure differential over the entire range of both vacuum and turbocharger boost. 
These two components along with a solenoid-actuated shut-off valve and some rubber hose comprise the complete natural gas delivery system.

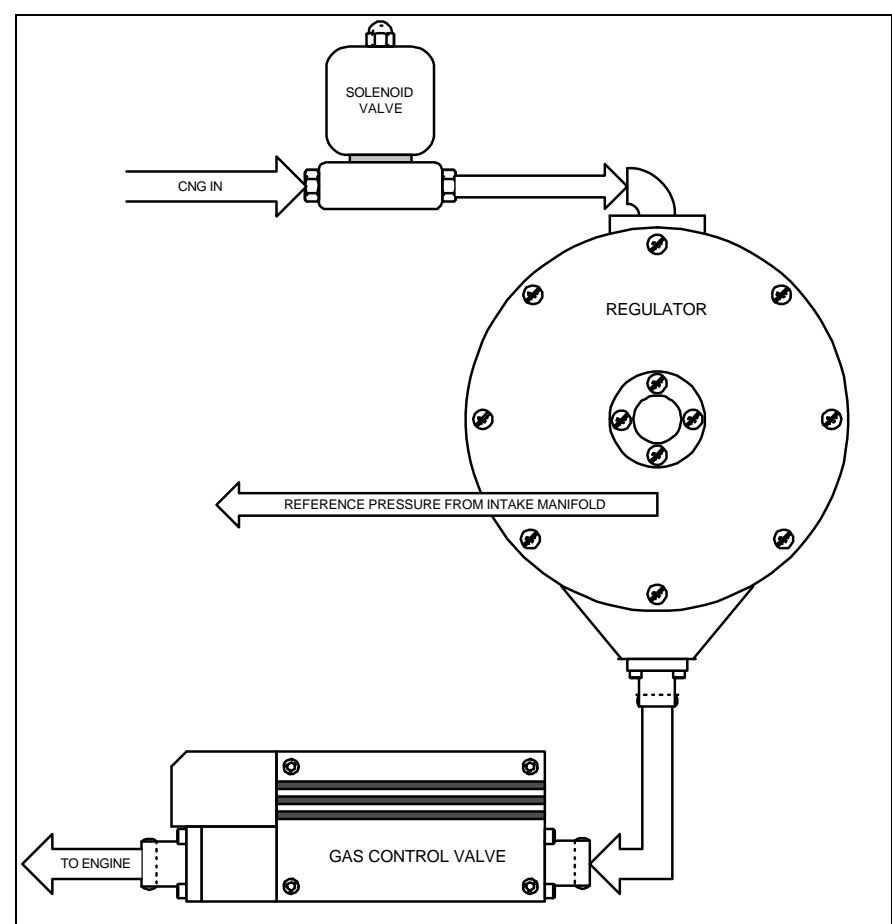

Figure 1: Schematic of the natural gas delivery system

\subsubsection{Instrumentation}

Upon review of the control requirements of this project, it was determined that incylinder pressure data would be necessary for understanding the dual fuel combustion process and for the development of a control scheme for the engine when running in dual fuel mode. A new cylinder head for the Navistar T444E was procured. The glow plug ports of two adjacent, centrally located cylinders were adapted to accept PCB Piezotronics, Inc. quartz piezoelectric in-cylinder pressure transducers. The modified cylinder head was then fitted to the engine. 


\begin{tabular}{|l|l|}
\hline Pressure Sensor Specifications & \\
\hline Model & $145 \mathrm{~A} 01$ \\
\hline Type & Quartz piezoelectric \\
\hline Dynamic Range & $27,580 \mathrm{kPa}(4,000 \mathrm{psi})$ \\
\hline Maximum Static Pressure & $34,475 \mathrm{kPa}(5,000 \mathrm{psi})$ \\
\hline Resolution & $0.69 \mathrm{kPa}(0.01 \mathrm{psi})$ \\
\hline Sensitivity & $0.131 \mathrm{pC} / \mathrm{kPa}(0.9 \mathrm{pC} / \mathrm{psi})$ \\
\hline Operating Temperature Range & $-54^{\circ} \mathrm{C}$ to $350^{\circ} \mathrm{C}\left(-65^{\circ} \mathrm{F}\right.$ to $\left.660^{\circ} \mathrm{F}\right)$ \\
\hline Maximum Flash Temperature & $1650^{\circ} \mathrm{C}\left(3000^{\circ} \mathrm{F}\right)$ \\
\hline Supporting Hardware & \\
\hline In-line charge amplifier & $\mathrm{PCB}$ Model number $422 \mathrm{E} 03$ \\
\hline Charge to voltage converter & $\mathrm{PCB}$ Model number 483A \\
\hline
\end{tabular}

Table 2: Pressure measurement hardware specifications

The angular position of the crankshaft must be known precisely when taking pressure measurements so that the pressure in the cylinder can be related to the position of the piston or the instantaneous cylinder volume during the cycle. A Sumtak optical shaft encoder (model number LEI-037-1024) was purchased to perform this task. It provided 1024 pulses per revolution which allowed for very precise $\left(360^{\circ} / 1024\right.$ or $0.3516^{\circ}$ resolution) measurement of the crankshaft position.

Other engine run-time parameters were recorded to monitor the engine operating conditions. Wherever possible, the stock engine sensors were used for both engine control and for monitoring through the data acquisition system. The sensors were calibrated for conversion of the signals into engineering units. These parameters and the sensors that were used are listed in the following table. 


\begin{tabular}{|l|l|}
\hline Engine Sensors & \\
\hline Engine Oil Pressure (EOP) & Navistar part \# 1813658C2 \\
\hline Engine Oil Temperature (EOT) & Navistar part \# 1814320C1 \\
\hline Engine Coolant Temperature (ECT) & Navistar part \# 1814320C1 \\
\hline Manifold Absolute Pressure (MAP) & Navistar part \# 1807330C1 \\
\hline Cam Position (CMP) & Navistar part \# 1821720C97 \\
\hline Injection Control Pressure (ICP) & Navistar part \# 1812818C2 \\
\hline Air Temperature Sensor (ATS) & Navistar part \# 1814320C1 \\
\hline Exhaust Temperature (pre turbo) & Omega grounded K-type, part \# KQSS-18G-12 \\
\hline Intake Temperature & Omega grounded K-type, part \# KQSS-18G-12 \\
\hline
\end{tabular}

Table 3: List of engine sensors with part numbers

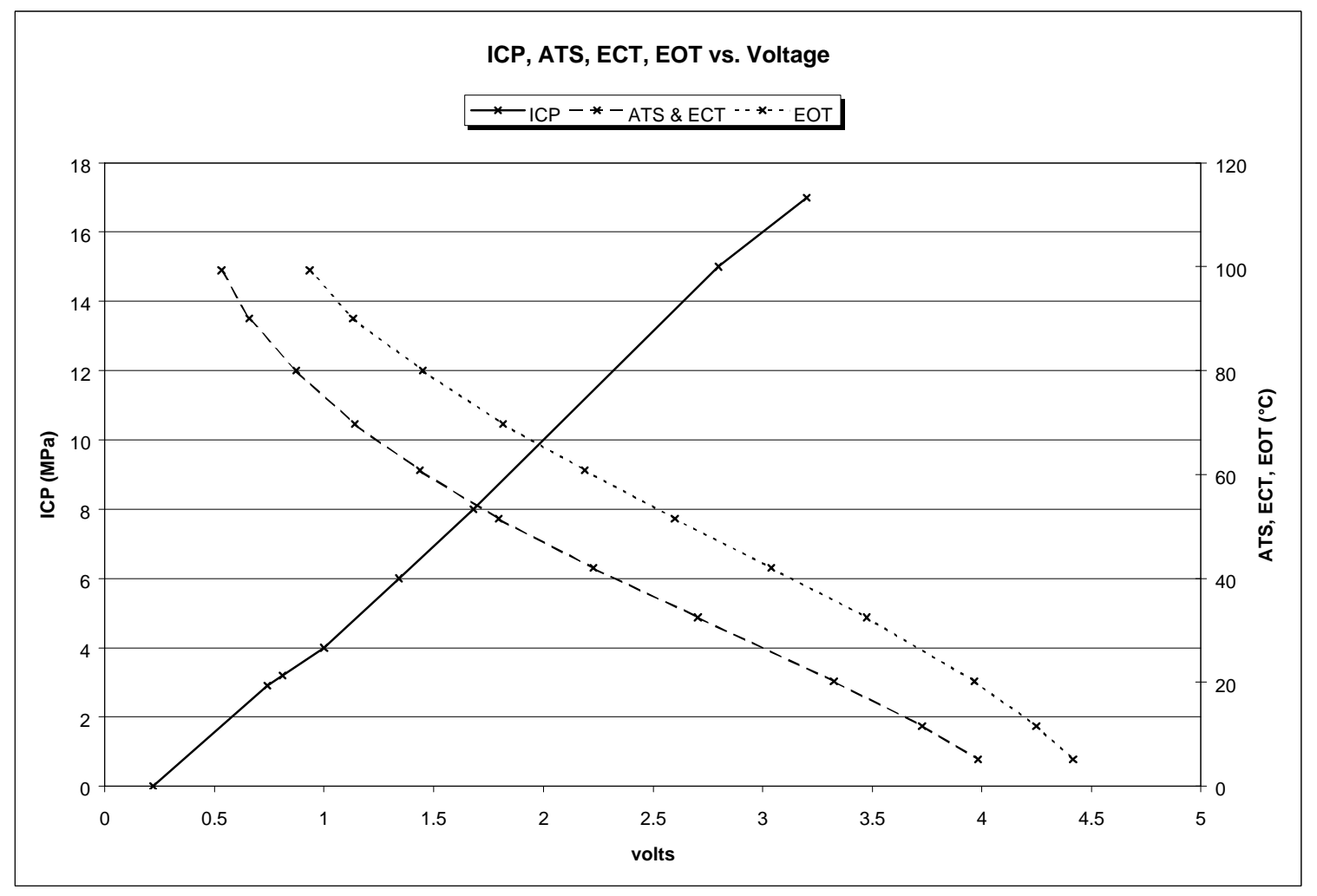

Figure 2: Calibration of Navistar temperature and pressure sensors

All of the signals from the engine including the in-cylinder pressure, crank position and various temperatures and pressure were monitored and stored using a computerized data acquisition system. A Gateway, Inc. 486 personal computer was equipped with a Cyber Research DAS-16 analog to digital data acquisition board for slow speed data acquisition of analog signals. The engine run-time parameters came from a 
Ford-Rotunda EEC-IV breakout box (model number 007-00033) that allowed monitoring of the signals traveling between the engine and ECU without interrupting or affecting engine operation. Emissions, dynamometer, and dilution tunnel data were also collected with the DAS-16. Also installed in the data acquisition computer was a Keithley DAS-58 analog to digital acquisition board capable of storing up to 1 megasample $\left(1.048 \times 10^{6}\right.$ samples) of data for high speed data acquisition of the in-cylinder pressure and crank position, and a Cyber Research CTM-10 counter-timer board for time based signals.

\begin{tabular}{|l|l|}
\hline Cyber Research DAS-16 & Engine Coolant Temperature (ECT) \\
\hline & Engine Oil Temperature (EOT) \\
\hline & Accelerator Pedal Sensor (APS) \\
\hline & Exhaust Temperature \\
\hline & Intake Temperature \\
\hline & Dynamometer Torque \\
\hline & HC Analyzer \\
\hline & $\mathrm{NO}_{\mathrm{x}}$ Analyzer \\
\hline & $\mathrm{CO}_{2}$ Analyzer \\
\hline & $\mathrm{CO}$ Analyzer \\
\hline & Venturi Temperature \\
\hline Cyber Research CTM-10 & Venturi Pressure \\
\hline & Manifold Absolute Pressure (MAP) \\
\hline & Injection Control Pressure (ICP) \\
\hline & Engine Speed \\
\hline Keithley DAS-58 & CNG Flow \\
\hline & In-cylinder Pressure \\
\hline & Crank Position (TDC Location) \\
\hline
\end{tabular}

Table 4: Data acquisition card assignments 


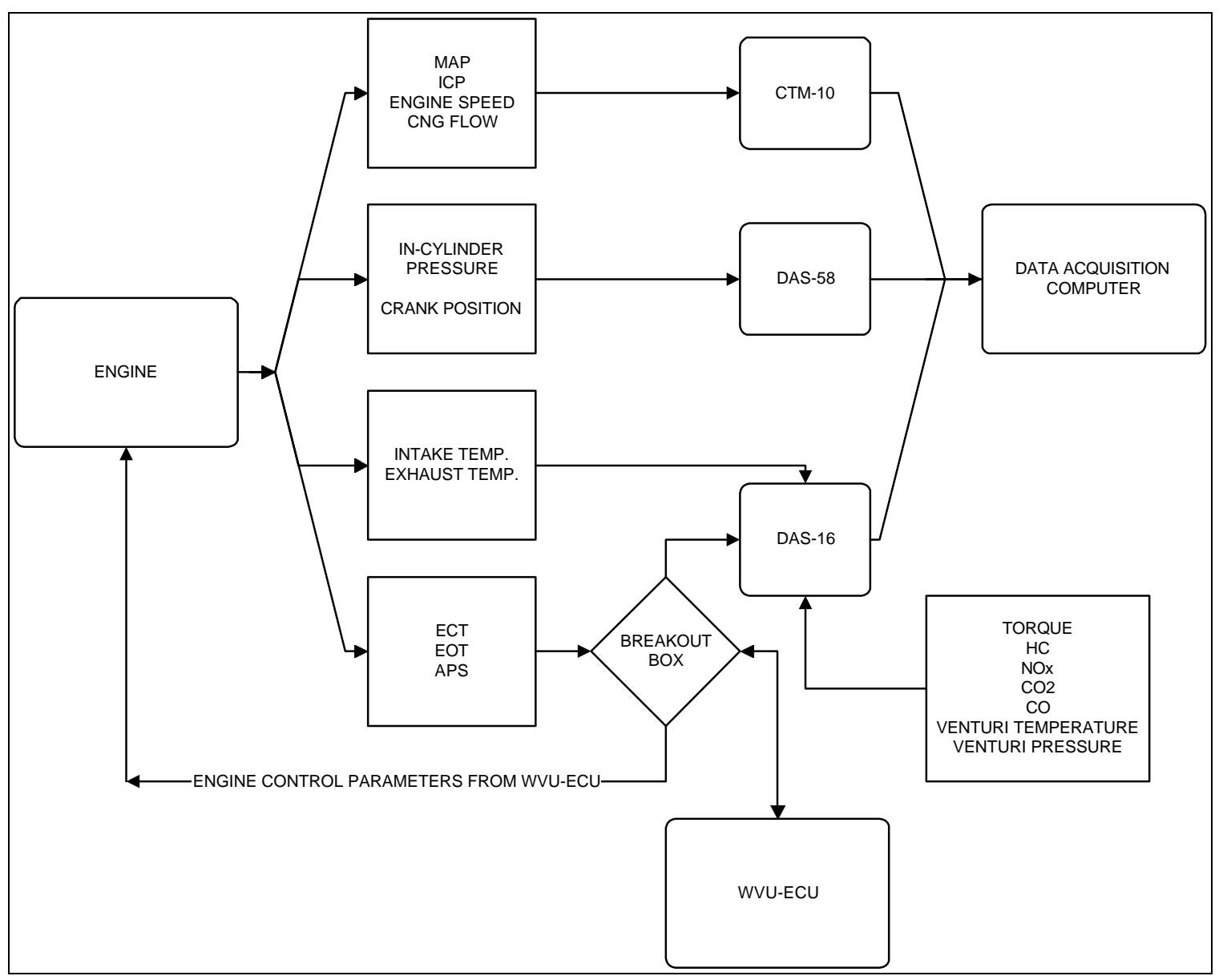

Figure 3: Block diagram of data acquisition setup

A data acquisition program (written by M. Traver, West Virginia University) displayed the signals on the screen in engineering units, compiled the individual signals into a data file, and saved this on the hard drive. Another program (also written by M. Traver and modified by the author) took the data files from each test and performed pressure smoothing and peak finding to extract pertinent information from the pressure traces. The slow speed data from the DAS-16 was also reduced into engineering units, and specific engine performance parameters such as thermal efficiency, indicated mean effective pressure (IMEP), and brake specific emissions were calculated. 


\subsubsection{Electronic Control Unit}

A fully functional electronic control unit (ECU) was designed and built cooperatively by Richard J. Atkinson from West Virginia University, and the author. The ECU was designed to control diesel fuel injection pulse width (FIPW), injection advance (ADV) or start of injection, ICP, and CNG flow. The ECU uses two Microchip PICbased microcontrollers; one to perform initialization of a Silicon Systems 67F687 engine interface peripheral and the other to perform the run-time algorithms. This ECU was developed by reverse engineering the stock Ford EEC-IV controller to determine the required signal protocol and then designing a system to mimic it.

The stock Ford EEC-IV engine control system consisted of three separate units: (1) the EEC-IV engine controller that contains the fueling, timing, injection pressure, and temperature compensation maps; (2) the injector drive module (IDM) that receives the desired fueling in the form of a digital pulsewidth modulated (PWM) signal and the desired injection advance in the form of a cylinder identification signal and fuel injection synchronization pulse; and (3) the vehicle personality module (VPM) which supplies the EEC-IV with information about the vehicle in which it is installed. The signal from the IDM to the fuel injectors was viewed on an oscilloscope and it was determined that this signal would be extremely difficult to reproduce because of its complexity. The fueling signals from the EEC-IV to the IDM, however, were simple square waves and could be easily mimicked and so the IDM was retained for use with the WVU-ECU. The VPM was ignored for this stage of the project. 


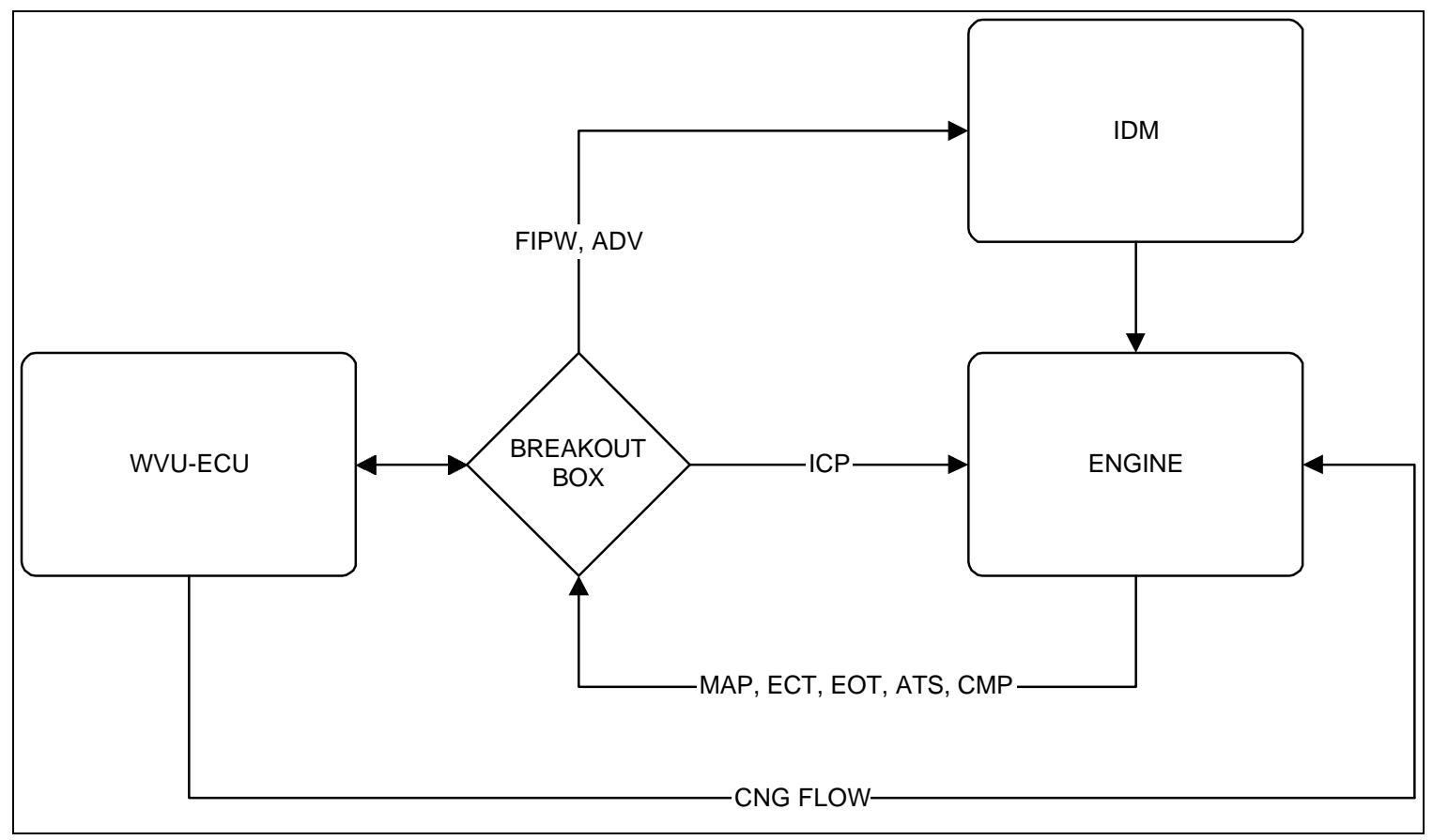

Figure 4: Experimental electronic control system setup

The WVU-ECU was designed to allow manual adjustment of engine control parameters with the engine running. This makes development of the control strategy simpler, since the ECU does not have to be taken off-line to upload new maps or change control algorithms. The ECU has four potentiometers that are used to set FIPW, ADV, ICP, and CNG flow manually. However, at the discretion of the user, any one of these parameters may be controlled automatically through the accelerator pedal sensor (APS) input. The dynamometer control computer uses a proportional-integral-differential (PID) feedback control algorithm that generates a throttle position (rack position on a diesel) signal to maintain a set engine torque. This signal is read by the WVU-ECU as the APS which is then used to vary the selected control parameter to maintain the desired torque. The DC dynamometer described in Section 3.2.2 is used to control the desired speed of the engine. The ECU operation has two stages: the first stage is initialization where the 
Microchip PIC16C84 uploads initialization routines such as cam wheel configuration and PWM signal frequency settings to the Silicon Systems (SSi) 67F687 engine interface peripheral. The second stage is when the Parallax BASIC Stamp II microcontroller takes over control of the SSi67F687 and runs the engine based on the potentiometer settings. The primary function of the SSi67F687 is to act as a communications link between the engine and the microcontroller. It uses a tooth counting scheme - the Navistar T444E has an indexed wheel attached to the camshaft which the SSi67F687 uses to keep track of the exact position of the crank at all times and, in turn, updates the microcontroller. It also takes the diesel FIPW, ADV, ICP, and CNG flow values from the microcontroller and sends them to the appropriate devices as square waves or PWM signals. A Maxim MAX147 12-bit, 8 channel analog to digital converter (ADC) is used to read the analog voltage signals from sensors on the engine such as engine oil temperature (EOT), engine coolant temperature (ECT), intake air temperature (IAT), and accelerator pedal position (APS) and the potentiometer settings and transfer the values to the microcontroller in digital form.

This setup allows the operator to have precise, "on the fly", control of the engine operating parameters by adjusting the potentiometers on the ECU while viewing the exact settings as they appear on the data acquisition computer screen. The goal of this project is to use the ECU as a development tool to optimize engine operation. In the future, when optimized engine control algorithms or lookup tables are generated, this ECU is capable of bypassing the potentiometer inputs and running autonomously from the stored algorithms or tables. 


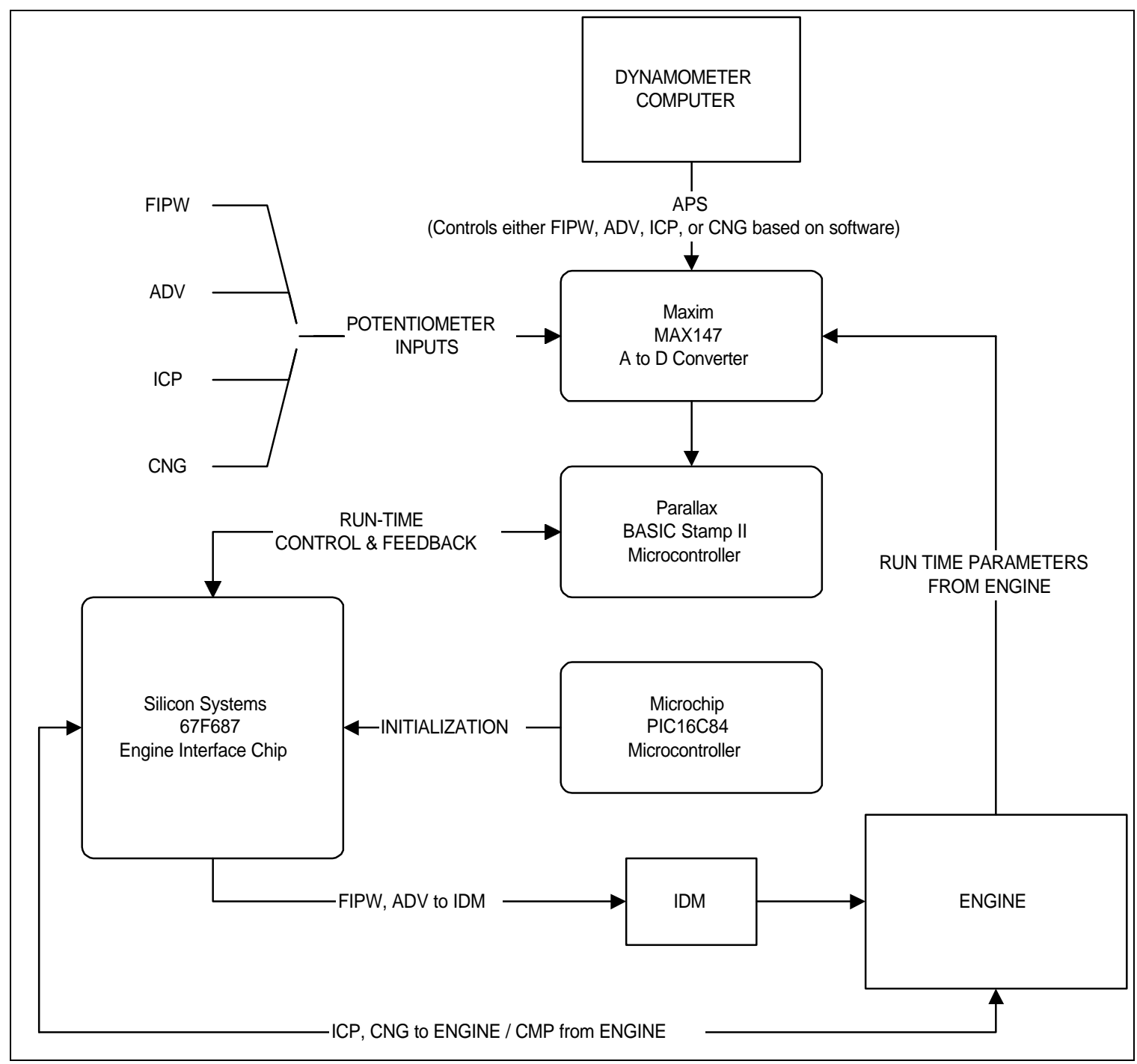

Figure 5: Simplified block diagram of WVU-ECU

\subsection{Testing Facility \& Equipment}

The experiments for this project were completed at the West Virginia University Mechanical \& Aerospace Engineering Department Engine \& Emissions Research Center.

\subsubsection{Analyzers \& Dilution Tunnel}

Analyzers to measure the concentration of $\mathrm{HC}, \mathrm{NO}_{\mathrm{x}}, \mathrm{CO}$, and $\mathrm{CO}_{2}$ (carbon dioxide) in the diluted exhaust were used. The HC analyzer was a flame ionization detector (FID) (model number 402) manufactured by Rosemount Analytical, Inc.. Prior 
to testing, the FID was "peaked" to determine the optimum flame air-fuel ratio for detector sensitivity. The $\mathrm{NO}_{\mathrm{x}}$ analyzer (Rosemount model number 955) uses a chemiluminescent method of detection and was efficiency tested using a Rosemount $\mathrm{NO}_{\mathrm{x}}$ efficiency tester. The $\mathrm{CO}$ (Rosemount model number 880A) and the $\mathrm{CO}_{2}$ analyzer (Beckman Industrial model number 868) are both non-dispersive infrared analyzers. The exhaust samples were drawn from the dilution tunnel and transferred to the analyzers through heated probes and heated lines to prevent condensation of the water vapor and heavy hydrocarbons present in the exhaust gases.

The dilution tunnel was used to mix the exhaust gases with ambient air before sampling to simulate the mixing and reactions that take place when the exhaust leaves the tailpipe of a vehicle. The flow of air and exhaust into the tunnel was prescribed with a set of critical flow venturis. The pressure and temperature at the venturis were measured to calculate the mass flow rate through the tunnel. Prior to testing, the dilution tunnel was tested for leaks by propane injection with a Horiba propane injection kit. During a propane injection, a measured quantity of propane was injected into the tunnel and compared with the amount of propane detected by the hydrocarbon analyzer. The sample plane, where the gases are extracted from the dilution tunnel, is located $4.57 \mathrm{~m}$ from the tunnel opening.

To measure PM, $70 \mathrm{~mm}$ microfiber filters were conditioned at $21^{\circ} \mathrm{C}$ and $50 \%$ relative humidity for at least four hours and then weighed. The filters were then loaded with a continuous $4 \mathrm{scfm}$ flow from the dilution tunnel during a test. After the test, the filters were again conditioned for four hours and weighed. The difference between the loaded and unloaded filter weights was used to calculate the engine's PM production. 
Sample bags were filled with dilute exhaust from the dilution tunnel for further speciation analysis in a Varian model 3600 gas chromatograph (GC). Gas chromatography is useful for determining the concentration of methane (MHC) and nonmethane hydrocarbons (NMHC) in a particular sample as well as complete component identification. The GC draws a 250 microliter sample into a holding area called the loop where it is conditioned to $35^{\circ} \mathrm{C}$. From there it is injected into a $\mathrm{J} \& \mathrm{~W}$ Scientific Co. column that is conditioned at $35^{\circ} \mathrm{C}$ for 2.5 minutes and then raised to $200^{\circ} \mathrm{C}$ at a rate of $20^{\circ} \mathrm{C}$ per minute to slowly drive the gasses out of the column. The gas exiting the column is analyzed using a flame ionization detector (FID). The sample analysis is then compared to a 300 part per million ( $\mathrm{ppm}$ ) methane standard calibration gas to determine the methane concentration in the sample.

\subsubsection{Dynamometer}

The engine was loaded with a transient-capable General Electric DC dynamometer. The dynamometer was controlled with a rack-mounted computer to maintain user specified speeds at all times. Software on the computer was designed to allow the user to input operational set points of engine speed and load. The dynamometer maintained the set speed throughout the test and the software attempted to maintain the specified torque by varying the throttle or rack position (APS value) with a proportional-integraldifferential (PID) control algorithm.

\subsection{Experimental Approach}

In order to determine the benefits of a dual fuel conversion of a production diesel engine, it was necessary to conduct emissions tests. The engine was tested while 
operating on diesel fuel in original condition to compare with the dual fuel emissions collected later. The information gathered from the diesel tests would also be used to find general engine parameter starting points for the dual fuel experimentation to be carried out later. The Navistar T444E was tested at two steady state set points with a speed and load of $1500 \mathrm{rpm}, 335 \mathrm{~N}-\mathrm{m}$ and $1500 \mathrm{rpm}, 580 \mathrm{~N}-\mathrm{m}$. These points were selected because they represented the intermediate speed of the engine at half and near-full load and would most likely represent the operating conditions of the engine while cruising. Exhaust concentrations of $\mathrm{HC}, \mathrm{NO}_{x}, \mathrm{CO}_{2}, \mathrm{CO}$ and $\mathrm{PM}$ filter weights were recorded. Engine operation parameters such as FIPW, ADV, and ICP were also recorded. In-cylinder pressure data was taken to calculate heat release rate (HRR), gross indicated mean effective pressure (IMEPg), and ignition delay. Each four minute set-point was repeated three times.

Once the engine was tested in original condition, the WVU-ECU was fitted to the wiring harness and the engine was tested once again on diesel fuel only. Sweeps of FIPW and ADV at a speed of $1500 \mathrm{rpm}$ were done to characterize the fuel injectors and to determine the emissions effects. PM data was not collected for these tests because the number of filters required to measure PM at each sweep point would have been prohibitively large. The torque curves generated from the FIPW sweeps were used to determine the minimum FIPW for the injectors.

Dual fuel sweeps of diesel FIPW and ADV were carried out with CNG flow controlled with the APS signal to maintain the set torque. The ICP sweeps were executed with FIPW controlled by the APS. For each set of sweeps, the minimum emissions points (with emphasis on $\mathrm{NO}_{\mathrm{x}}$ ) were found and those values were used for the next set of 
sweeps. Through this method, optimum values for diesel FIPW, ADV, ICP, and CNG flow were determined for $1500 \mathrm{rpm}, 335 \mathrm{~N}-\mathrm{m}$ and $1500 \mathrm{rpm}, 580 \mathrm{~N}-\mathrm{m}$.

Finally, the dual fuel steady state tests were run at $1500 \mathrm{rpm}, 335 \mathrm{~N}-\mathrm{m}$ and 1500 rpm, $580 \mathrm{~N}$-m to compare the emissions (including PM), efficiency, diesel fuel usage, and in-cylinder pressure data with the stock, diesel-only tests conducted earlier. These tests were conducted in exactly the same manner as the tests with the engine in stock configuration to maximize the validity of the comparison.

\begin{tabular}{|l|l|}
\hline Diesel Tests & \\
\hline EEC-IV Baseline & $1500 \mathrm{rpm} ; 335 \mathrm{~N}-\mathrm{m} \& 580 \mathrm{~N}-\mathrm{m}$ \\
\hline FIPW Sweep & ADV: $6.5^{\circ} \mathrm{BTDC} ; \mathrm{ICP}: 10.5 \mathrm{MPa}$ \\
\hline ADV Sweep & FIPW: $900 \mu \mathrm{s} \& 2380 \mu \mathrm{s} ;$ ICP $10.5 \mathrm{MPa}$ \\
\hline Dual Fuel Tests & \\
\hline FIPW Sweep & ADV \& ICP constant; APS controlled CNG \\
\hline ADV Sweep & Optimum FIPW; ICP constant; APS controlled CNG \\
\hline ICP Sweep & Optimum ADV; CNG constant; APS controlled FIPW \\
\hline Dual Fuel Steady State Tests & $1500 \mathrm{rpm} ; 335 \mathrm{~N}-\mathrm{m} \& 580 \mathrm{~N}-\mathrm{m}$ \\
\hline
\end{tabular}

Table 5: Diesel and dual fuel test table

\subsubsection{Analysis of In-Cylinder Pressure Data}

Before testing began, proper phasing (location relative to TDC) of the index pulse from the Sumtak had to be verified. The index pulse must be located at exactly TDC or erroneous values derived from pressure data will be generated. Verification is done by evaluating a logarithmic P-V diagram for certain telltale signs of improper phasing. According to Lancaster et al. [20], to ensure proper phasing the compression line on the logarithmic P-V diagram must be without curvature. There also must be no crossover of the compression and expansion lines on the diagram. It can be seen in Figure 7 that neither of these indicators is present. The compression line is straight and there is no crossover of the compression and expansion lines. 


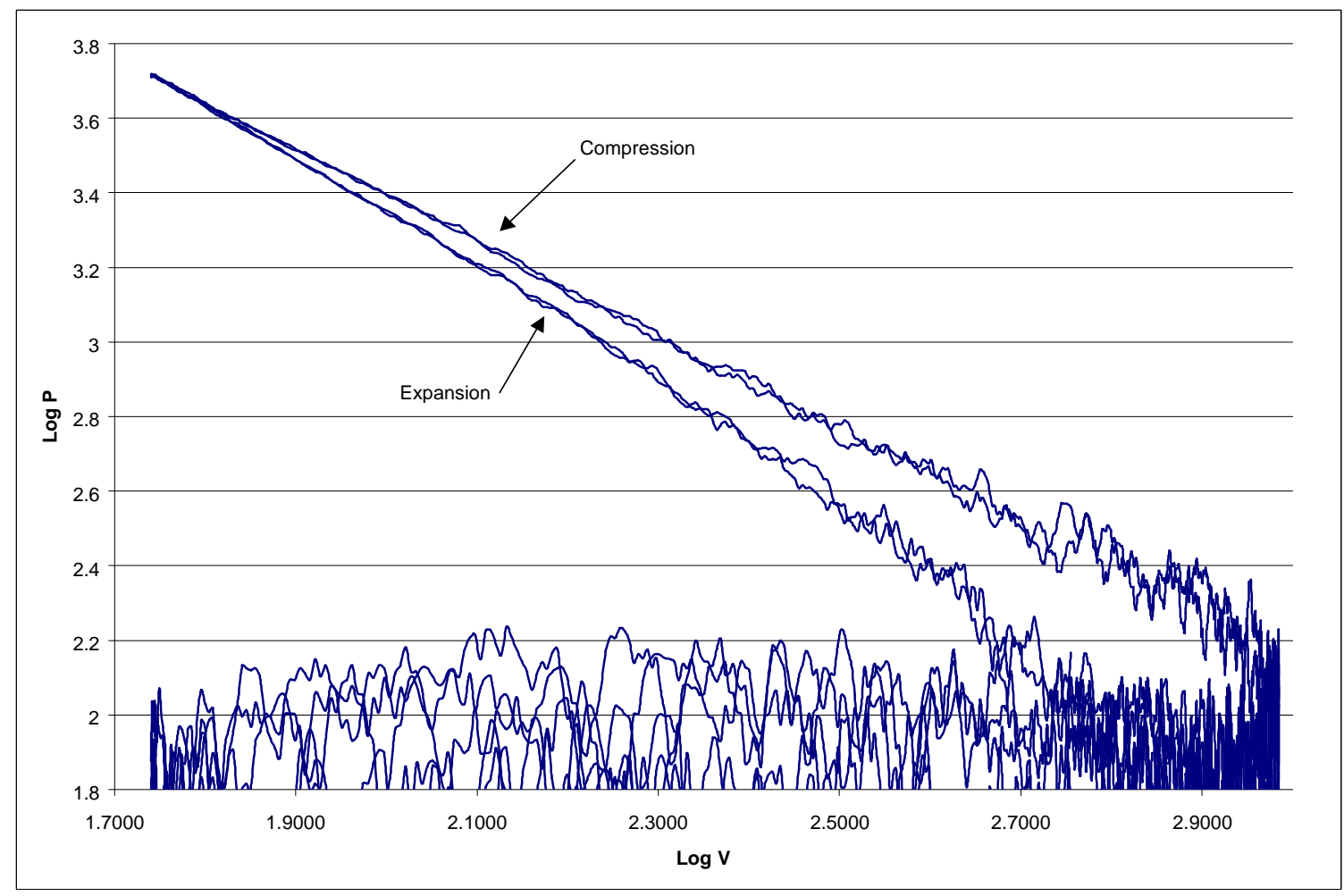

Figure 6: $\log P$ vs Log V diagram for 2 consecutive motoring cycles to verify proper phasing

In-cylinder pressure data versus crank angle can offer valuable insight into the combustion process taking place in the cylinder. Heat release rate (HRR) is an important calculated parameter because from it, many other values such as ignition delay, premixed combustion phase and diffusion combustion phase are derived. It can be seen from Figure 7 that there is significant data scatter during the diffusion combustion phase. This is likely due to the physical characteristics of the pressure transducers. Pressure transducers that operate on the piezoelectric phenomenon can only measure dynamic pressures. Near-static pressures over an extended period of time will produce excessive drift and erratic readings. 


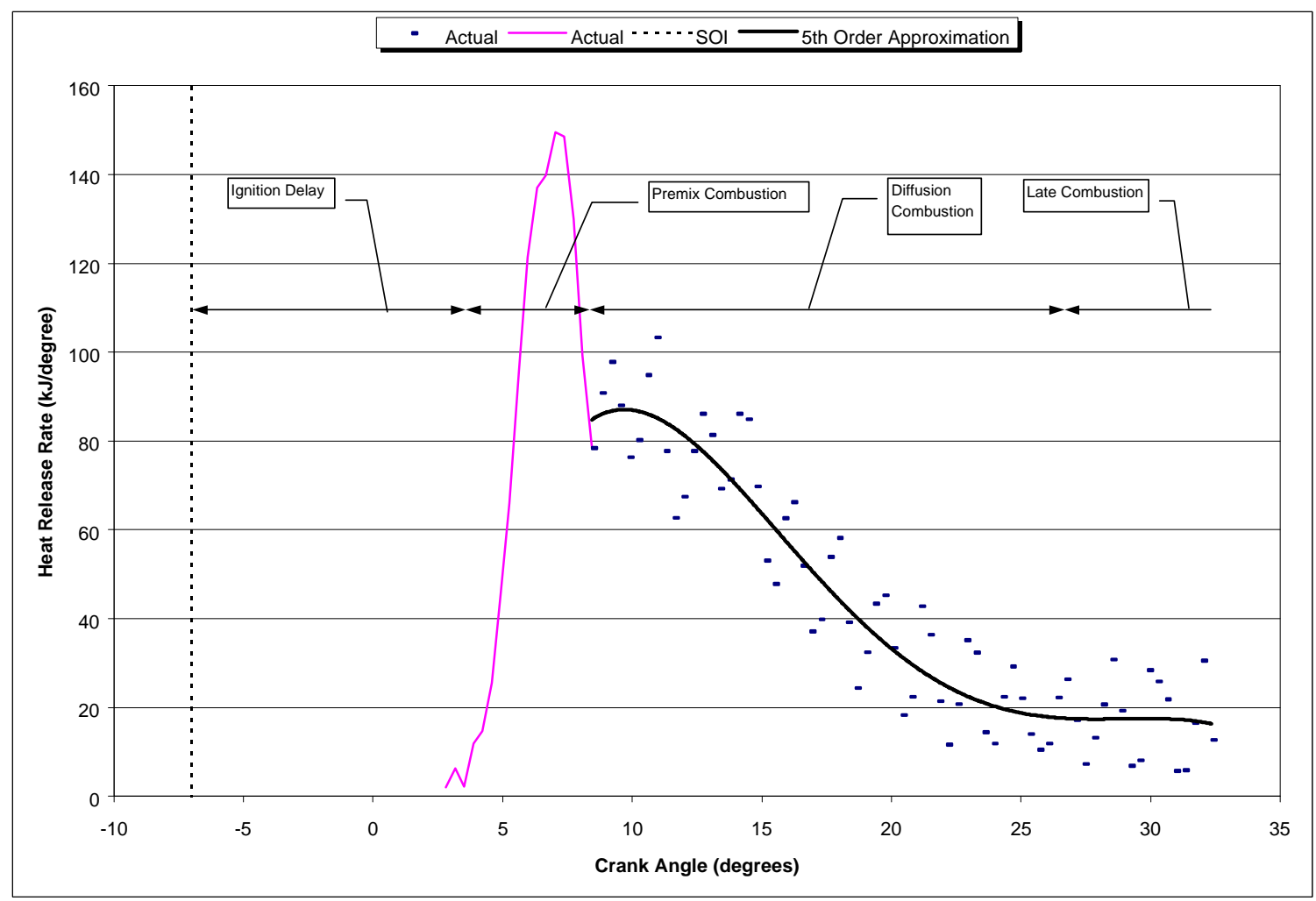

Figure 7: Example diesel-only heat release rate diagram with combustion stages labeled (1500 rpm; $335 \mathrm{~N}-\mathrm{m}$ )

The following derivation of the HRR equation is adapted from Heywood [21]: In a direct injected diesel engine, the combustion chamber is a single open system in which the only flow across the boundary when the valves are closed is the fuel (neglecting crevice flow or blow-by). The first law equation for this system is:

$\frac{d Q}{d t}-p \frac{d V}{d t}+\dot{m}_{f} h_{f}=\frac{d U}{d t}$

Now, if the net heat release rate is assumed to be the difference between the heat released due to combustion (positive) and the heat transfer out of the system (negative) the equation becomes:

$\frac{d Q_{n}}{d t}=\frac{d Q_{c h}}{d t}-\frac{d Q_{h t}}{d t}=p \frac{d V}{d t}+\frac{d U_{s}}{d t}$ 
If the cylinder contents are assumed to be an ideal gas the equation becomes:

$$
\frac{d Q_{n}}{d t}=p \frac{d V}{d t}+m c_{v} \frac{d T}{d t}
$$

Then, from the ideal gas law with constant R:

$\frac{d p}{p}+\frac{d V}{V}=\frac{d T}{T}$

Using the above equation to remove $\mathrm{T}$, net heat release rate is:

$\frac{d Q_{n}}{d t}=\frac{\gamma}{\gamma-1} p \frac{d V}{d t}+\frac{1}{\gamma-1} V \frac{d p}{d t}$

Where $\gamma=c_{p} / c_{v}$ (ratio of specific heats, 1.35 was used for both the diesel and dual fuel analysis)

The indicated mean effective pressure (IMEP) is a useful measure of an engine's ability to do work with respect to engine size. The gross mean effective pressure (IMEPg) is the IMEP with the pumping and frictional losses omitted. The pressure data are related to an incremental change in the cylinder volume and numerical integration is applied from the beginning of the compression stroke $\left(180^{\circ} \mathrm{BTDC}\right)$ to the end of the power stroke ( $\left.180^{\circ} \mathrm{ATDC}\right)$. The IMEPg is computed by dividing the numerically integrated sum by the displacement of one cylinder. Finding the cycle-to-cycle coefficient of variation (COV) of the IMEPg is useful for providing an indication of the relative combustion stability or "smoothness" of the engine. The COV(IMEPg) is the standard deviation in IMEPg divided by the mean IMEPg and is usually expressed as a percentage [21]:

$C O V(I M E P g)=\frac{\sigma_{I M E P g}}{I M E P g} \times 100$ 
The COV(IMEPg) is used to as a standard indication of the cycle-to-cycle variations of the combustion in the engine and is generally considered to have an upper limit of $10 \%$ before the engine becomes undriveable [22].

Although not derived from the in-cylinder pressure data, thermal efficiency which is also known as fuel conversion efficiency, is an important indicator of engine performance. This is defined as the ratio of the work produced by the engine and the amount of fuel energy supplied to the engine [21].

$\eta=\frac{W}{m_{f} Q_{L H V}}$

Where $W=$ work, $\mathrm{m}_{\mathrm{f}}=$ mass of fuel, and $Q_{L H V}=$ lower heating value of the fuel. If the brake specific fuel consumption (BSFC) is used then equation 7 becomes:

$\eta=\frac{1}{B S F C \cdot Q_{L H V}}$

For diesel-only operation the $Q_{L H V}$ was $43.2 \mathrm{MJ} / \mathrm{kg}$, for dual fuel operation the $Q_{L H V}$ was a composite value based on the diesel/natural gas mass ratio and the respective $Q_{L H V}$ of each fuel (43.2 MJ/kg for diesel, $50 \mathrm{MJ} / \mathrm{kg}$ for CNG) [21]. 


\section{Data, Results \& Discussion}

\subsection{Diesel Operation}

\subsubsection{Diesel Steady State Test Data Using EEC-IV}

The emissions results of the two steady state set points (1500 rpm, $335 \mathrm{~N}-\mathrm{m}$ and $1500 \mathrm{rpm}, 580 \mathrm{~N}-\mathrm{m})$ were collected and converted to brake specific values. Exhaust concentrations of THC, $\mathrm{NO}_{\mathrm{x}}, \mathrm{CO}_{2}, \mathrm{CO}$, and $\mathrm{PM}$ were recorded. Table 6 shows the averaged results of these tests.

\begin{tabular}{|c|c|c|c|c|c|c|}
\hline & $\begin{array}{c}\mathrm{PM} \\
(\mathrm{g} / \mathrm{kWh})\end{array}$ & $\begin{array}{c}\mathrm{THC} \\
(\mathrm{g} / \mathrm{kWh})\end{array}$ & $\begin{array}{c}\mathrm{NMHC} \\
(\mathrm{g} / \mathrm{kWh})\end{array}$ & $\begin{array}{c}\mathrm{CO} \\
(\mathrm{g} / \mathrm{kWh})\end{array}$ & $\begin{array}{c}\mathrm{CO}_{2} \\
(\mathrm{~g} / \mathrm{kWh})\end{array}$ & $\begin{array}{c}\mathrm{NO}_{\mathrm{x}} \\
(\mathrm{g} / \mathrm{kWh})\end{array}$ \\
\hline $335 \mathrm{~N}-\mathrm{m}$ & 0.076 & 0.087 & 0.087 & 0.533 & 764.7 & 8.92 \\
\hline $580 \mathrm{~N}-\mathrm{m}$ & 0.213 & 0.026 & 0.026 & 4.610 & 746.6 & 7.78 \\
\hline
\end{tabular}

Table 6: Averaged diesel emissions with EEC-IV (335 N-m \& $580 \mathrm{~N}-\mathrm{m}$ at $1500 \mathrm{rpm})$

Dilution bags for each test were taken and analyzed using gas chromatography to determine the concentration of non-methane hydrocarbons and methane in the exhaust. Only trace amounts of methane were detected in the samples so it was determined that the exhaust contained predominantly non-methane hydrocarbons. It should also be noted that the brake specific $\mathrm{HC}$ production is very low. This is characteristic of direct injection (DI) diesel engines which typically have very complete fuel combustion.

In-cylinder pressure data were recorded for each mode and analyzed to characterize the engine. The IMEPg, ignition delay, and HRR were calculated from the in-cylinder pressure. A P-V diagram for each mode was also generated. From table 7 it can be seen that the diesel combustion process is very stable with the highest COV(IMEPg) of less than 3\%. The ignition delay is defined as the difference between the start of injection and the location of the first positive value of IMEPg on the 
compression stroke. The switch of HRR from negative to positive during the compression stroke indicates that combustion of the fuel has initiated and is sufficient to overcome the heat loss due to compression alone. Table 7 shows the average COV(IMEPg) and ignition delay for each mode.

\begin{tabular}{|c|c|c|}
\hline & $\begin{array}{c}\text { COV(IMEPg) } \\
\%\end{array}$ & $\begin{array}{c}\text { Ign. Delay } \\
{ }^{\circ} \text { After SOI }\end{array}$ \\
\hline $335 \mathrm{~N}-\mathrm{m}$ & 2.19 & 10.37 \\
\hline $580 \mathrm{~N}-\mathrm{m}$ & 1.44 & 9.33 \\
\hline
\end{tabular}

Table 7: $\operatorname{COV}(I M E P g) \&$ ignition delay for diesel with EEC-IV

The in-cylinder pressure data were averaged over 128 engine cycles to smooth out any noise and cycle-to-cycle variations which provided a good representation of the cylinder pressure over time. The heat release rates were calculated from these averaged in-cylinder pressure traces. $P d V / d \theta$ was also calculated and plotted versus crank angle to show the net energy release during the compression and expansion strokes. 


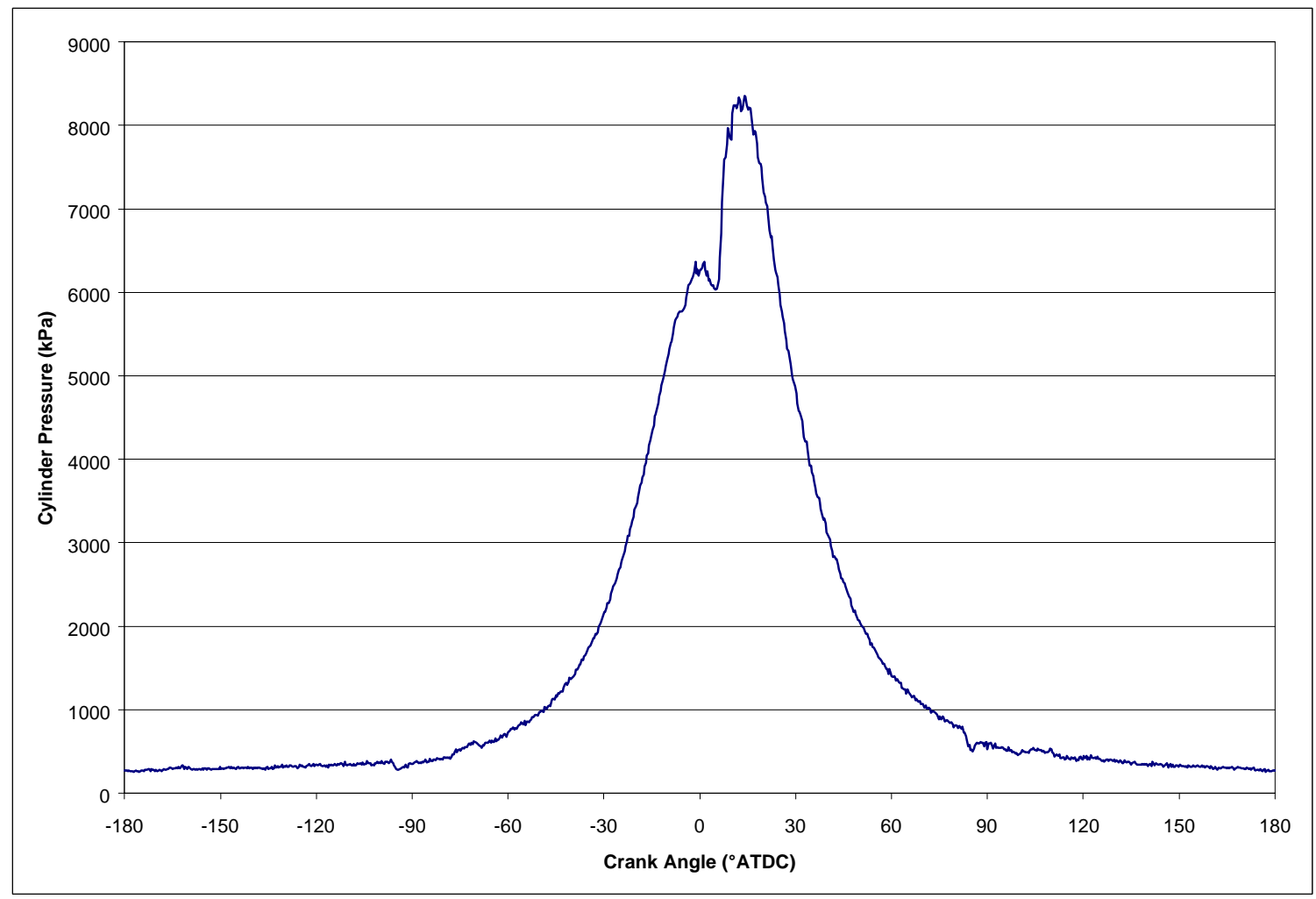

Figure 8: In-cylinder pressure vs. CA for diesel EEC-IV (1500 rpm; 335 N-m)

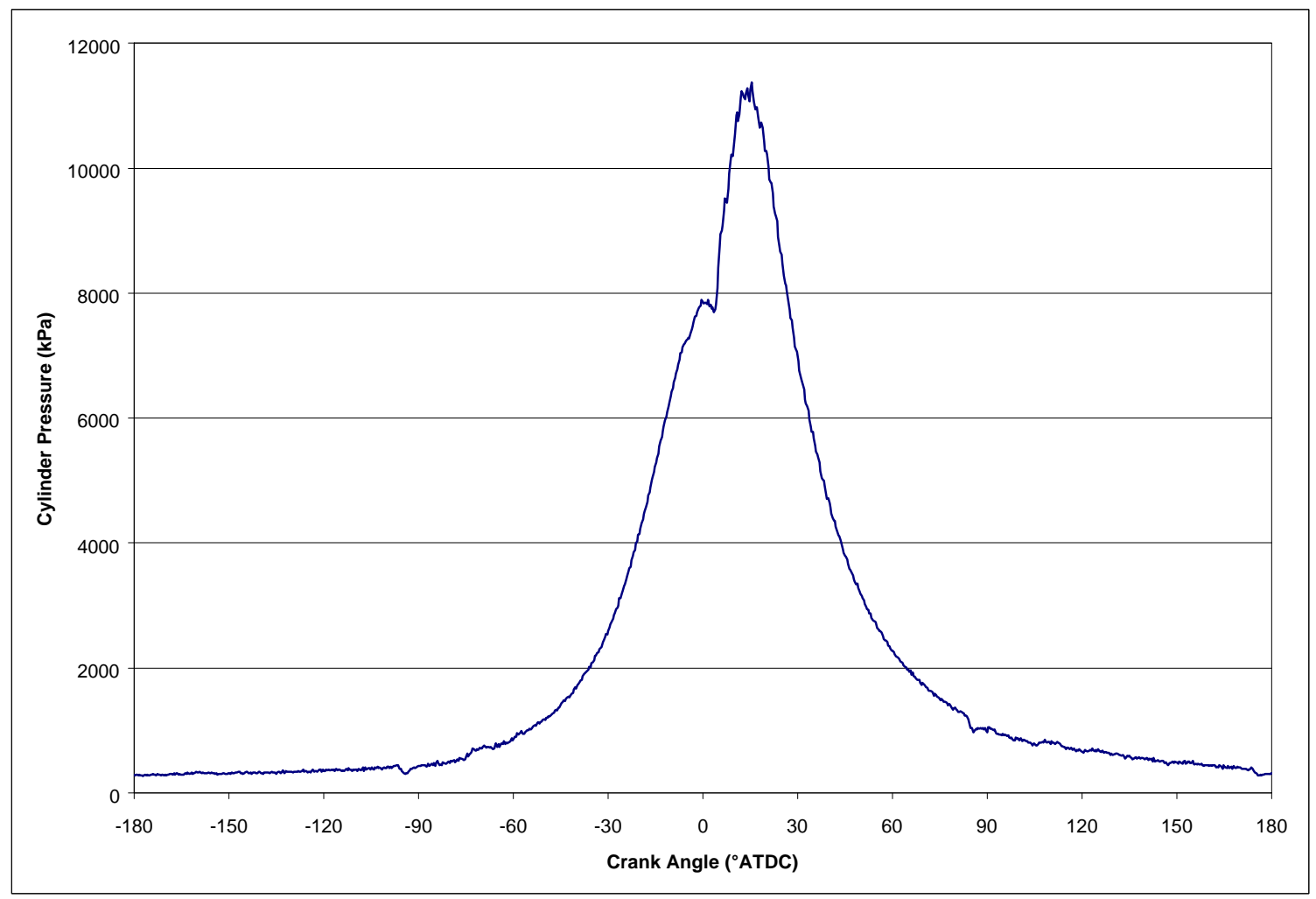

Figure 9: In-cylinder pressure vs. CA for diesel EEC-IV (1500 rpm; 580 N-m) 


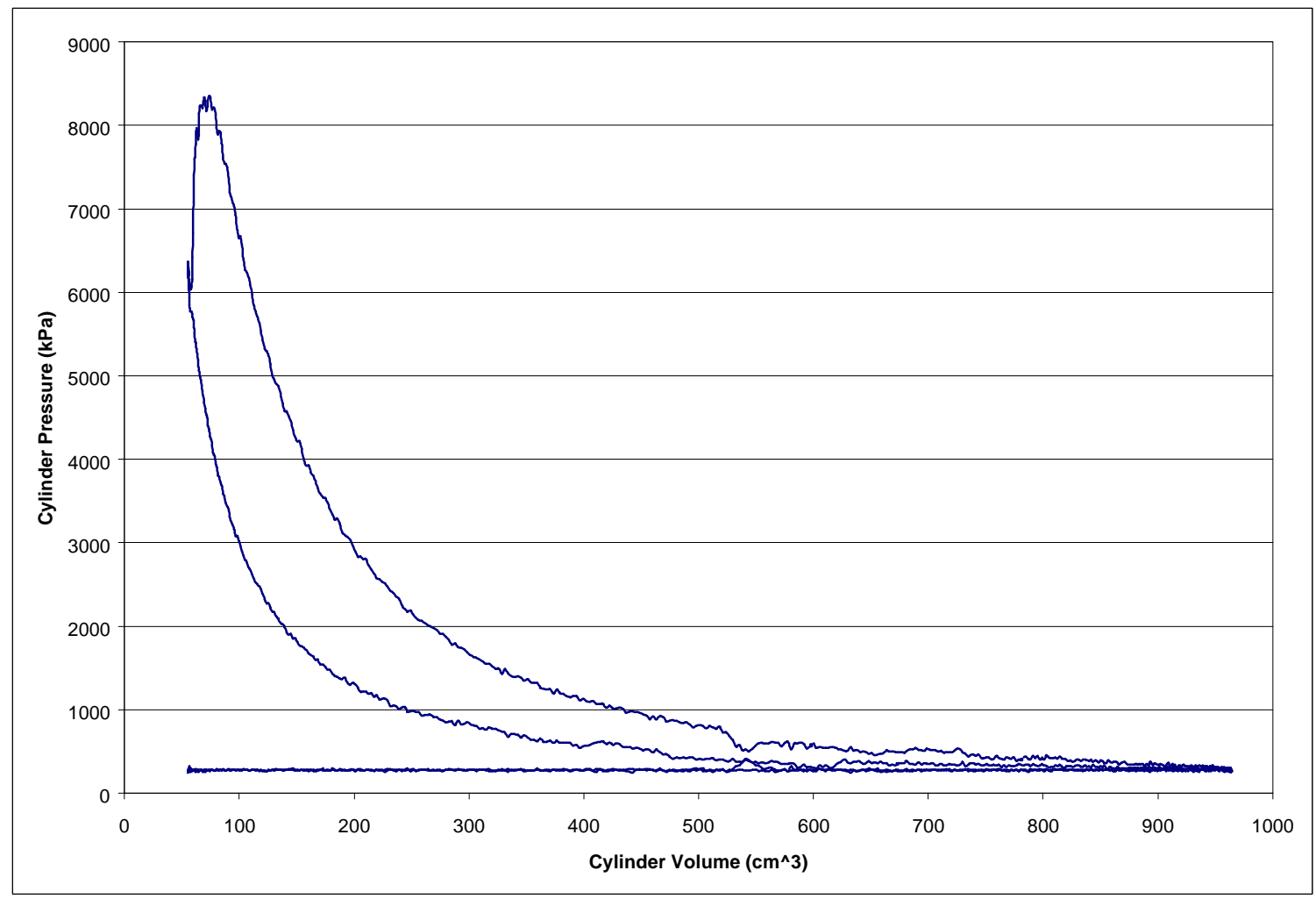

Figure 10: P-V diagram for diesel EEC-IV (1500 rpm; 335 N-m)

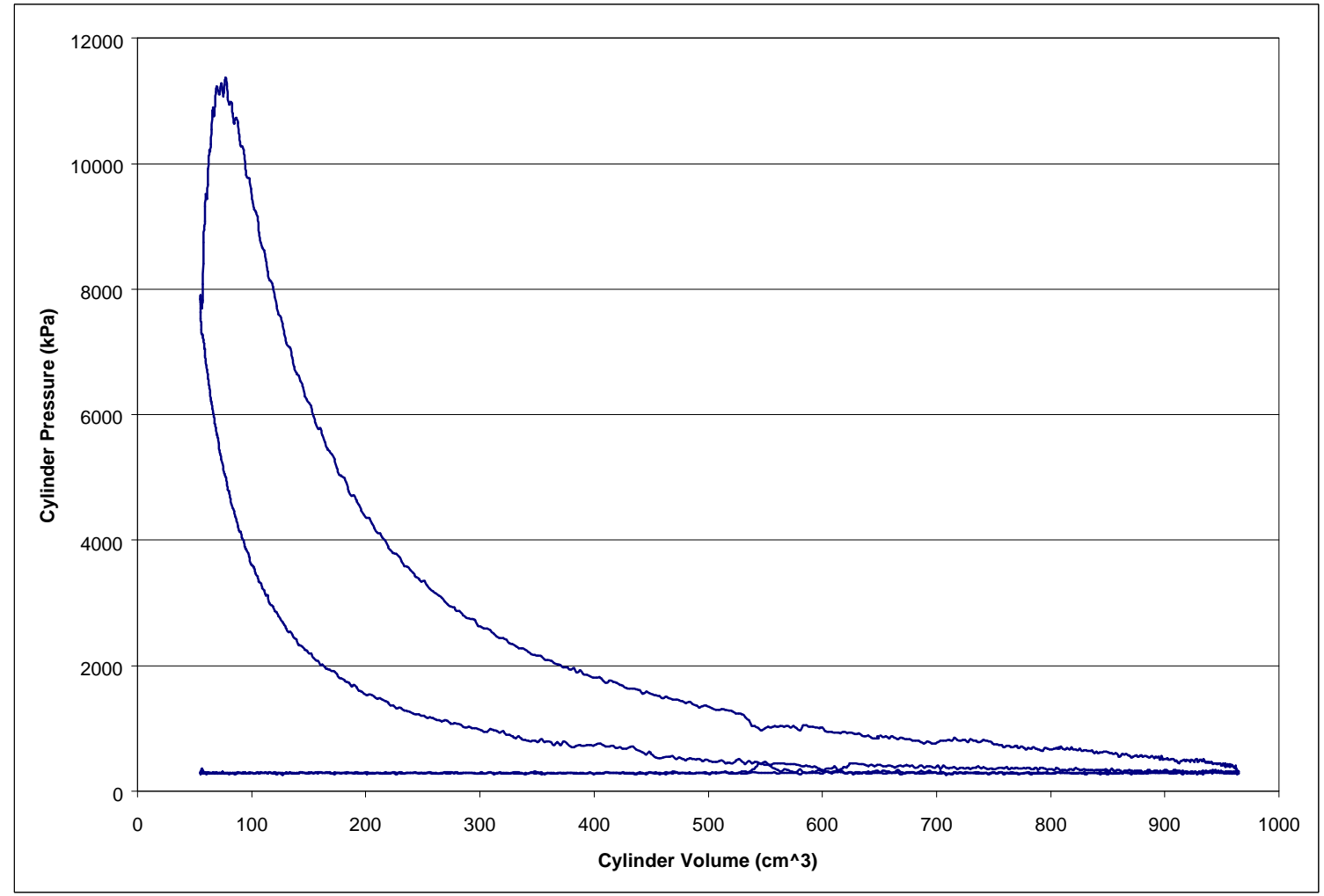

Figure 11: P-V diagram for diesel EEC-IV (1500 rpm; 580 N-m) 


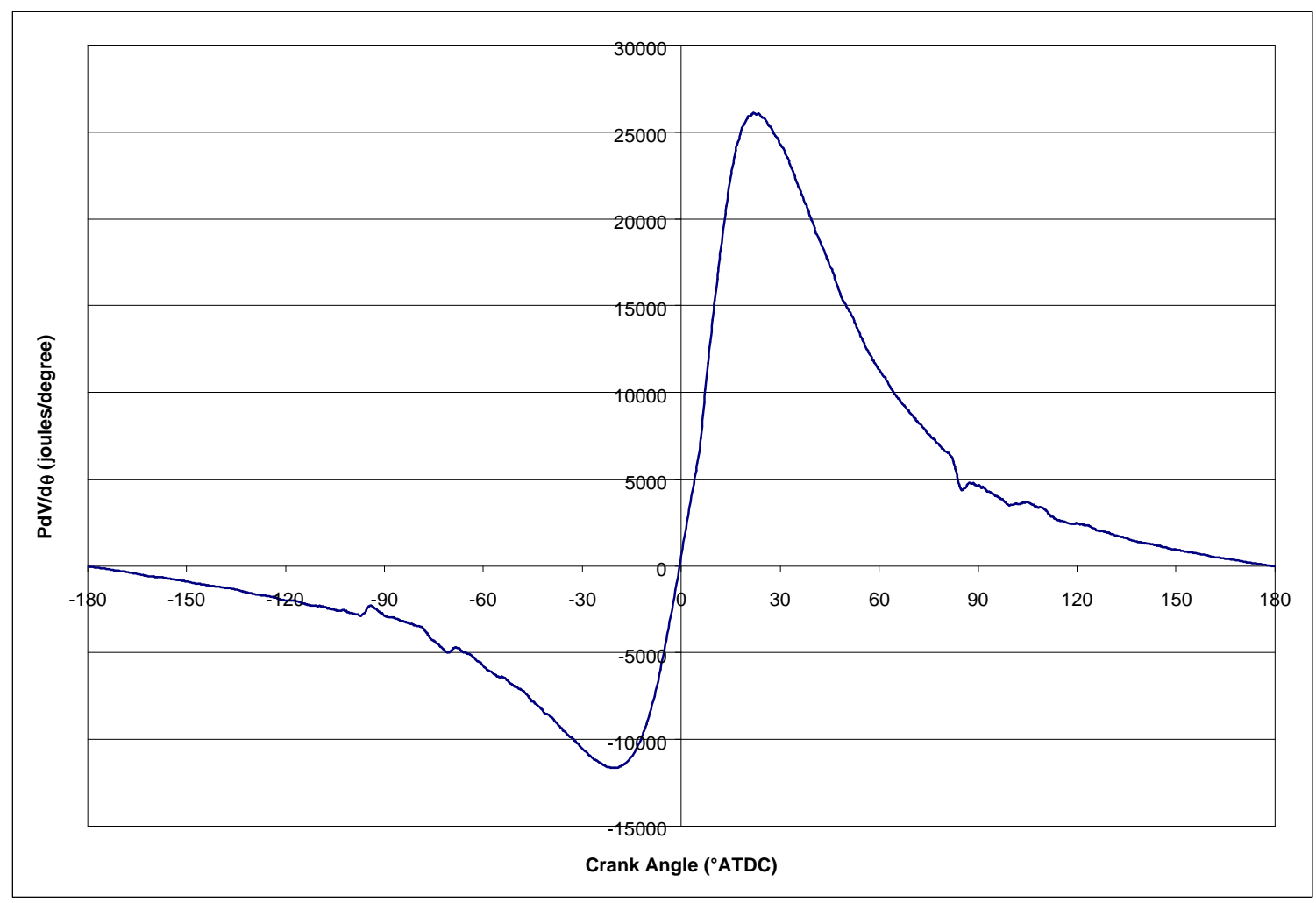

Figure 12: PdV/d $\theta$ vs. CA for diesel EEC-IV ( 1500 rpm; 335 N-m)

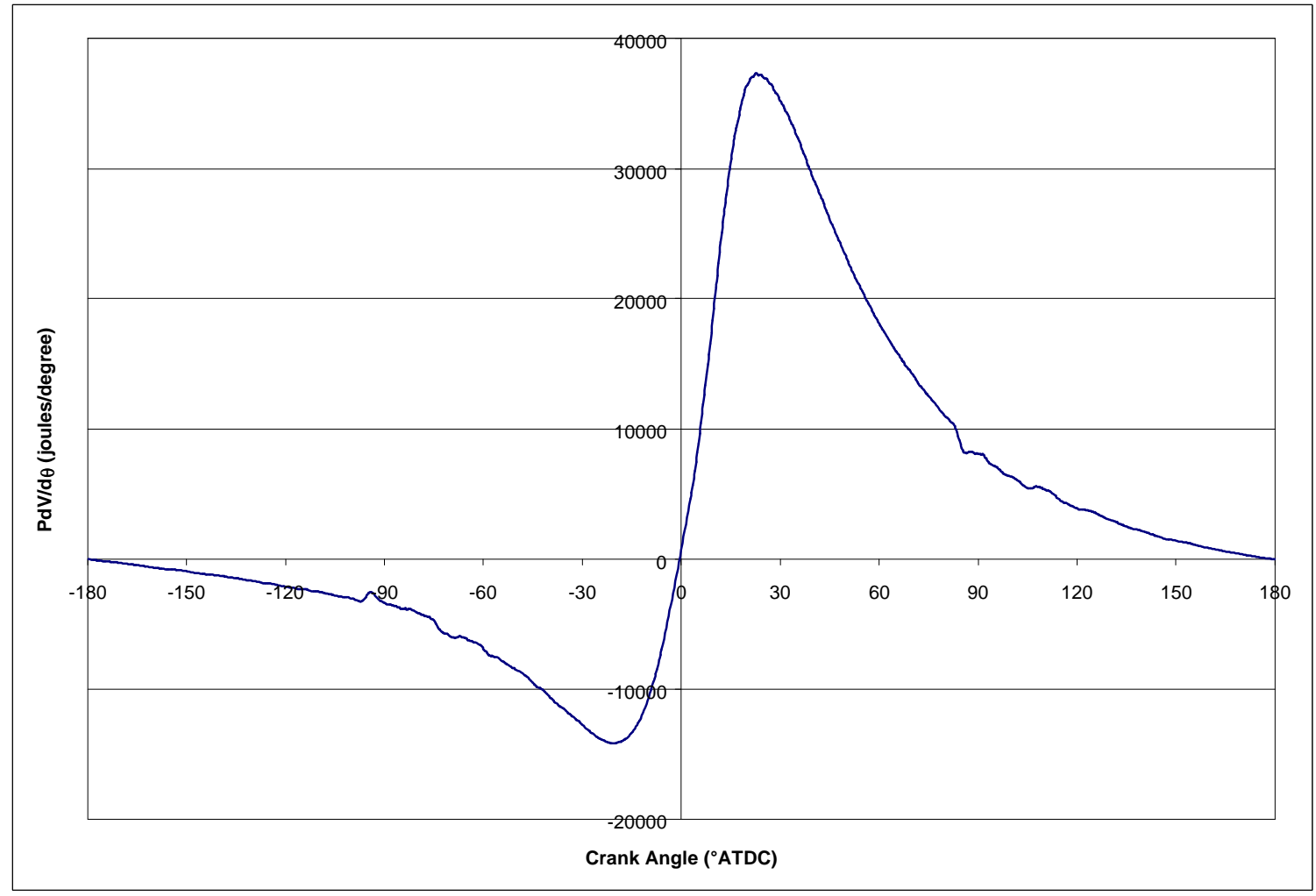

Figure 13: PdV/d $\theta$ vs. CA for diesel EEC-IV (1500 rpm; 580 N-m) 


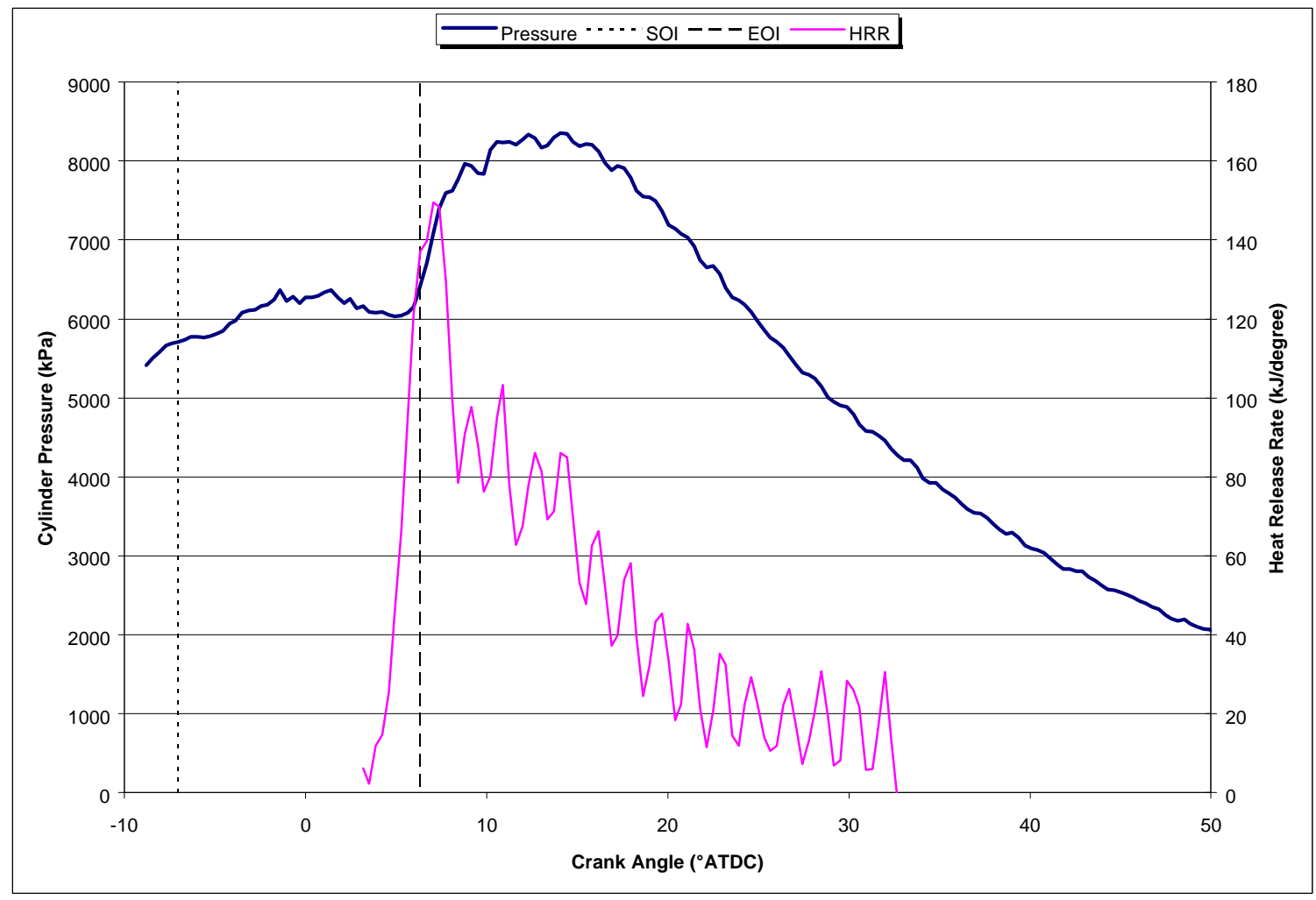

Figure 14: HRR \& in-cylinder pressure for diesel EEC-IV (1500 rpm; 335 N-m)

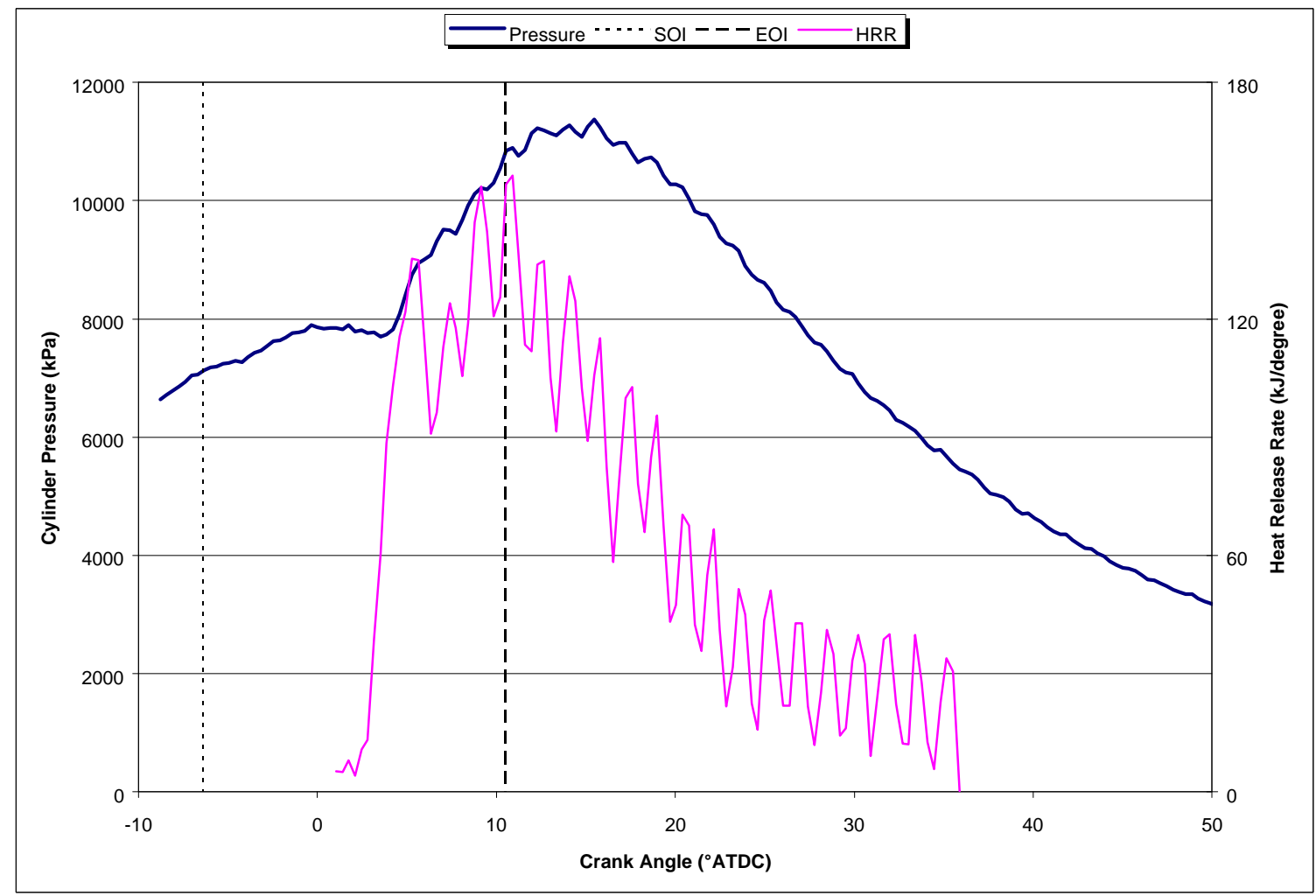

Figure 15: HRR \& in-cylinder pressure for diesel EEC-IV (1500 rpm; 580 N-m) 


\subsubsection{Diesel Sweep Data Using WVU-ECU}

It was necessary to characterize the engine running on diesel fuel using the WVUECU. Sweeps of FIPW over the entire range of operation were performed to determine what engine torque and emissions were produced. It was found from the FIPW sweep that there were some peculiar injector characteristics with which to contend. It can be seen from Figure 16 that FIPW between $650 \mu$ s and $900 \mu$ s causes the engine torque to drop off significantly and the engine produces no torque at about $800 \mu$ s. From the visible drop in exhaust emissions in Figure 17 it is evident that the injectors were not delivering the expected fuel between $650 \mu$ s and $900 \mu$ s. From this information, it was decided that the injectors were operating outside of their designed range below $900 \mu \mathrm{s}$ and that all future tests would be carried out above this FIPW to take advantage of the near linear characteristics of the injectors in this range. No tests were carried out with FIPW below $900 \mu \mathrm{s}$.

The effects of ADV and FIPW were also explored. ADV was increased from $0^{\circ}$ BTDC to $17^{\circ} \mathrm{BTDC}$ in one degree increments and the thermal efficiency was calculated at each point. Figure 21 shows that ADV had little effect on the thermal efficiency, which increased from $34 \%$ to $35 \%$ at high load ( $2373 \mu$ s FIPW) and remained relatively constant at about $16 \%$ at low load (900 $\mu$ s FIPW). 


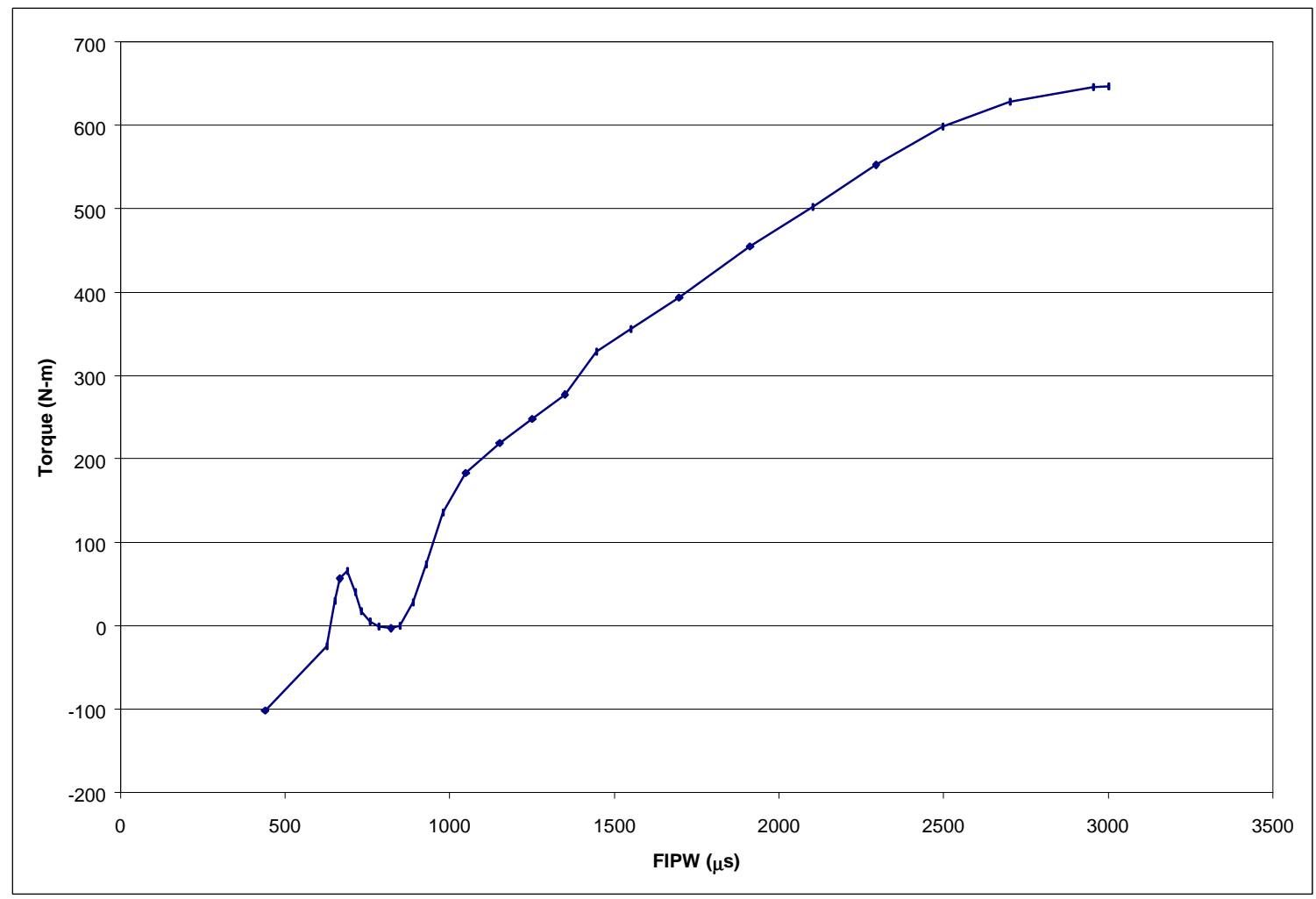

Figure 16: Torque vs. FIPW for diesel WVU-ECU (1500 rpm; $6.5^{\circ} \mathrm{ADV}$; 10-10.5 MPa ICP)

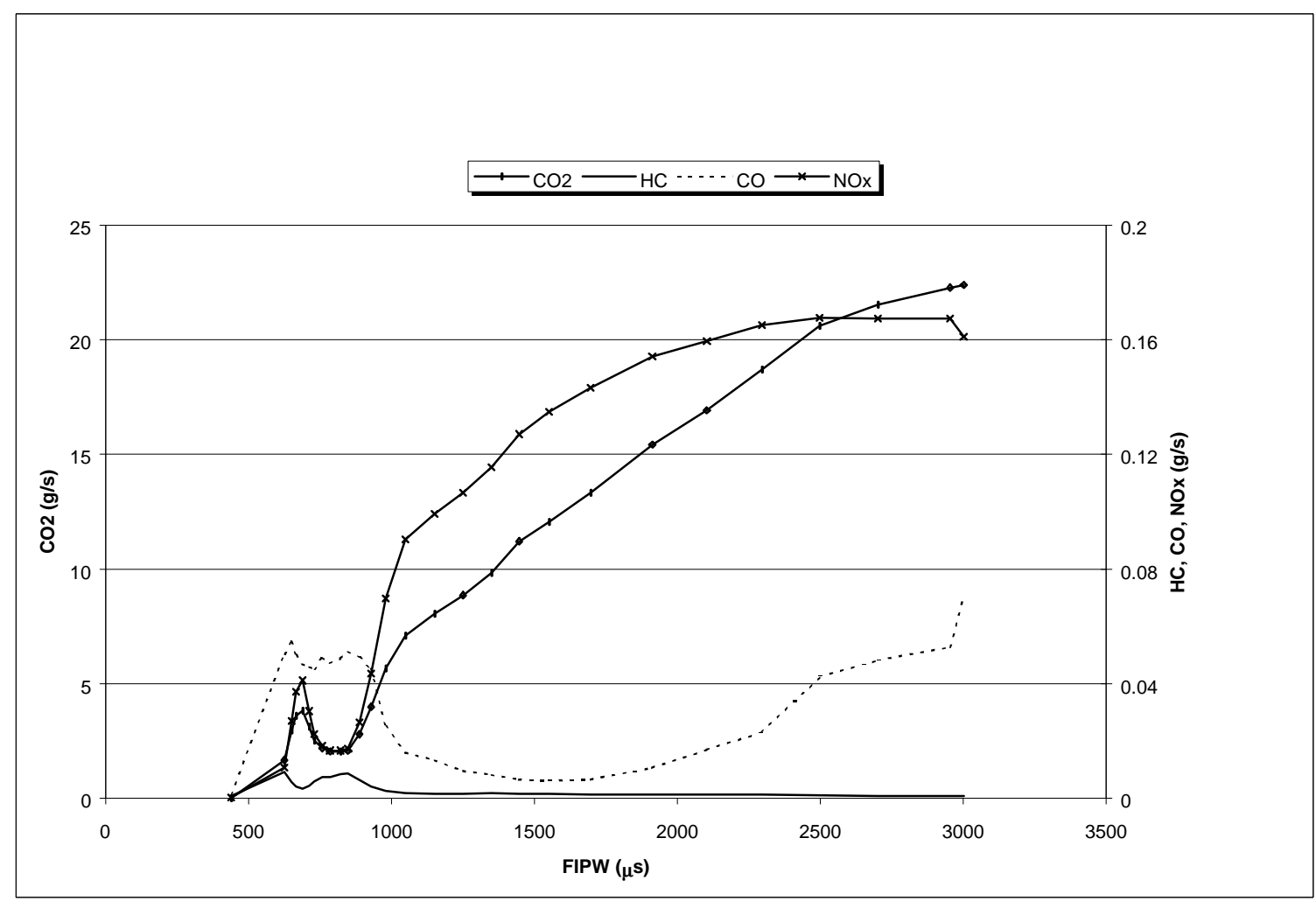

Figure 17: Emissions vs. FIPW for diesel WVU-ECU (1500 rpm; $6.5^{\circ}$ ADV; 10-10.5 MPa ICP) 
It can be seen from Figure 18 that the thermal efficiency is affected by the amount of fuel injected (which is a direct function of the FIPW). As the FIPW is increased from $900 \mu$ s to $3000 \mu$ s the efficiency rapidly increases from $15 \%$ to a maximum of $34 \%$ at $1500 \mu \mathrm{s}$. The low efficiency at small FIPW is likely caused by the engine running at near no-load conditions. At low loads, the frictional losses account for a higher percentage of the total fuel energy available which lowers thermal efficiency. This means that the engine was using most of the fuel energy it consumed to overcome the internal losses and produced very little net power, therefore causing lower thermal efficiency.

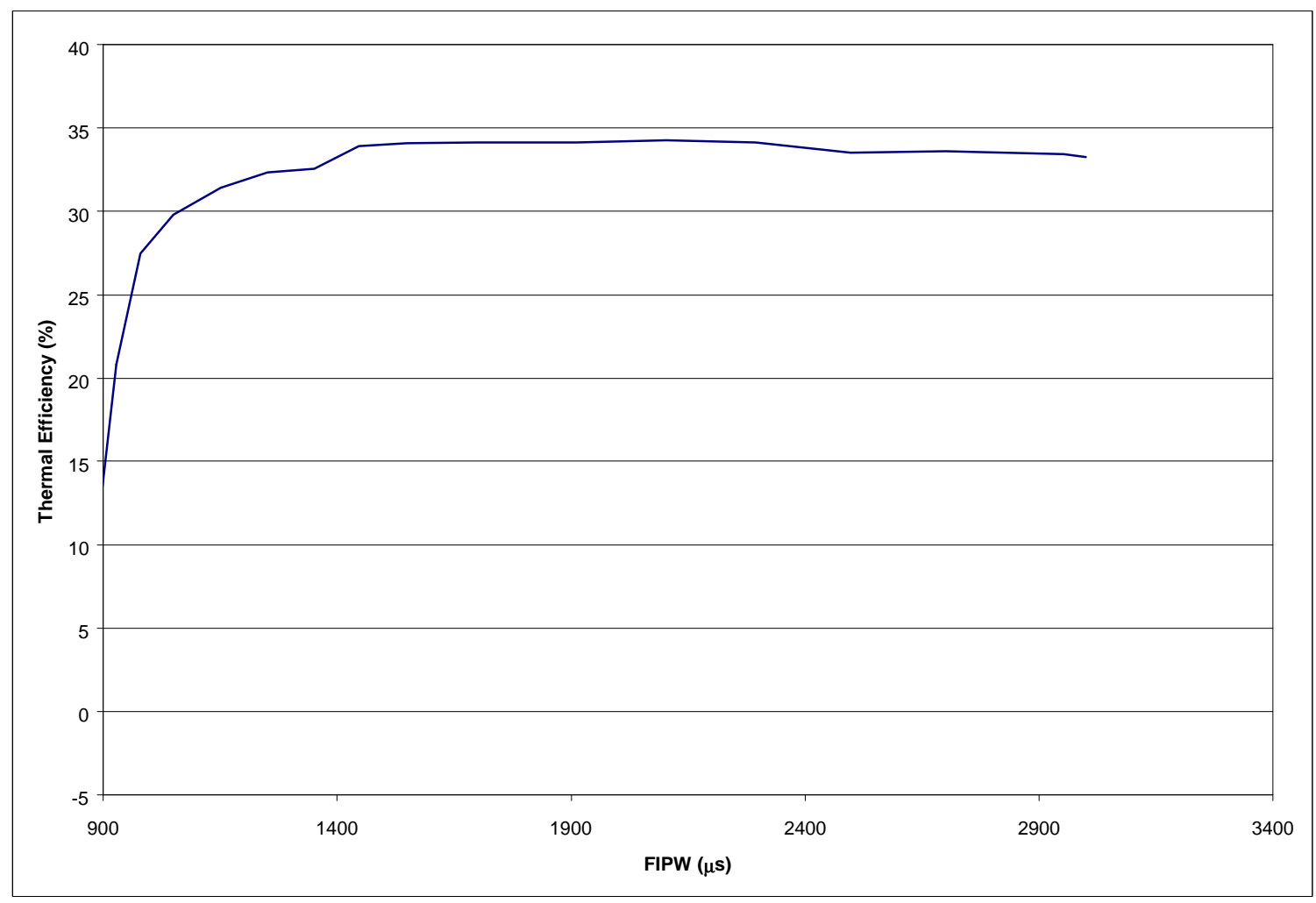

Figure 18: Thermal efficiency vs. FIPW for diesel WVU-ECU $\left(1500 \mathrm{rpm} ; 6.5^{\circ} \mathrm{ADV} ; 10-10.5 \mathrm{MPa}\right.$ ICP)

Exhaust emissions are also affected by injection advance. Once again ADV was swept from $0^{\circ} \mathrm{BTDC}$ to $17^{\circ} \mathrm{BTDC}$ and emissions data were recorded. For light load (FIPW: $900 \mu \mathrm{s}$ ) all exhaust emissions except for $\mathrm{NO}_{\mathrm{x}}$ underwent a sudden decrease as 
advance went from $0^{\circ} \mathrm{BTDC}$ to $6^{\circ} \mathrm{BTDC}$ and then leveled off. $\mathrm{NO}_{\mathrm{x}}$, however, steadily increased across the entire range. At high load (FIPW: $2373 \mu$ s) ADV was swept from $3^{\circ}$ BTDC to $17^{\circ} \mathrm{BTDC}$. $\mathrm{HC}$ emissions remained very low throughout, $\mathrm{CO}_{2}$ decreased, and $\mathrm{CO}$ and $\mathrm{NO}_{\mathrm{x}}$ both increased. The increase in $\mathrm{NO}_{\mathrm{x}}$ production as $\mathrm{ADV}$ increased is caused by a shift in the location of peak pressure. The closer to TDC the peak pressure occurs, the higher the overall in-cylinder pressure, and therefore also temperature. The high temperatures cause the increased $\mathrm{NO}_{\mathrm{x}}$ production.

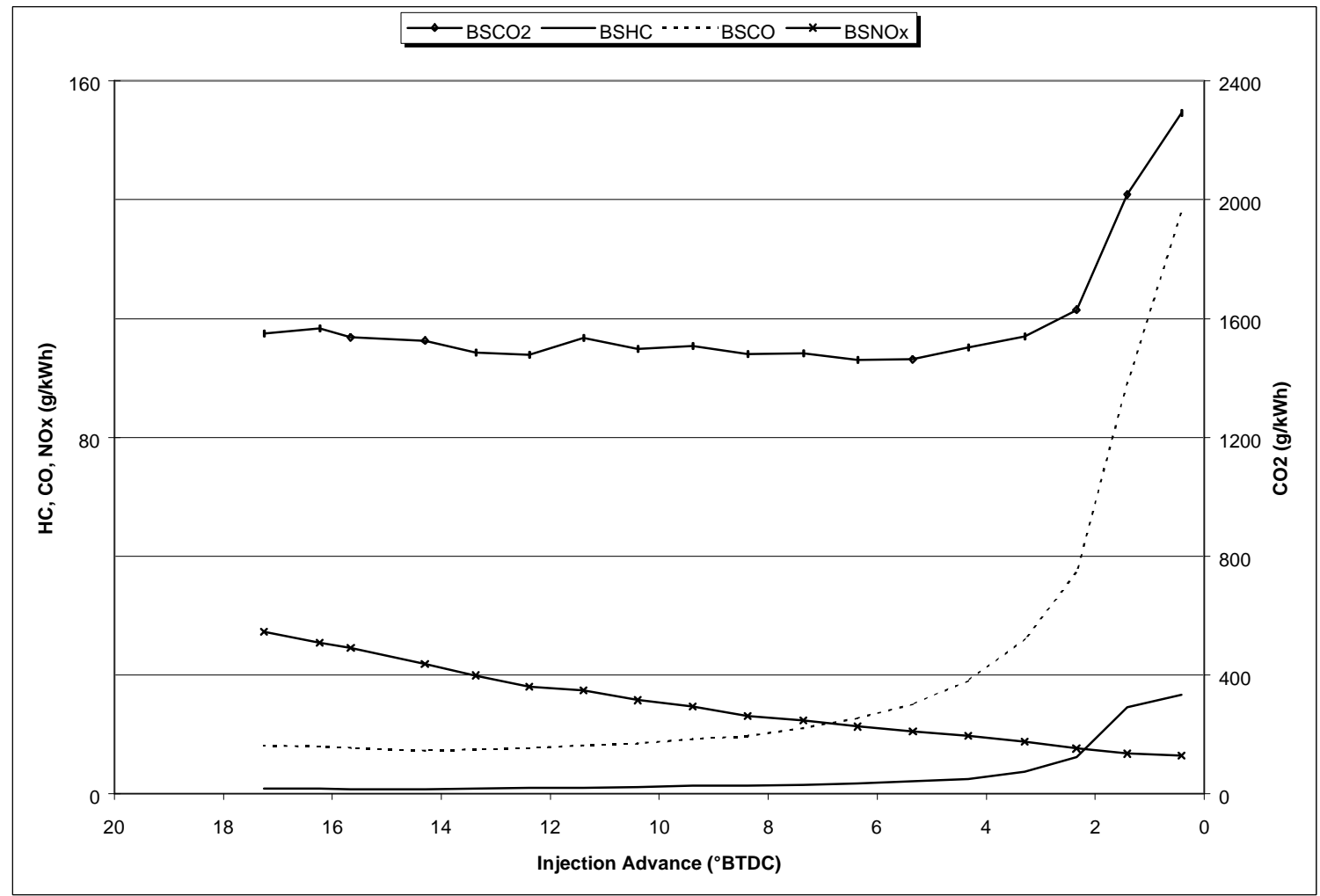

Figure 19: Emissions vs. ADV for diesel WVU-ECU (1500 rpm; $900 \mu$ s FIPW; 10-10.5 MPa ICP) 


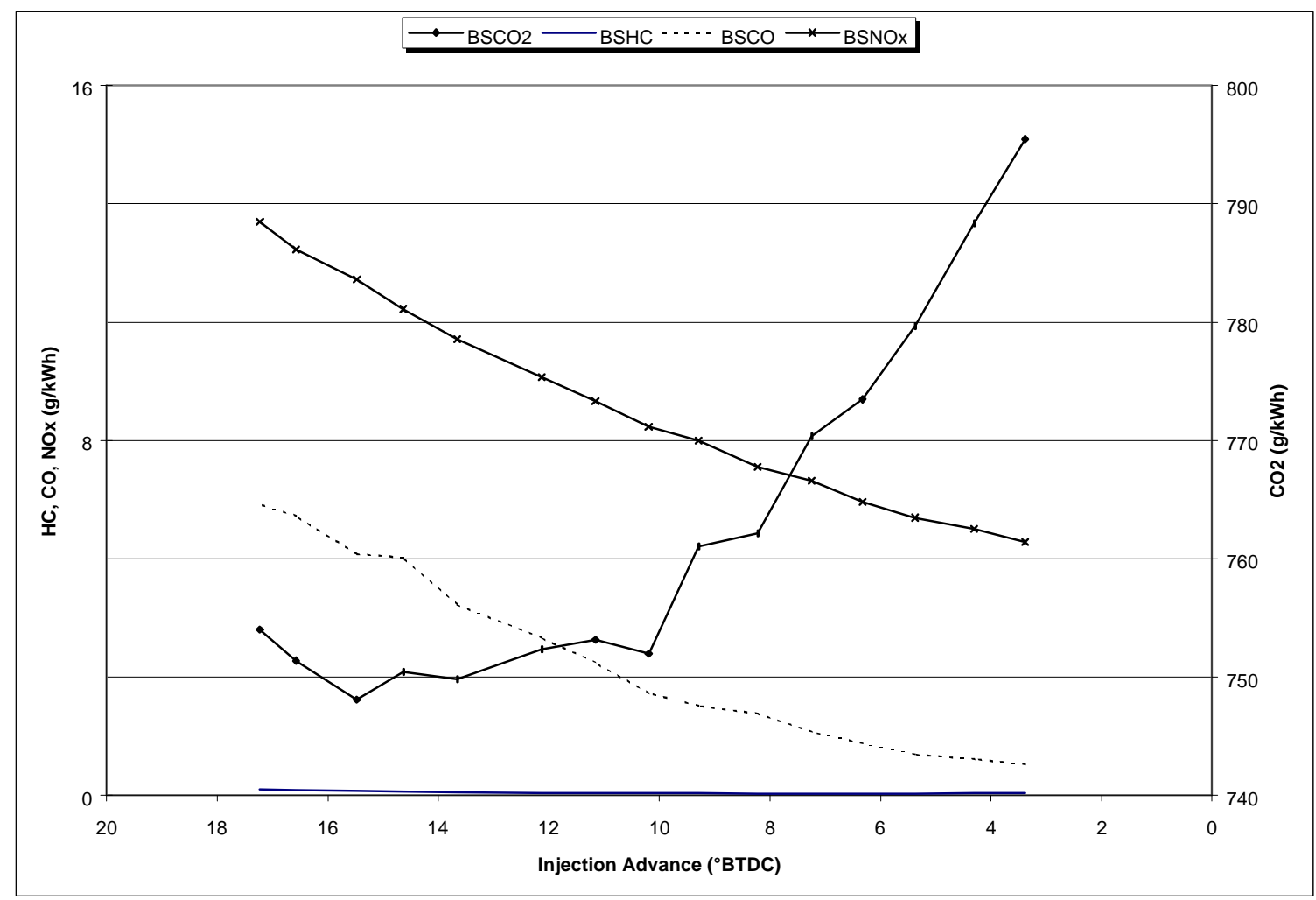

Figure 20: Emissions vs. ADV for diesel WVU-ECU (1500 rpm; $2373 \mu$ s FIPW; 10-10.5 MPa ICP)

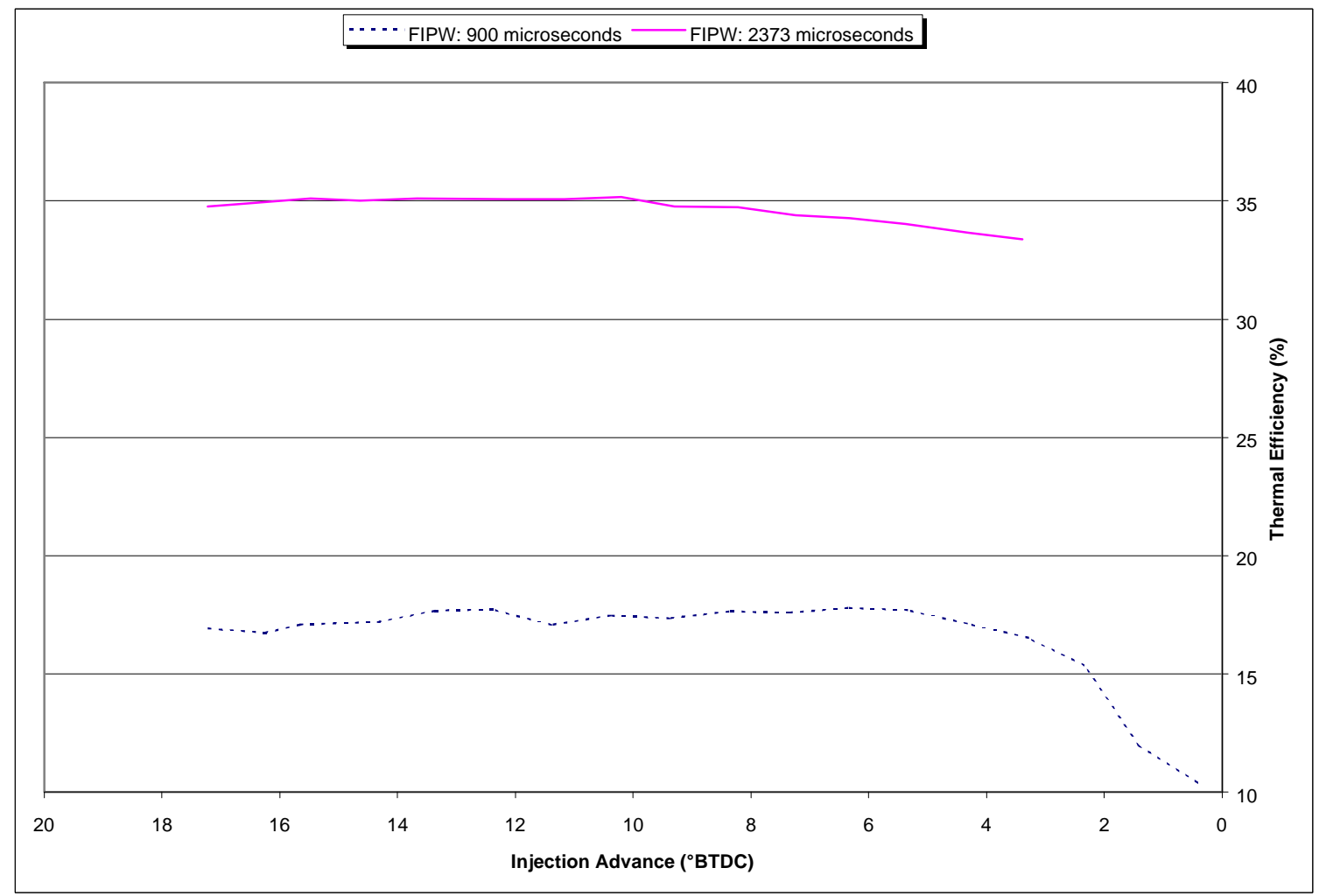

Figure 21: Thermal Efficiency vs. ADV for diesel WVU-ECU (1500 rpm; 10-10.5 MPa ICP) 


\subsection{Dual Fuel Operation}

Operation of the engine in dual fuel mode was carried out in two stages. The first stage consisted of a series of sweeps designed to optimize FIPW, ADV, ICP, and CNG flow, to minimize exhaust emissions, and maximize diesel replacement while maintaining diesel-like thermal efficiencies. The second stage was a set of steady state tests identical to those performed during diesel operation with the Ford EEC-IV to provide a comparison between the two modes of operation.

\subsubsection{Dual Fuel Sweep Data Using WVU-ECU}

The first set of sweeps was of FIPW. The FIPW was stepped up in discrete increments while ADV and ICP were held constant. The CNG flow was then adjusted to hold the torque output steady.

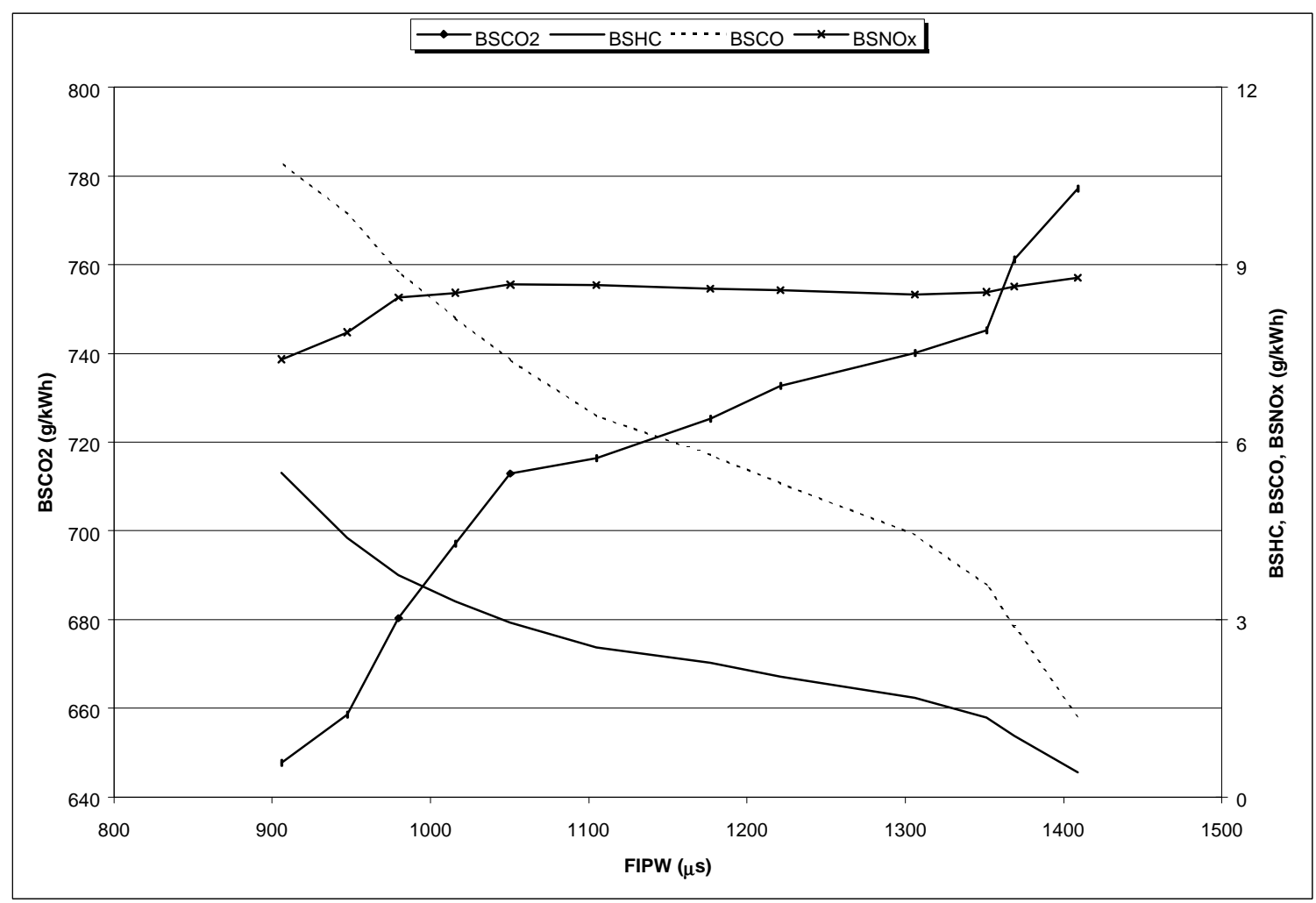

Figure 22: Dual fuel emissions vs. FIPW (1500 rpm; 335 N-m; 6.5 ${ }^{\circ}$ BTDC; 11 MPa ICP) 


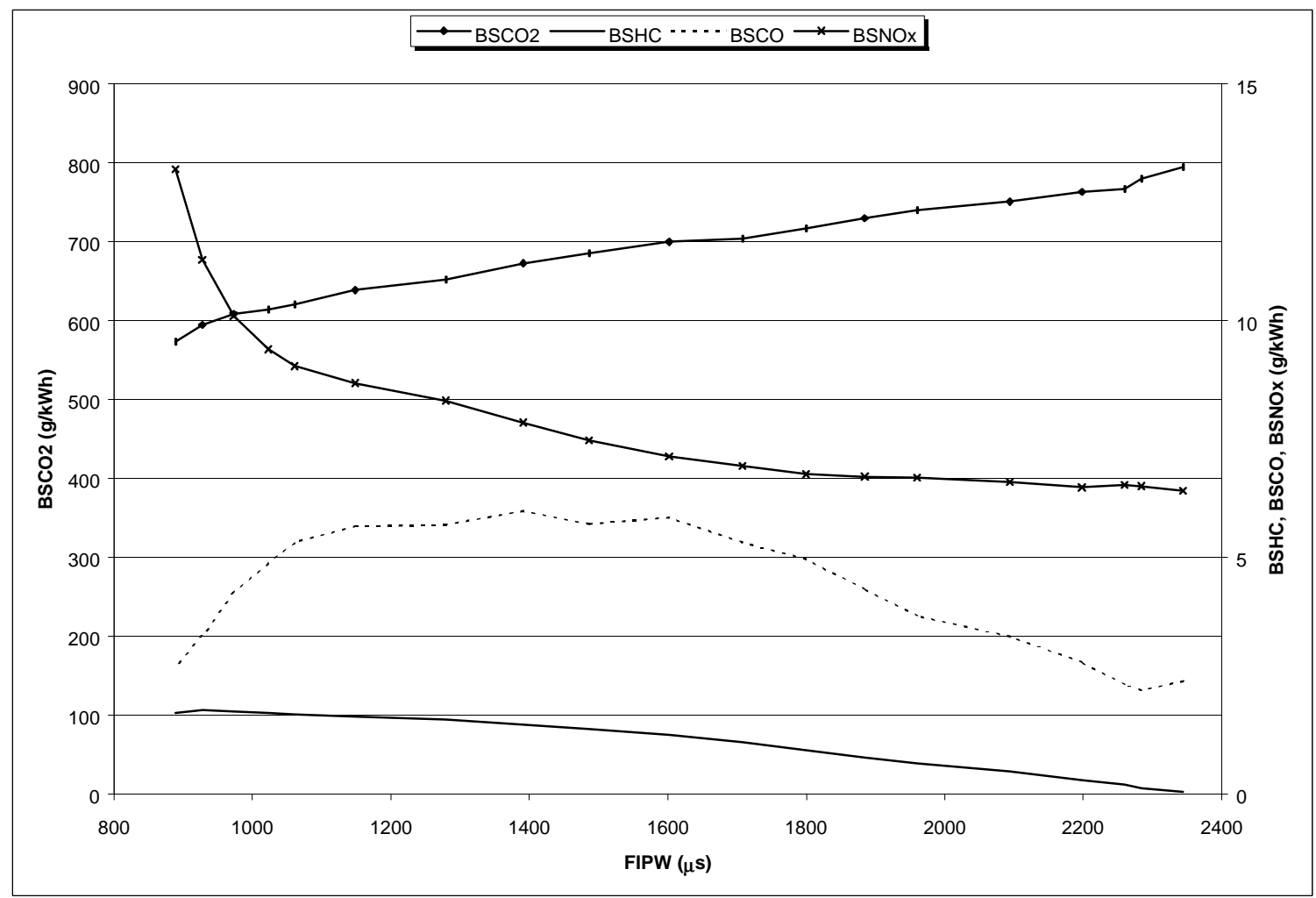

Figure 23: Dual fuel emissions vs. FIPW (1500 rpm; 580 N-m; 6.5 ${ }^{\circ}$ BTDC; 11 MPa ICP)

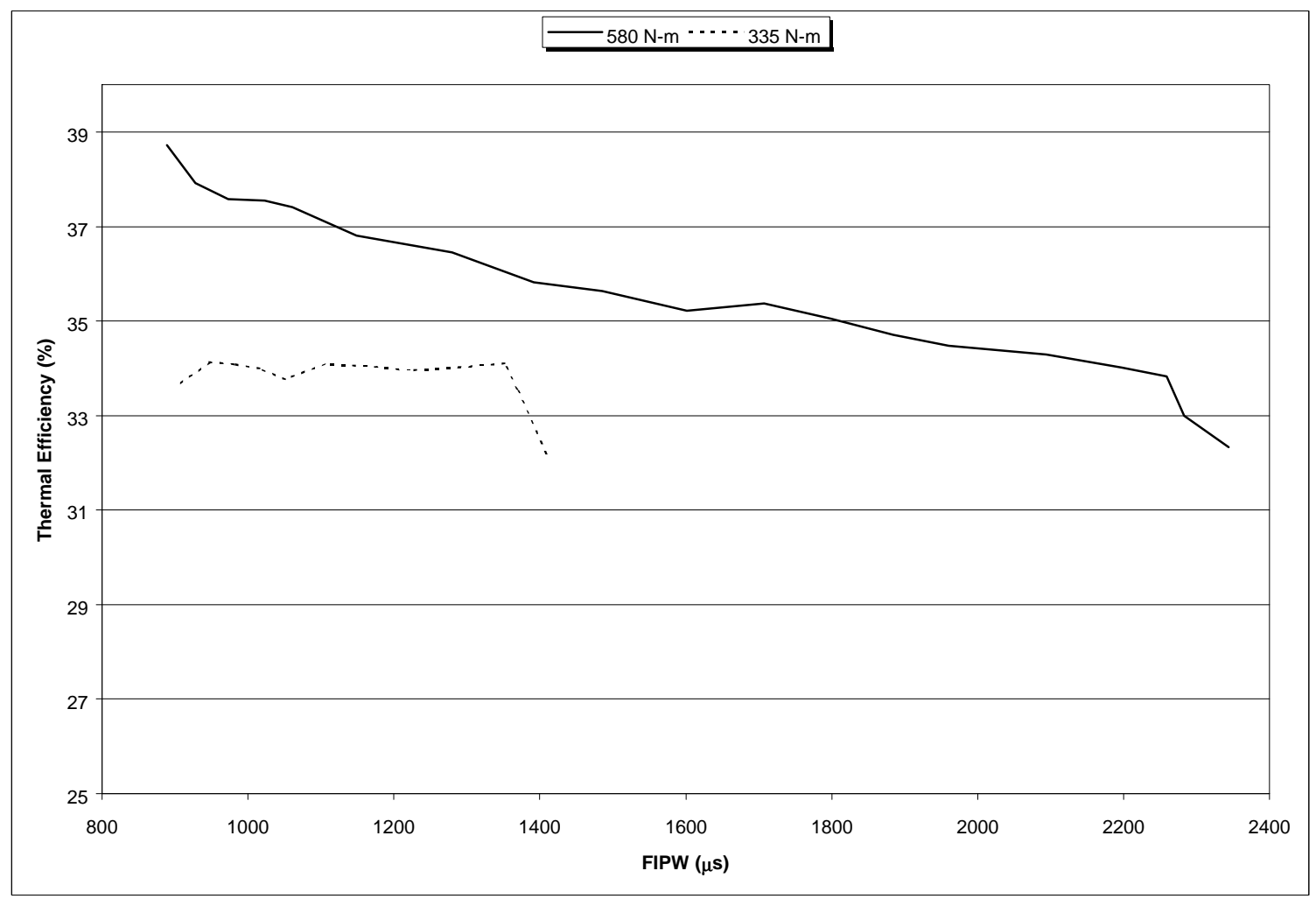

Figure 24: Dual fuel efficiency vs. FIPW (1500 rpm; 335 N-m \& 580 N-m) 
Since maximizing the diesel replacement was a goal of this project, a FIPW of $900 \mu \mathrm{s}$ was chosen for subsequent sweeps of ADV. Figure 22 shows that the lowest $\mathrm{NO}_{\mathrm{x}}$ and $\mathrm{CO}_{2}$ emissions were produced at $900 \mu \mathrm{s}$, which coincides with previously chosen pilot injection FIPW. Figure 23, however, shows that the $\mathrm{NO}_{\mathrm{x}}$ emissions were highest at $900 \mu \mathrm{s}$ for $580 \mathrm{~N}-\mathrm{m}$. Thermal efficiency, at nearly 34\%, was high at $900 \mu \mathrm{s}$ FIPW for $335 \mathrm{~N}-\mathrm{m}$, but was even higher for $580 \mathrm{~N}-\mathrm{m}$ at nearly 39\% (Figure 24).

Sweeps of ADV were done at $335 \mathrm{~N}-\mathrm{m}$ and $580 \mathrm{~N}-\mathrm{m}$ with FIPW of $900 \mu$ s and ICP of 11-11.5 MPa. Again, CNG flow rate was varied to keep torque constant at either $335 \mathrm{~N}-\mathrm{m}$ or $580 \mathrm{~N}-\mathrm{m}$ and emissions and thermal efficiency were recorded for each point. The $\mathrm{HC}-\mathrm{NO}_{\mathrm{x}}$ tradeoff was of particular interest for this set of tests and it was determined from this information that the optimum ADV at $335 \mathrm{~N}-\mathrm{m}$ was $4.5^{\circ} \mathrm{BTDC}$ (Figure 27)

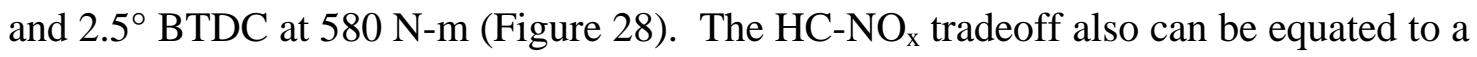
$\mathrm{NO}_{\mathrm{x}}$-efficiency tradeoff because the efficiency is directly related to the amount of unburned hydrocarbons in the exhaust. $\mathrm{CO} 2$ emissions decreased with increasing ADV for both modes while $\mathrm{CO}$ decreased at $335 \mathrm{~N}$-m and remained relatively unchanged at $580 \mathrm{~N}-\mathrm{m}$ with increasing ADV (Figures $25 \& 26$ ). It can be seen from Figure 29 that the thermal efficiency benefits greatly from advancing the start of injection, exceeding $39 \%$ at $9^{\circ} \mathrm{BTDC}$ for the $580 \mathrm{~N}-\mathrm{m}$ set point and $37 \%$ at $13^{\circ} \mathrm{BTDC}$ for the $335 \mathrm{~N}-\mathrm{m}$ set point. However, this efficiency increase does come with a significant $\mathrm{NO}_{\mathrm{x}}$ penalty $\left(\mathrm{NO}_{\mathrm{x}}{ }^{-}\right.$ efficiency tradeoff) which is unacceptable. 


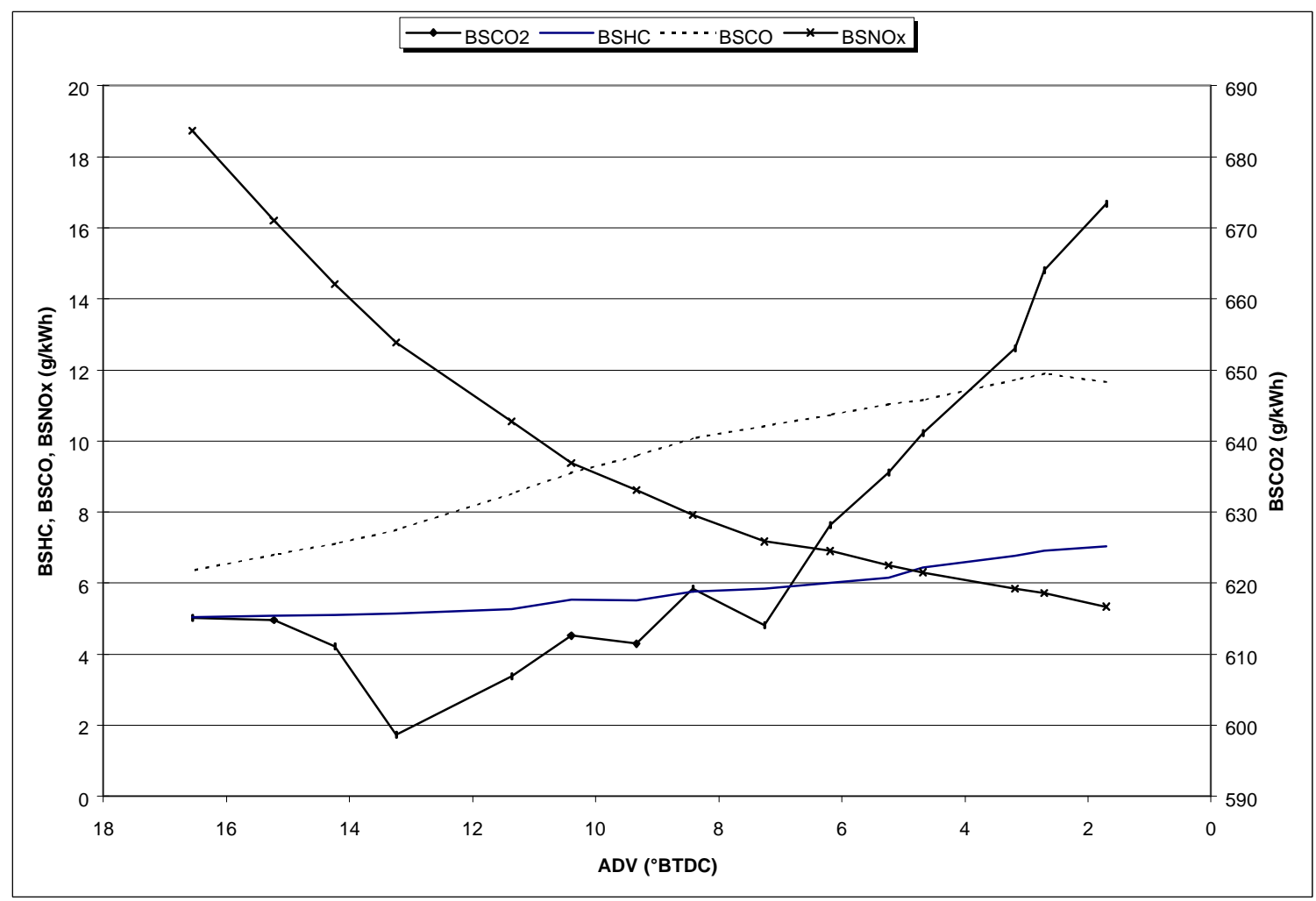

Figure 25: Dual fuel emissions vs. ADV (1500 rpm; 335 N-m; 900 $\mu$ s FIPW; 11 MPa ICP)

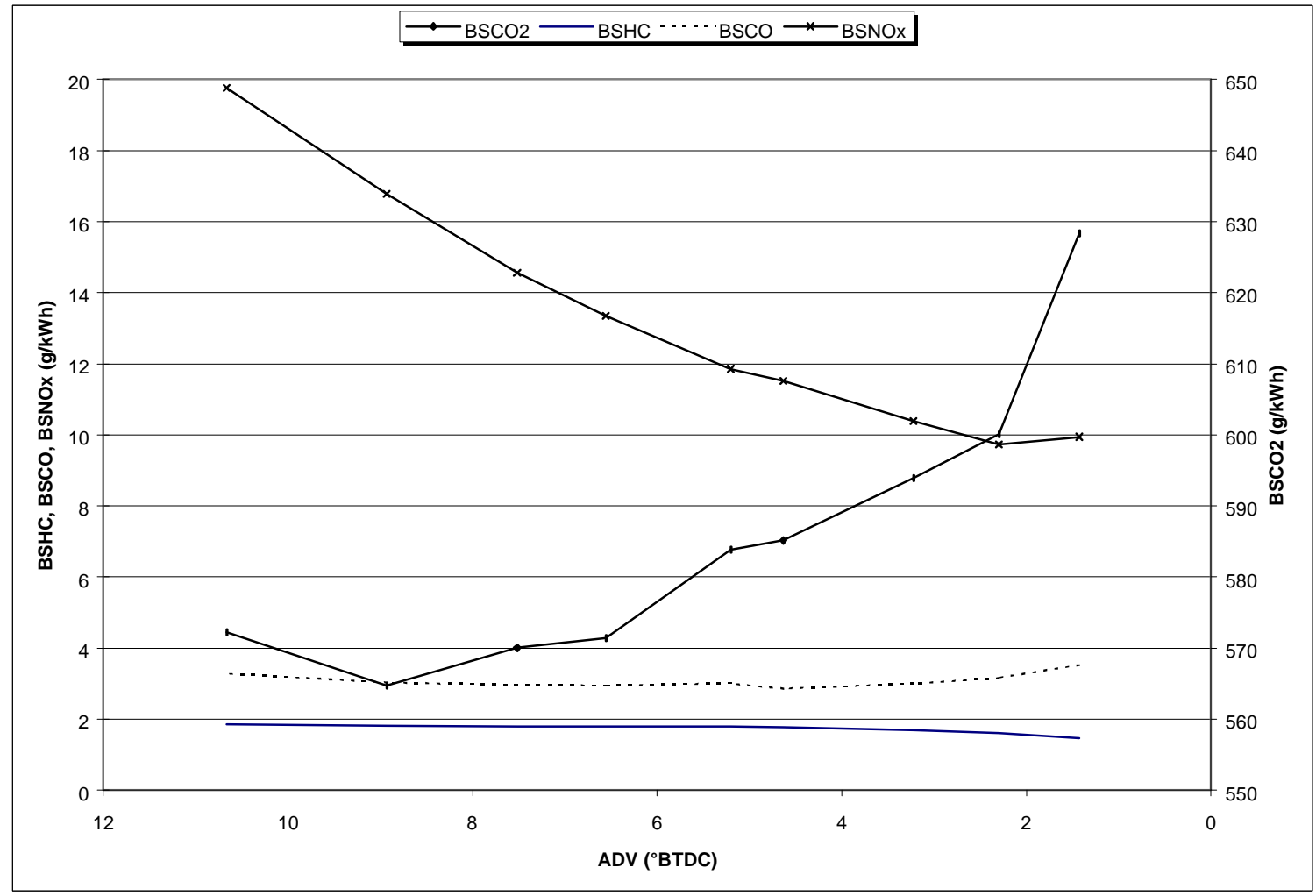

Figure 26: Dual fuel emissions vs. ADV (1500 rpm; 580 N-m; 900 $\mu$ s FIPW; 11 MPa ICP) 


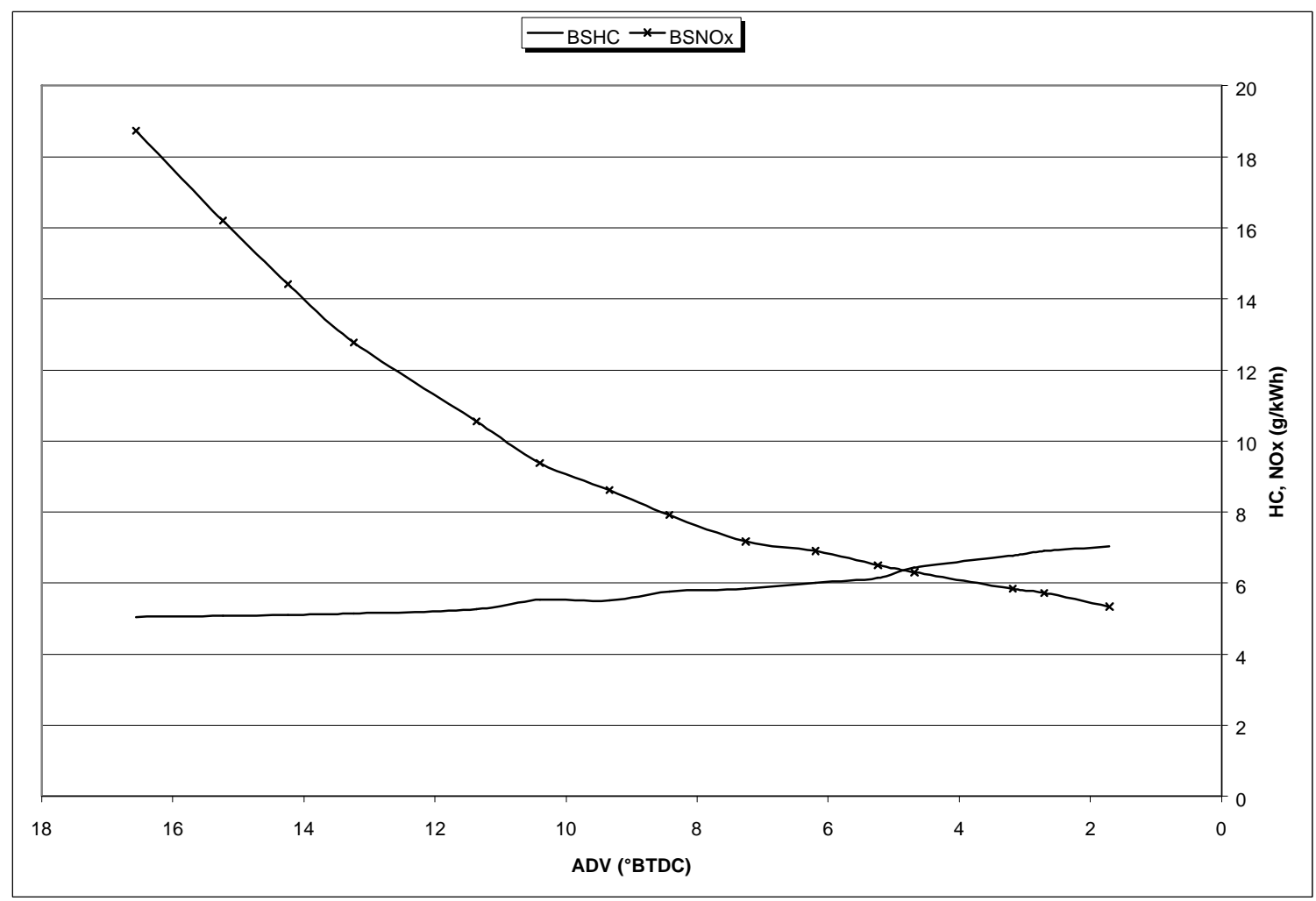

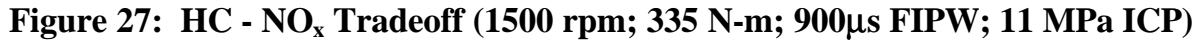

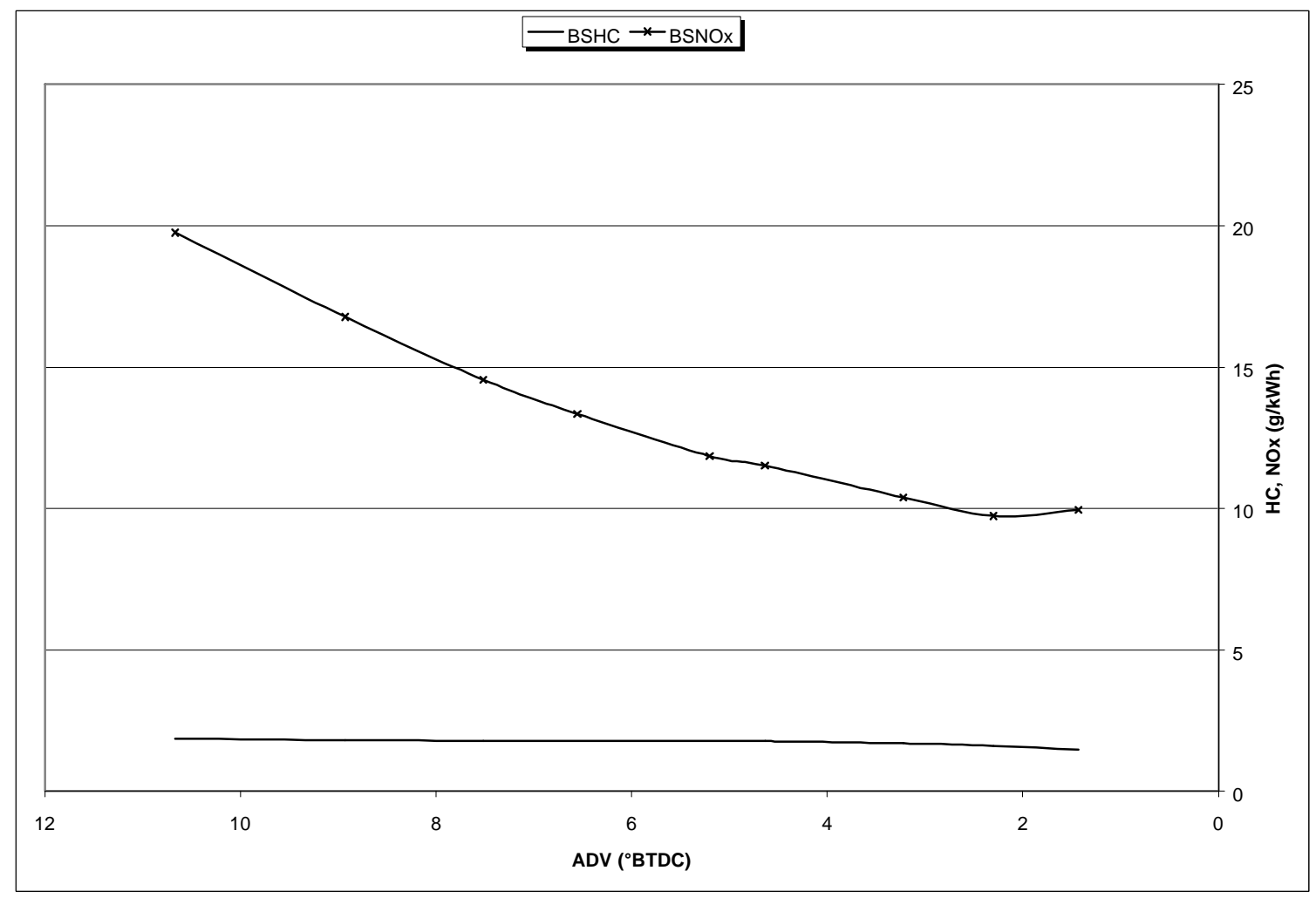

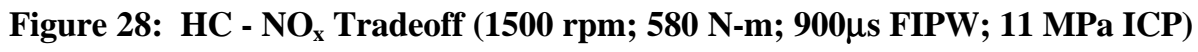




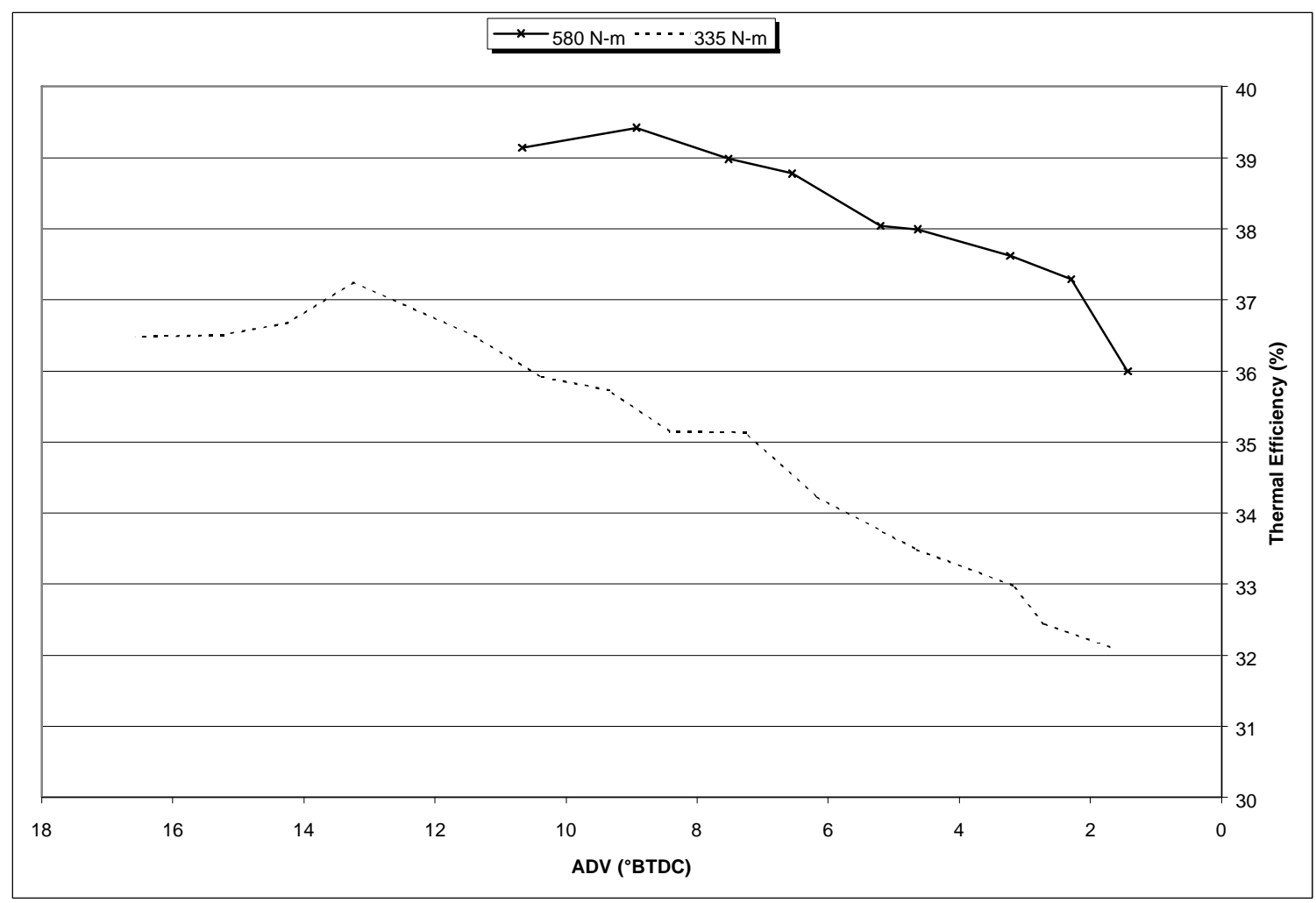

Figure 29: Dual fuel efficiency vs. ADV (1500 rpm; 335 N-m \& 580 N-m)

Finally, the effects of ICP were investigated. ICP and FIPW control the amount of diesel fuel injected. ICP was stepped from 4 to $14 \mathrm{MPa}$ in $1 \mathrm{MPa}$ increments and the FIPW was adjusted to maintain a constant torque. CNG flow and ADV were held constant and emissions and thermal efficiency were recorded. From Figures $30 \& 31$ it can be seen that the $\mathrm{NO}_{\mathrm{x}}$ levels were lowest at the lowest ICP, but from Figure 32 thermal efficiencies were also at a minimum (33\% at $335 \mathrm{~N}-\mathrm{m}$ and $35 \%$ at $580 \mathrm{~N}-\mathrm{m})$ at this point. At $335 \mathrm{~N}-\mathrm{m}, \mathrm{HC}$ and $\mathrm{CO}$ were at a maximum at the lowest ICP, while at $580 \mathrm{~N}-\mathrm{m}, \mathrm{CO}_{2}$ and $\mathrm{CO}$ were at maximum levels at the lowest ICP. This data shows how emissions change when the pilot is delivered in a short, high pressure burst or in a long, low pressure stream. Table 8 shows that the peak pressure increases as ICP increases which accounts for the $\mathrm{NO}_{\mathrm{x}}$ increase at high ICP. From this information, an ICP of $6 \mathrm{MPa}$ for the $335 \mathrm{~N}$-m set point and 4.5 MPa for the $580 \mathrm{~N}$-m set point were chosen. 


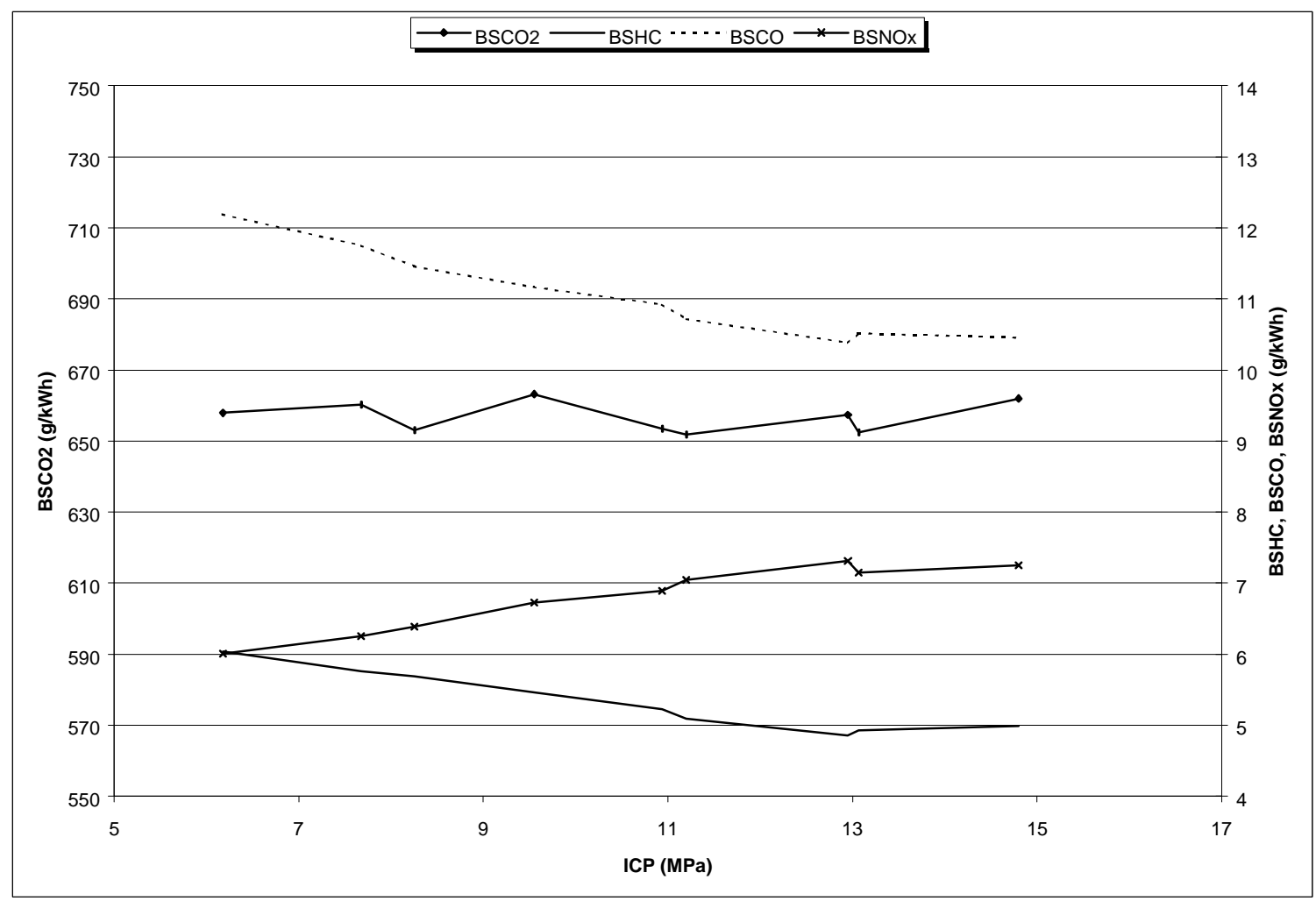

Figure 30: Dual fuel emissions vs. ICP (1500 rpm; 335 N-m; $4.75^{\circ}$ BTDC)

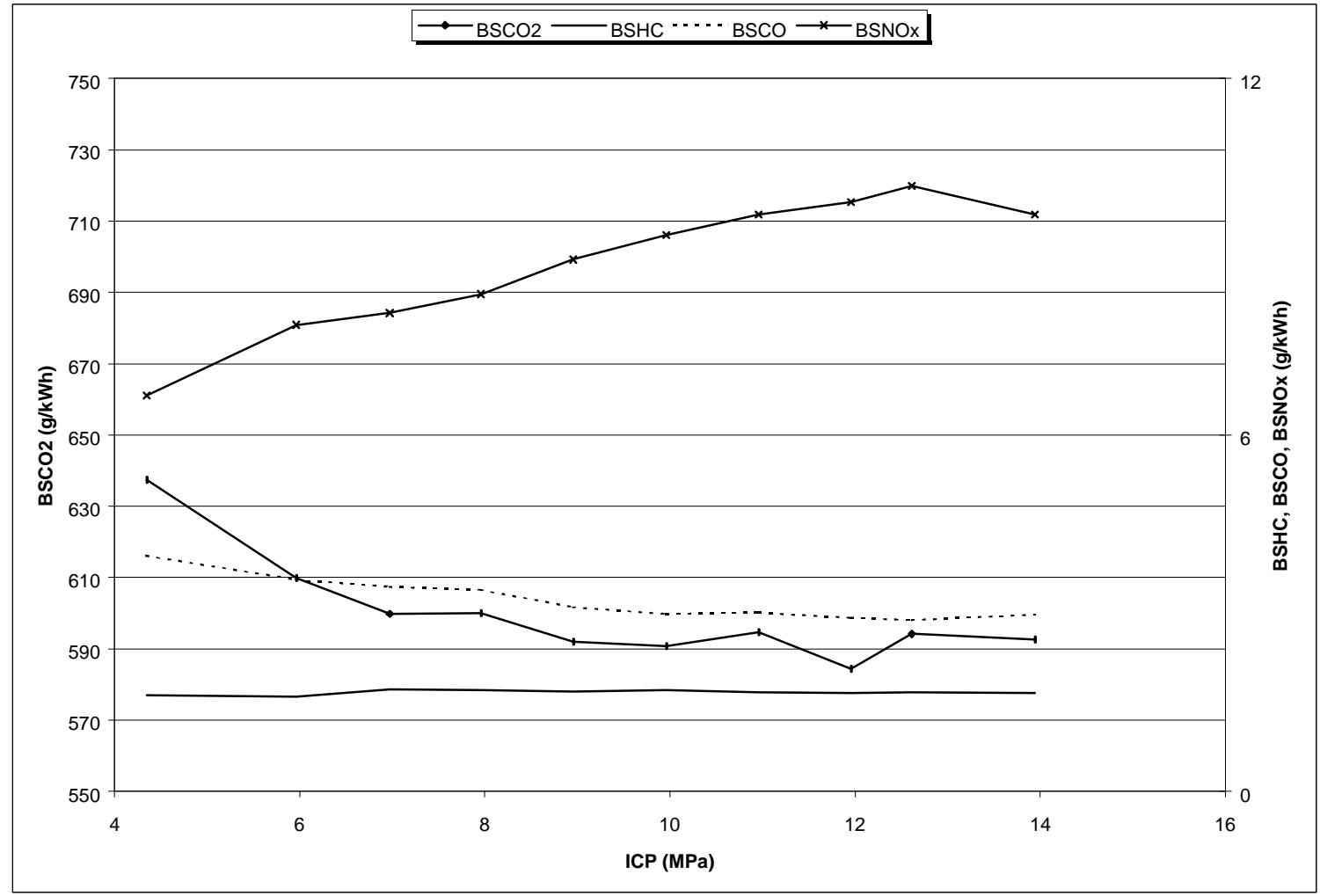

Figure 31: Dual fuel emissions vs. ICP (1500 rpm; $580 \mathrm{~N}-\mathrm{m} ; 2.5^{\circ}$ BTDC) 


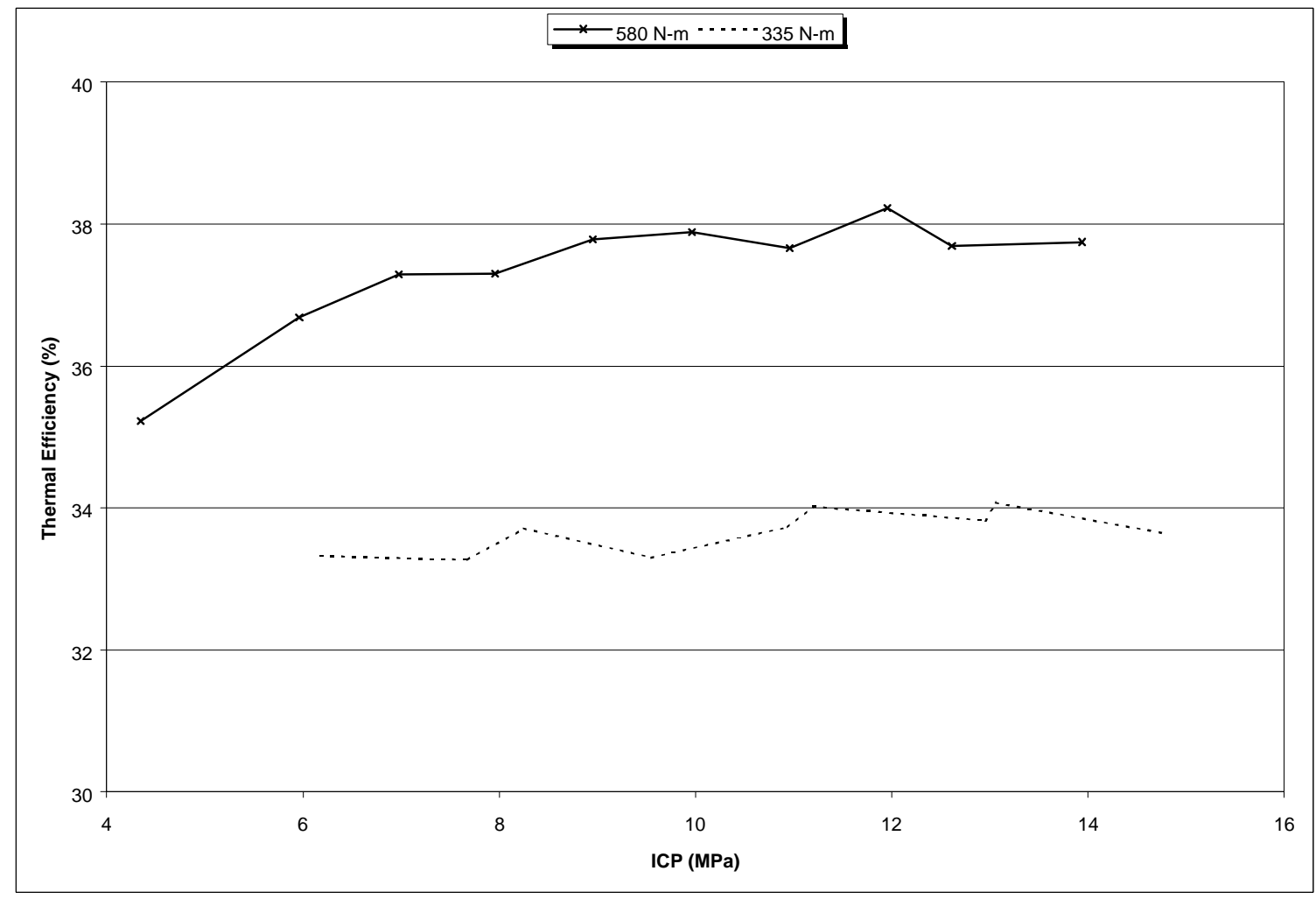

Figure 32: Dual fuel efficiency vs. ICP (1500 rpm; 335 N-m \& 580 N-m)

\begin{tabular}{|c|c|c|}
\hline & $\begin{array}{c}\text { ICP } \\
(\mathrm{MPa})\end{array}$ & $\begin{array}{c}\text { Peak Pres. } \\
(\mathrm{kPa})\end{array}$ \\
\hline $335 \mathrm{~N}-\mathrm{m}$ & 7 & 6562 \\
\hline & 13 & 7770 \\
\hline $580 \mathrm{~N}-\mathrm{m}$ & 7 & 8259 \\
\hline & 13 & 9751 \\
\hline
\end{tabular}

Table 8: Peak in-cylinder pressure for different ICP (335 N-m \& 580 N-m)

From these data, the final optimum settings based on emissions and efficiency were determined to be:

\begin{tabular}{|c|c|c|c|}
\hline & $\begin{array}{c}\text { FIPW } \\
(\mu \mathrm{s})\end{array}$ & $\begin{array}{c}\text { ADV } \\
\left({ }^{\circ} \mathrm{BTDC}\right)\end{array}$ & $\begin{array}{c}\text { ICP } \\
(\mathrm{MPa})\end{array}$ \\
\hline $335 \mathrm{~N}-\mathrm{m}$ & 1145 & 5.6 & 6 \\
\hline $580 \mathrm{~N}-\mathrm{m}$ & 1398 & 2.4 & 5 \\
\hline
\end{tabular}

Table 9: Dual fuel optimized FIPW, ADV, ICP (335 N-m \& 580 N-m) 


\subsubsection{Dual Fuel Steady State Test Data Using WVU-ECU}

With the optimum settings for FIPW, ADV, and ICP determined, the second set of comparative steady state tests was conducted with the engine running in dual fuel mode. The engine produced the following averaged emissions while running in the optimized dual fuel mode.

\begin{tabular}{|c|c|c|c|c|c|c|}
\hline & $\begin{array}{c}\mathrm{PM} \\
(\mathrm{g} / \mathrm{kWh})\end{array}$ & $\begin{array}{c}\mathrm{THC} \\
(\mathrm{g} / \mathrm{kWh})\end{array}$ & $\begin{array}{c}\mathrm{NMHC} \\
(\mathrm{g} / \mathrm{kWh})\end{array}$ & $\begin{array}{c}\mathrm{CO} \\
(\mathrm{g} / \mathrm{kWh})\end{array}$ & $\begin{array}{c}\mathrm{CO}_{2} \\
(\mathrm{~g} / \mathrm{kWh})\end{array}$ & $\begin{array}{c}\mathrm{NO}_{\mathrm{x}} \\
(\mathrm{g} / \mathrm{kWh})\end{array}$ \\
\hline $335 \mathrm{~N}-\mathrm{m}$ & 0.032 & 6.266 & 0.597 & 12.08 & 631.6 & 6.01 \\
\hline $580 \mathrm{~N}-\mathrm{m}$ & 0.058 & 1.780 & 0.295 & 4.737 & 615.3 & 6.28 \\
\hline
\end{tabular}

Table 10: Averaged DF emissions (335 N-m \& 580 N-m)

As in the diesel tests, dilution bags were analyzed using a gas chromatograph. It can be seen that the primary hydrocarbon constituent is methane, which is not a regulated emission. The following methane percentages were adjusted for background methane levels and used to calculate the NMHC concentration before the emissions from each mode were averaged:

\begin{tabular}{|l|c|c|c|}
\hline & $\begin{array}{c}\text { Methane } \\
(\mathrm{ppm})\end{array}$ & $\begin{array}{c}\text { THC } \\
(\mathrm{ppm})\end{array}$ & $\begin{array}{c}\% \\
\text { Methane } \\
\text { (less BG) }\end{array}$ \\
\hline $335 \mathrm{~N}-\mathrm{m} \mathrm{1}$ & 476.7 & 500.4 & 95.21 \\
\hline $335 \mathrm{~N}-\mathrm{m} 2$ & 406.5 & 456.5 & 88.69 \\
\hline $335 \mathrm{~N}-\mathrm{m} \mathrm{3}$ & 373.0 & 424.1 & 87.51 \\
\hline $580 \mathrm{~N}-\mathrm{m} \mathrm{1}$ & 411.0 & 481.7 & 84.82 \\
\hline $580 \mathrm{~N}-\mathrm{m} 2$ & 217.5 & 266.3 & 80.38 \\
\hline $580 \mathrm{~N}-\mathrm{m} 3$ & 389.9 & 455.5 & 85.06 \\
\hline
\end{tabular}

Table 11: Gas chromatograph data showing \% MHC

In-cylinder pressure data were collected, and HRR, COV(IMEPg) and ignition delay were calculated. P-V diagrams were also generated. The COV(IMEPg) is below $10 \%$ (Table 12) which indicates stable combustion with minimal cycle-to-cycle 
variations. This suggests that the engine would be driveable while operating under these conditions.

\begin{tabular}{|c|c|c|}
\hline & $\begin{array}{c}\text { COV(IMEPg) } \\
\%\end{array}$ & $\begin{array}{c}\text { Ign. Delay } \\
{ }^{\circ} \text { After SOI }\end{array}$ \\
\hline $335 \mathrm{~N}-\mathrm{m}$ & 7.85 & 15.80 \\
\hline $580 \mathrm{~N}-\mathrm{m}$ & 6.20 & 17.74 \\
\hline
\end{tabular}

Table 12: Dual fuel COV(IMEPg) \& ignition delay (335 N-m \& 580 N-m)

In Figures $33 \& 34$ it can be seen that there are two distinct pressure peaks. The first peak is due to compression of the gases in the cylinder with no heat addition from burning fuel - the motoring pressure trace. The second peak is due to late combustion of the diesel fuel and natural gas that takes place entirely after TDC. This reduces the peak pressure in the cylinder and therefore causes a reduction in $\mathrm{NO}_{\mathrm{x}}$.

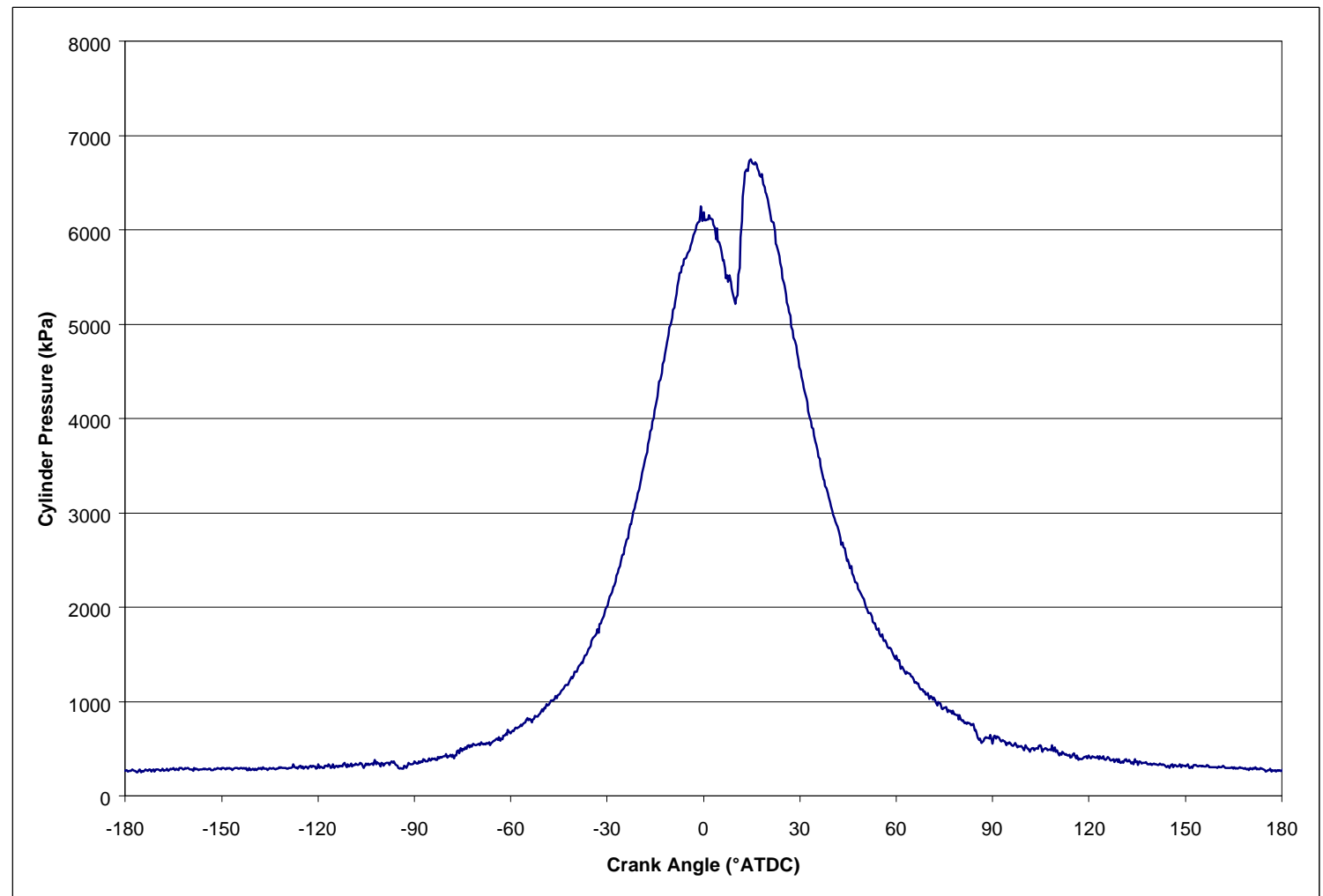

Figure 33: Dual fuel in-cylinder pressure vs. CA (1500 rpm; 335 N-m) 


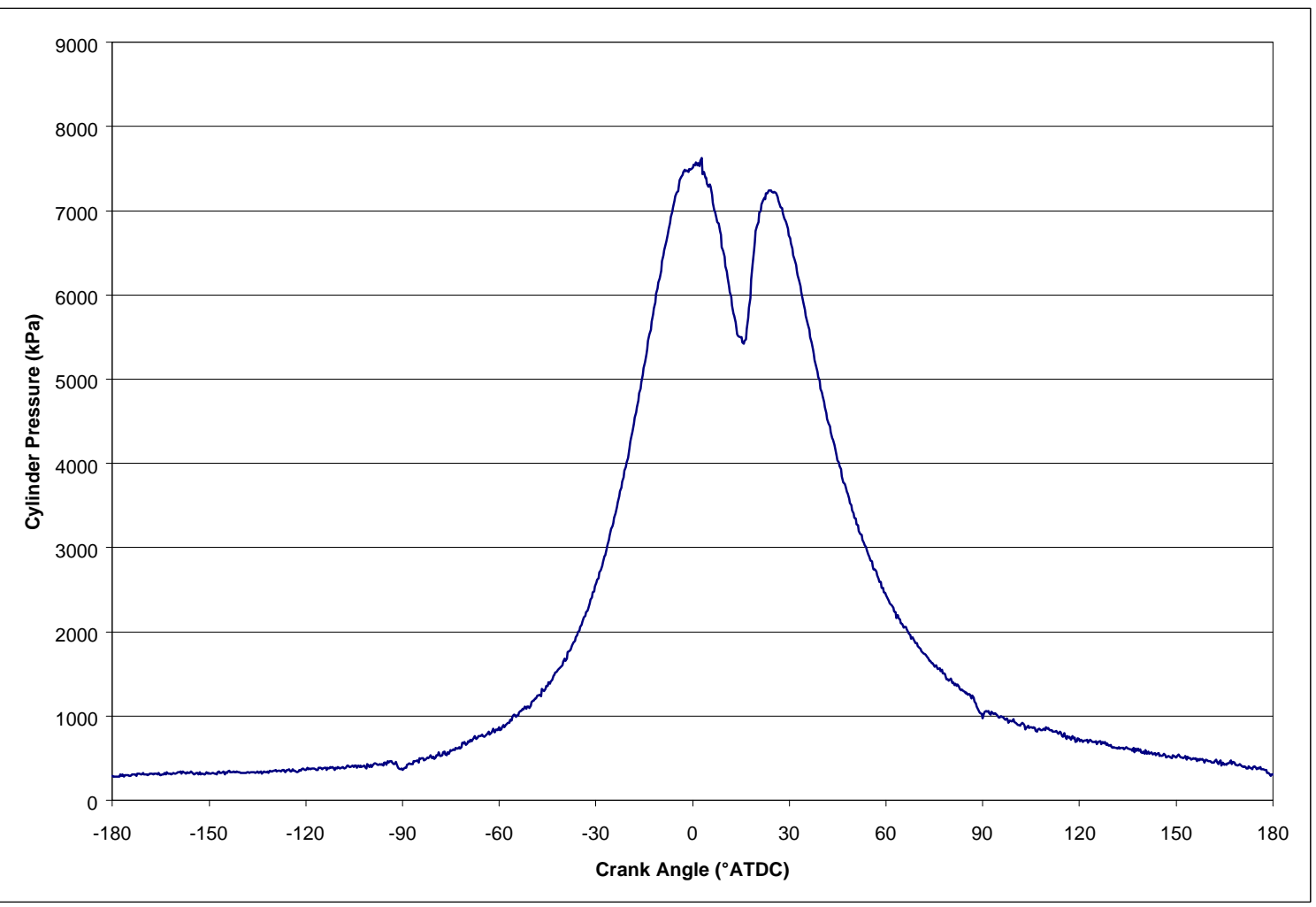

Figure 34: Dual fuel in-cylinder pressure vs. CA (1500 rpm; 580 N-m)

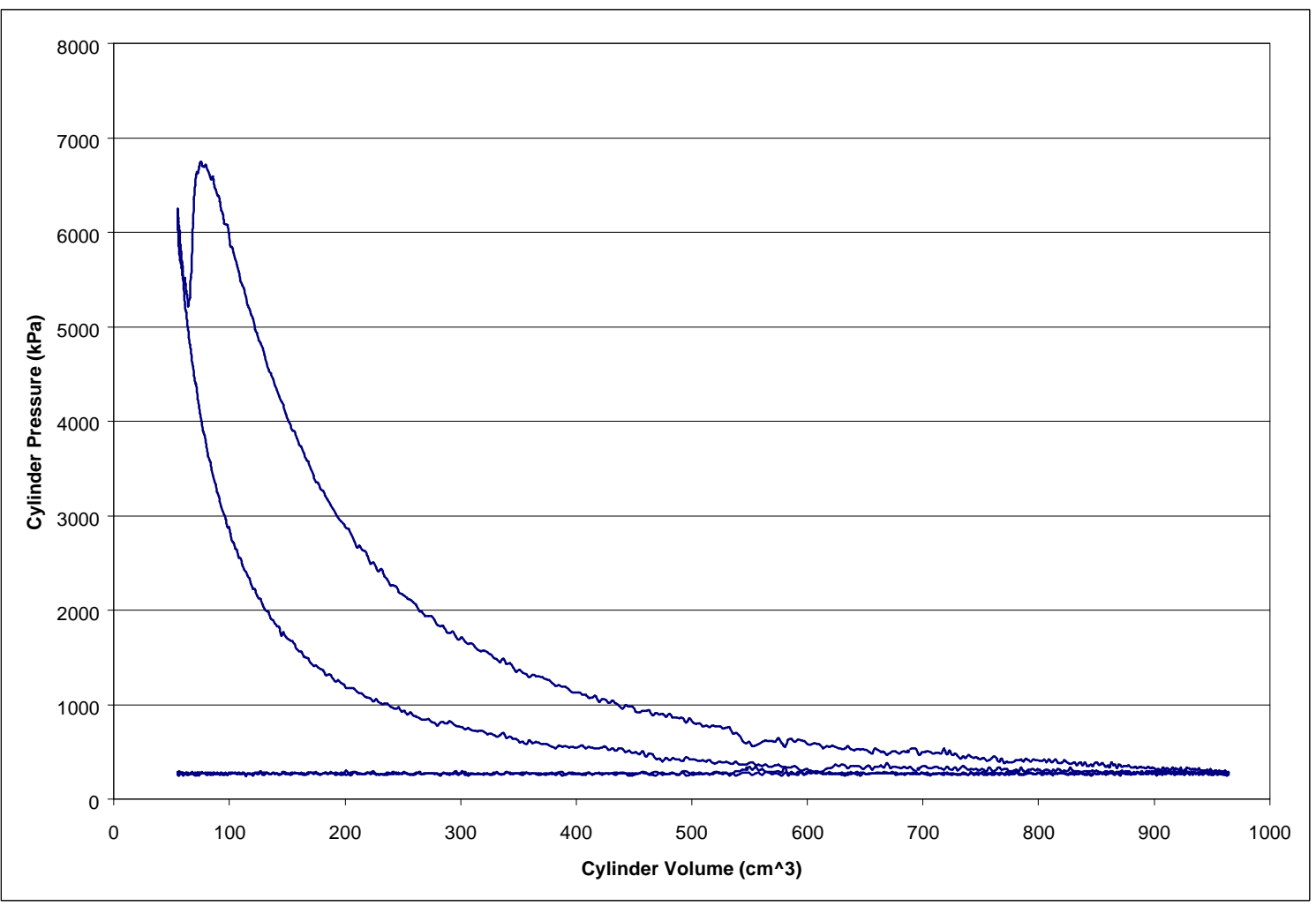

Figure 35: Dual fuel P-V diagram (1500 rpm; 335 N-m) 


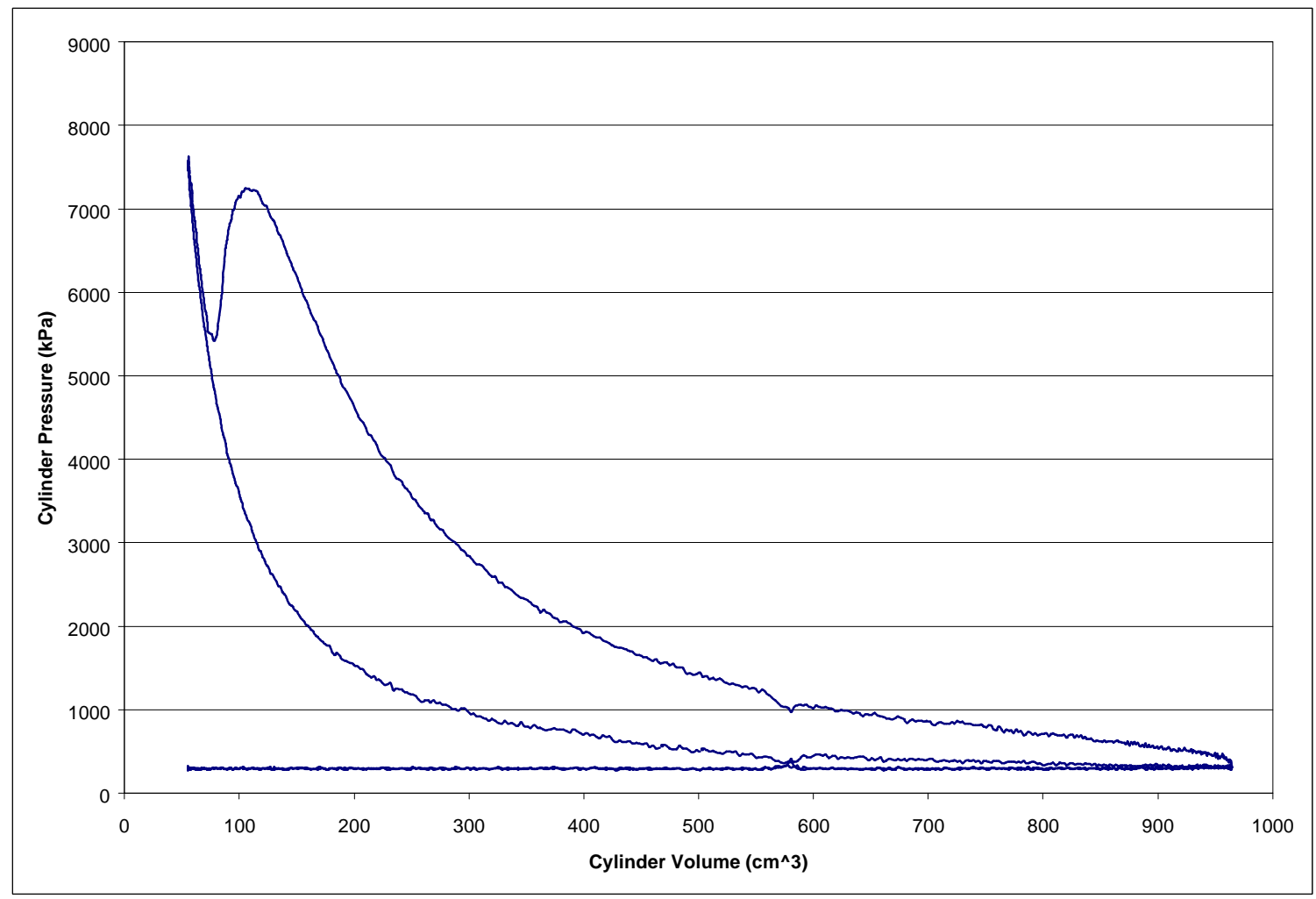

Figure 36: Dual fuel P-V diagram (1500 rpm; 580 N-m)

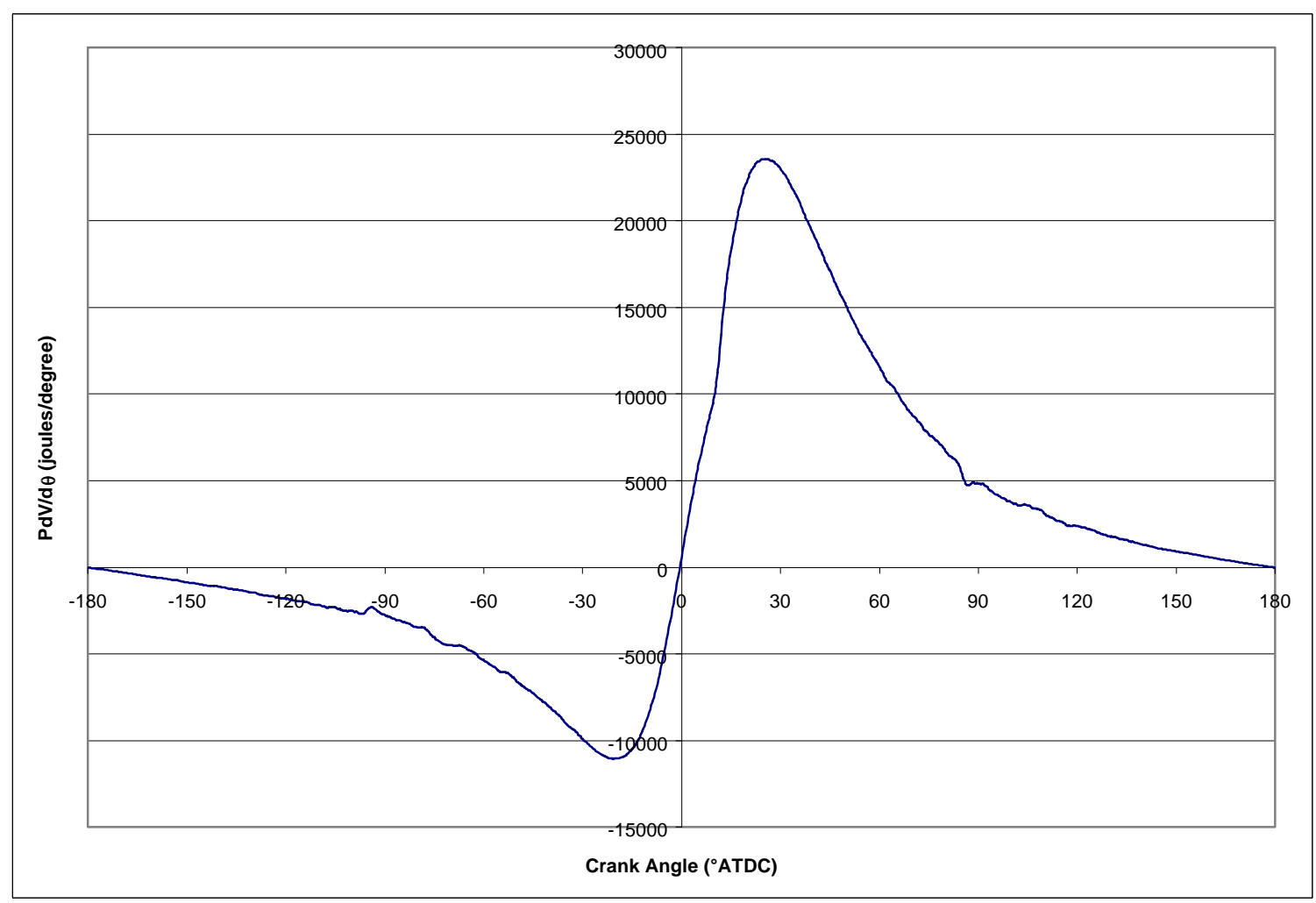

Figure 37: Dual fuel PdV/d $\theta$ vs. CA (1500 rpm; 335 N-m) 


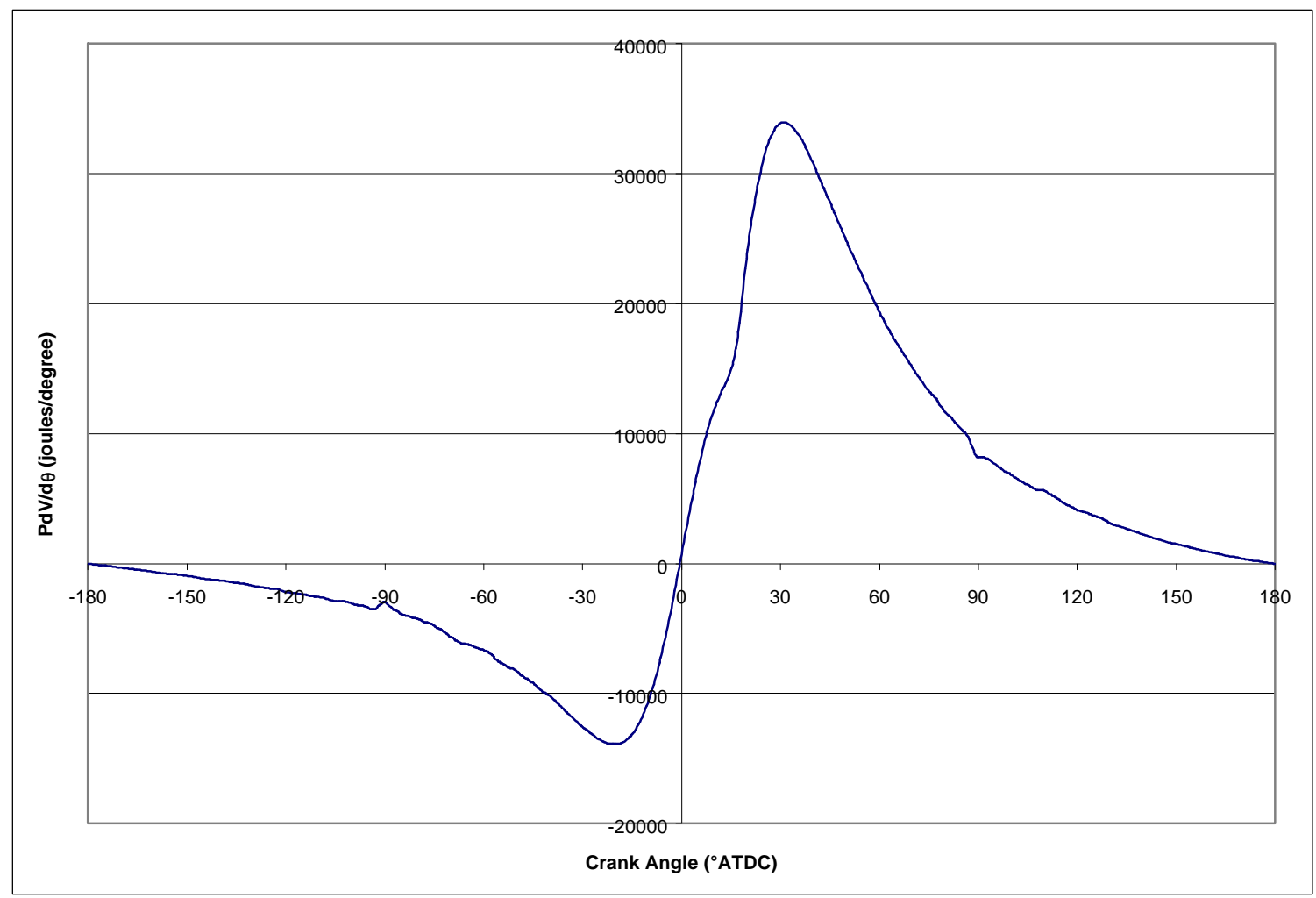

Figure 38: Dual fuel PdV/d $\theta$ vs. CA (1500 rpm; 580 N-m)

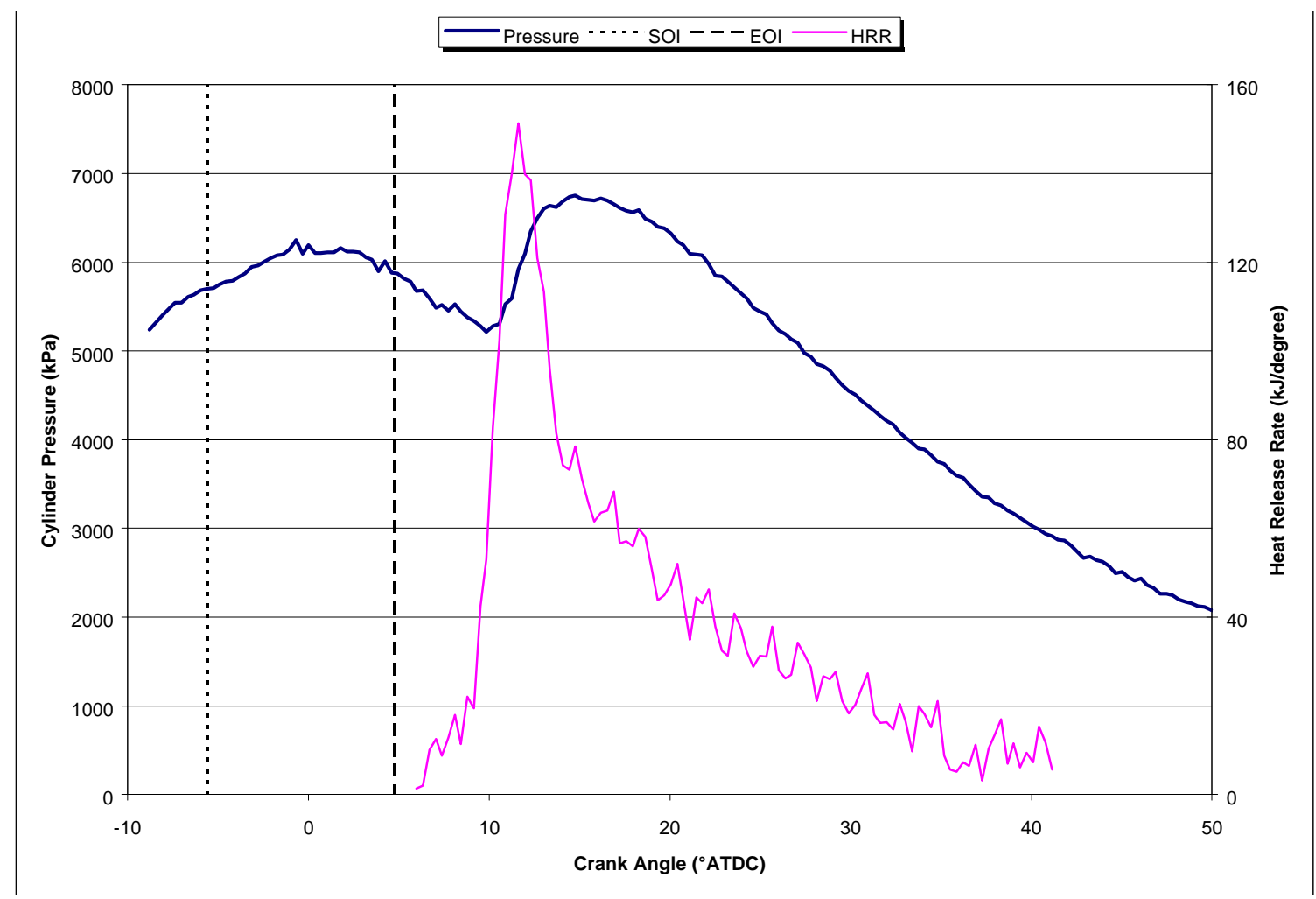

Figure 39: Dual fuel in-cylinder pressure \& HRR vs. CA (1500 rpm; 335 N-m) 


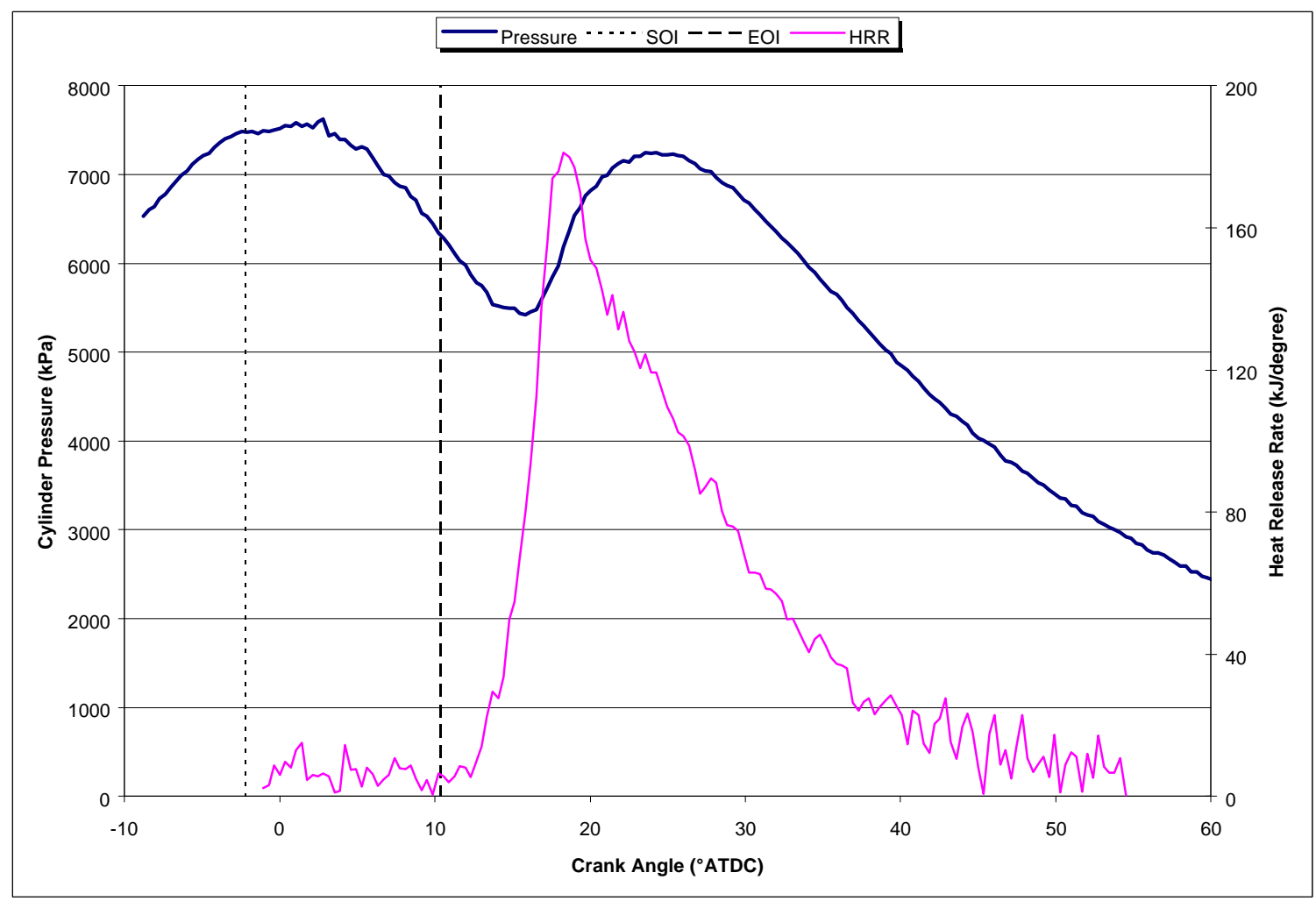

Figure 40: Dual fuel in-cylinder pressure \& HRR vs. CA (1500 rpm; 580 N-m)

The amount of diesel replacement was also calculated for each mode, using the diesel fuel flow rate from the fuel counter and the carbon balance, to find the CNG flow rate.

\begin{tabular}{|c|c|c|c|c|}
\hline & $\begin{array}{c}\text { CNG } \\
(\mathrm{g} / \mathrm{s})\end{array}$ & $\begin{array}{c}\text { D2 } \\
(\mathrm{g} / \mathrm{s})\end{array}$ & $\begin{array}{c}\text { CNG/D2 } \\
\text { (mass) }\end{array}$ & $\begin{array}{c}\text { CNG/D2 } \\
(\mathrm{LHV})\end{array}$ \\
\hline $335 \mathrm{~N}-\mathrm{m}$ & 3.016 & 1.229 & 2.454 & 2.840 \\
\hline $580 \mathrm{~N}-\mathrm{m}$ & 5.620 & 1.388 & 4.049 & 4.686 \\
\hline
\end{tabular}

Table 13: CNG/Diesel ratios (335 N-m \& 580 N-m)

\subsection{Comparison of Diesel and Dual Fuel Operation}

The dual fuel and diesel steady state tests were compared to determine what, if any, emissions and efficiency benefits were produced. $\mathrm{PM}, \mathrm{CO}_{2}$, and $\mathrm{NO}_{\mathrm{x}}$ emissions were significantly reduced compared to diesel operation, while there was a substantial increase 
in NMHC for both modes and an increase in $\mathrm{CO}$ at $335 \mathrm{~N}-\mathrm{m}$. The dramatic increase in $\mathrm{CO}$ is probably due to very late combustion. $\mathrm{CO}$ formation is a necessary intermediate step in $\mathrm{HC}$ oxidation as shown in the following equation in which $R$ represents the HC radical:

$$
R H \Rightarrow R \Rightarrow R O_{2} \Rightarrow R C H O \Rightarrow R C O \Rightarrow C O
$$

The $\mathrm{CO}$ is then oxidized in the following reaction:

$\mathrm{CO}+\mathrm{OH} \Leftrightarrow \mathrm{CO}_{2}+\mathrm{H}$

Since the combustion process is so late compared to diesel operation (see Figures $41 \&$ 42), this reaction never takes place and therefore, high amounts of $\mathrm{CO}$ remain in the exhaust gas [23].

\begin{tabular}{|c|c|c|c|c|c|c|c|}
\hline \multicolumn{2}{|c|}{ Emissions in $\mathrm{g} / \mathrm{kWh}$} & \multicolumn{2}{|c|}{1500 rpm, $335 \mathrm{~N}-\mathrm{m}$} & \multirow[b]{2}{*}{$\mathrm{CO}$} & \multirow[b]{2}{*}{$\mathrm{CO}_{2}$} & \multirow[b]{2}{*}{$\mathrm{NO}_{\mathrm{x}}$} & \multirow[b]{2}{*}{$\mathrm{NMHC}+\mathrm{NO}_{\mathrm{x}}$} \\
\hline & PM & THC & $\mathrm{NMHC}$ & & & & \\
\hline Diesel (EEC-IV) & 0.076 & 0.087 & 0.087 & 0.533 & 764.696 & 8.920 & 9.007 \\
\hline Dual Fuel & 0.032 & 6.266 & 0.597 & 12.075 & 631.617 & 6.011 & 6.608 \\
\hline$\%$ difference & -57.9 & 7094 & 585 & 2165 & -17.4 & -32.6 & -26.6 \\
\hline & & & & & & & \\
\hline \multicolumn{2}{|c|}{ Emissions in $\mathrm{g} / \mathrm{kWh}$} & \multicolumn{2}{|c|}{$1500 \mathrm{rpm}, 580 \mathrm{~N}-\mathrm{m}$} & & & & \\
\hline & PM & THC & NMHC & $\mathrm{CO}$ & $\mathrm{CO}_{2}$ & $\mathrm{NO}_{\mathrm{x}}$ & $\mathrm{NMHC}+\mathrm{NO}_{\mathrm{x}}$ \\
\hline Diesel (EEC-IV) & 0.213 & 0.026 & 0.026 & 4.610 & 746.576 & 7.781 & 7.808 \\
\hline Dual Fuel & 0.058 & 1.780 & 0.295 & 4.737 & 615.338 & 6.277 & 6.572 \\
\hline$\%$ difference & -73.0 & 6687 & 1025 & 2.8 & -17.6 & -19.3 & -15.8 \\
\hline
\end{tabular}

Table 14: Emissions comparison of DF \& diesel (335 N-m \& 580 N-m)

The engine obviously used less diesel fuel while operating in dual fuel mode. The exact quantity reduction was calculated and proved to be quite large.

\begin{tabular}{|c|c|c|c|}
\hline & $\begin{array}{c}\text { Diesel } \\
\text { Operation } \\
(\mathrm{g} / \mathrm{s})\end{array}$ & $\begin{array}{c}\text { Dual Fuel } \\
\text { Operation } \\
(\mathrm{g} / \mathrm{s})\end{array}$ & $\begin{array}{c}\text { Reduction } \\
\%\end{array}$ \\
\hline $335 \mathrm{~N}-\mathrm{m}$ & 3.5 & 1.3 & 64.6 \\
\hline $580 \mathrm{~N}-\mathrm{m}$ & 6.0 & 1.4 & 76.7 \\
\hline
\end{tabular}

Table 15: DF \& diesel operation diesel fuel usage (335 N-m \& $580 \mathrm{~N}-\mathrm{m})$ 
Thermal efficiency for diesel and dual fuel operation was calculated and compared. As can be seen in Table 16, there is slight increase in thermal efficiency for dual fuel operation.

\begin{tabular}{|c|c|c|c|}
\hline & $\begin{array}{c}\text { Diesel } \\
\text { Operation } \\
\%\end{array}$ & $\begin{array}{c}\text { Dual Fuel } \\
\text { Operation } \\
\%\end{array}$ & $\begin{array}{c}\text { Difference } \\
\%\end{array}$ \\
\hline $335 \mathrm{~N}-\mathrm{m}$ & 34.71 & 34.85 & 0.14 \\
\hline $580 \mathrm{~N}-\mathrm{m}$ & 35.26 & 36.67 & 1.41 \\
\hline
\end{tabular}

Table 16: Comparison of diesel and dual fuel thermal efficiency

A comparison of the heat release rates for diesel and optimized dual fuel operation was conducted. Boost pressure was checked and was found to be nearly unchanged from diesel (335 N-m: $114 \mathrm{kPa}, 580 \mathrm{~N}-\mathrm{m} 134 \mathrm{kPa}$ ) to dual fuel operation (335 N-m: $115 \mathrm{kPa}, 580 \mathrm{~N}-\mathrm{m} 139 \mathrm{kPa}$ ). Figure 41 shows that at $335 \mathrm{~N}-\mathrm{m}$ the diesel and dual fuel heat release rate curves are strikingly similar with slightly more heat released during the diffusion combustion phase for dual fuel operation than for diesel operation. However, in Figure 42, the diesel and dual fuel heat release rate profiles at $580 \mathrm{~N}-\mathrm{m}$ are very different from the $335 \mathrm{~N}-\mathrm{m}$ set point. There is no definitive premixed or diffusion combustion phase for diesel or dual fuel operation. This is probably due to the richer natural gas/air mixture which burns more rapidly than the leaner mixtures present in lighter load situations. In both the $335 \mathrm{~N}-\mathrm{m}$ and the $580 \mathrm{~N}-\mathrm{m}$ modes, the point of maximum heat release was later for dual fuel operation than for diesel. 


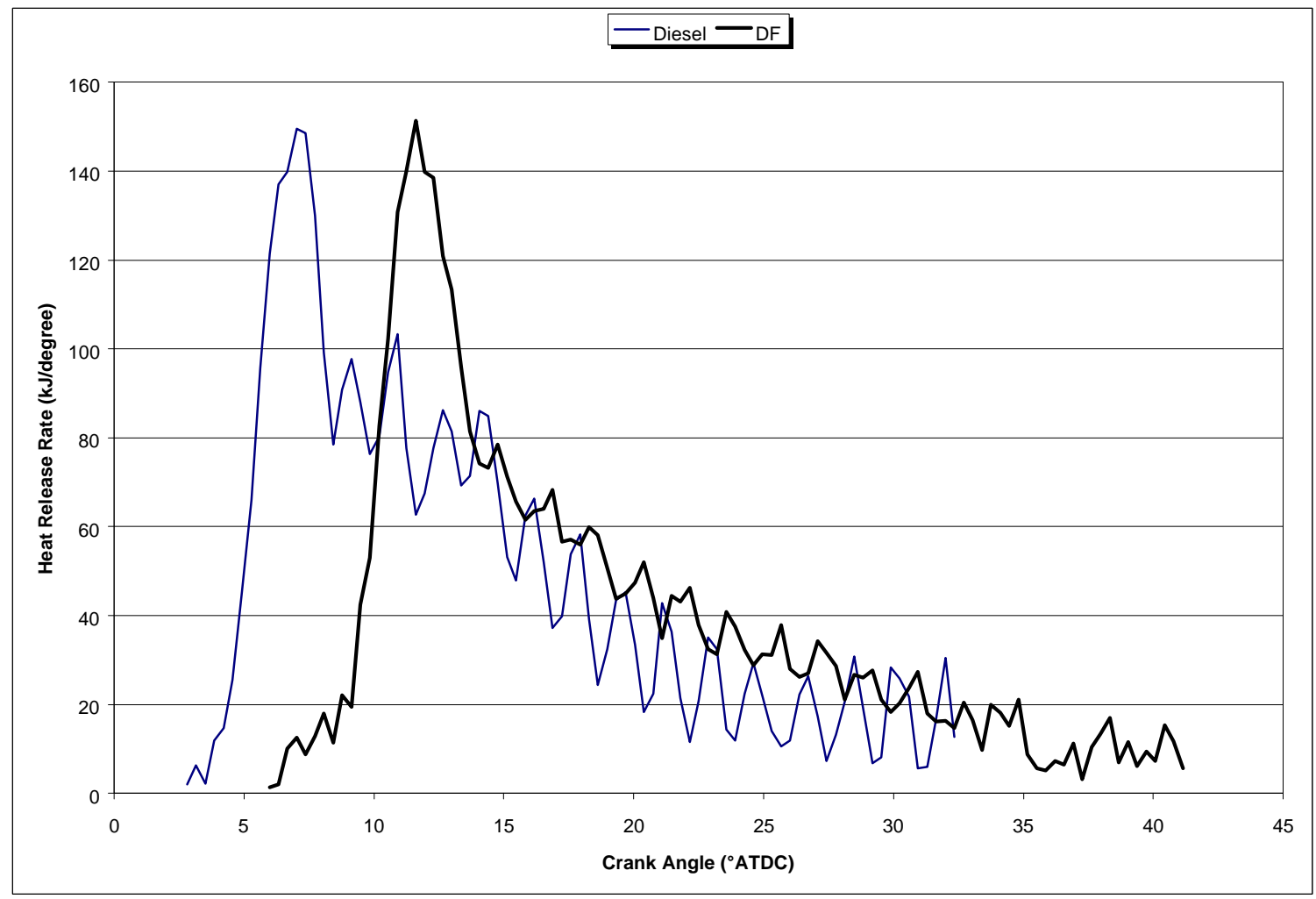

Figure 41: Dual fuel and diesel heat release rate comparison (1500 rpm; 335 N-m)

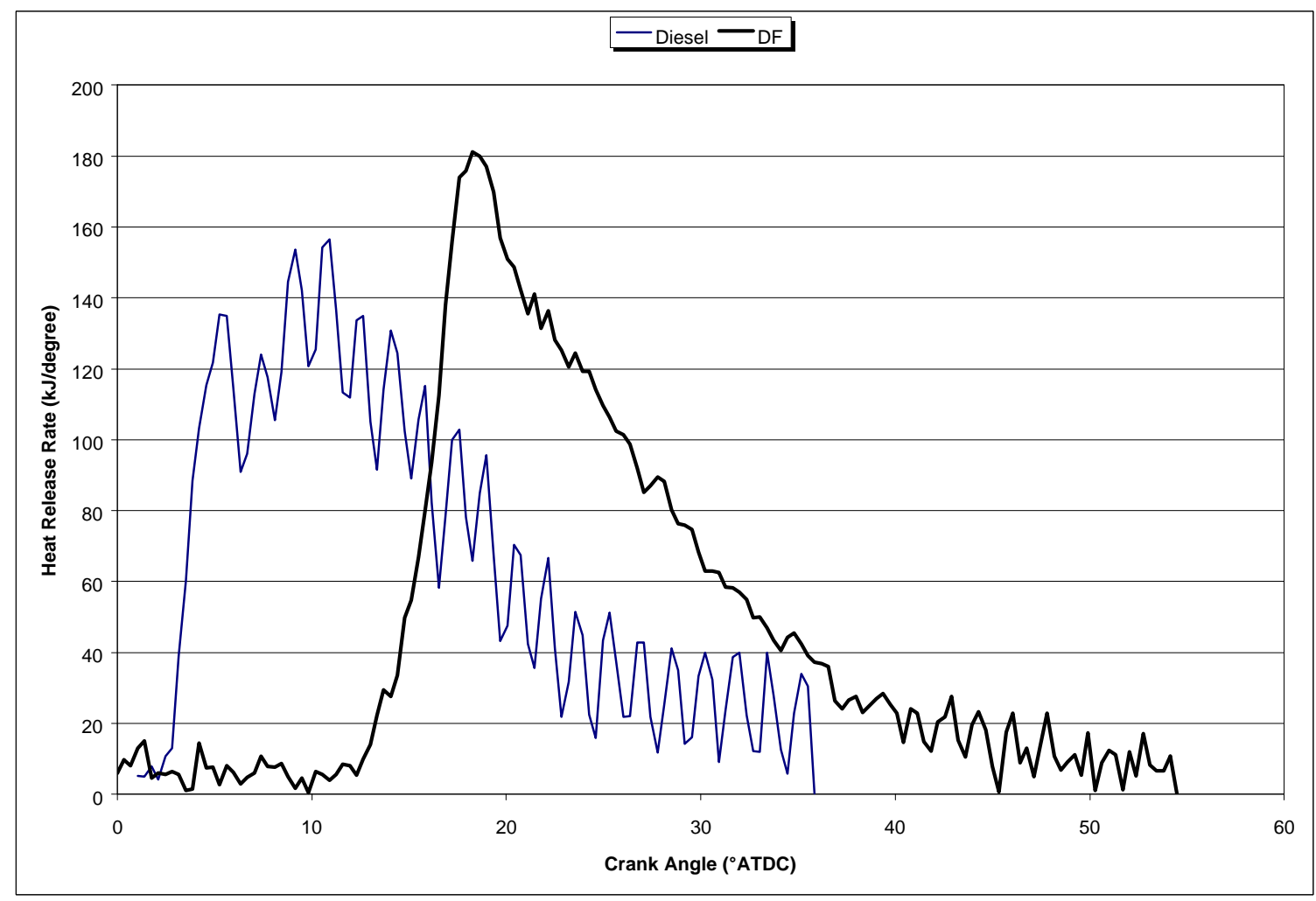

Figure 42: Dual fuel and diesel heat release rate comparison (1500 rpm; $580 \mathrm{~N}-\mathrm{m})$ 
Figures $43 \& 44$ compare the in-cylinder pressures for the engine running in diesel-only and dual fuel mode. Figures $45 \& 46$ compare the $\mathrm{PdV} / \mathrm{d} \theta$ plots. It can be seen that the pressure traces, as well as the $\mathrm{PdV} / \mathrm{d} \theta$ plots are very different. This initially caused concern since the engine was producing the same power for the diesel-only and dual fuel modes. However, upon further investigation, it was found that the IMEPg for each operating condition was similar (6\% difference for $335 \mathrm{~N}-\mathrm{m}$; $10 \%$ difference for $580 \mathrm{~N}$-m). Ideally, the IMEPg would have been identical for each mode regardless of fuel type since the engine was producing the same power. The small differences in IMEPg can be explained by the cylinder-to-cylinder injector variations that cause some cylinders to produce less power than others. This behavior was observed while the engine was idling on diesel fuel only, when one of the instrumented cylinders was actually operating parasitically, rather than making a contribution to the overall output of the engine. Another explanation is that uneven mixing of the natural gas and air caused a lower fuel/air ratio in one or more of the cylinders which would account for the lowered IMEPg in those cylinders. Since only two cylinders out of eight were instrumented for pressure, it must be assumed that some of the other cylinders were making up the IMEPg difference. An entirely different explanation of this behavior is that since the ICP was lower for the dual fuel operation (6 MPa at $335 \mathrm{~N}-\mathrm{m}$ and $5 \mathrm{MPa}$ at $580 \mathrm{~N}-\mathrm{m}$ compared to $11 \mathrm{MPa}$ for diesel-only operation) the parasitic losses to the high pressure oil pump were lowered. This would make the required IMEPg lower to achieve the same net power output. 


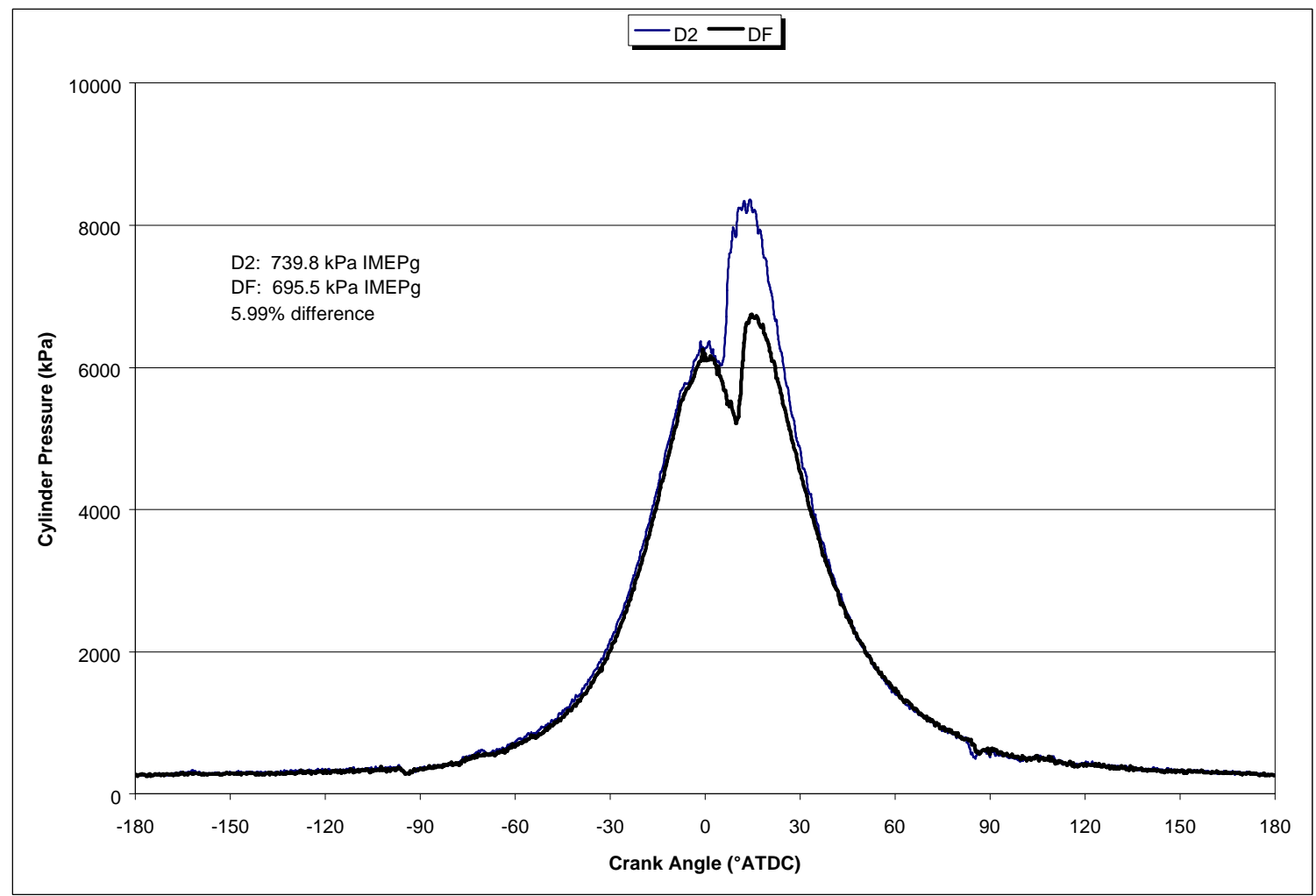

Figure 43: Dual fuel and diesel in-cylinder pressure and IMEPg comparison (1500 rpm; 335 N-m)

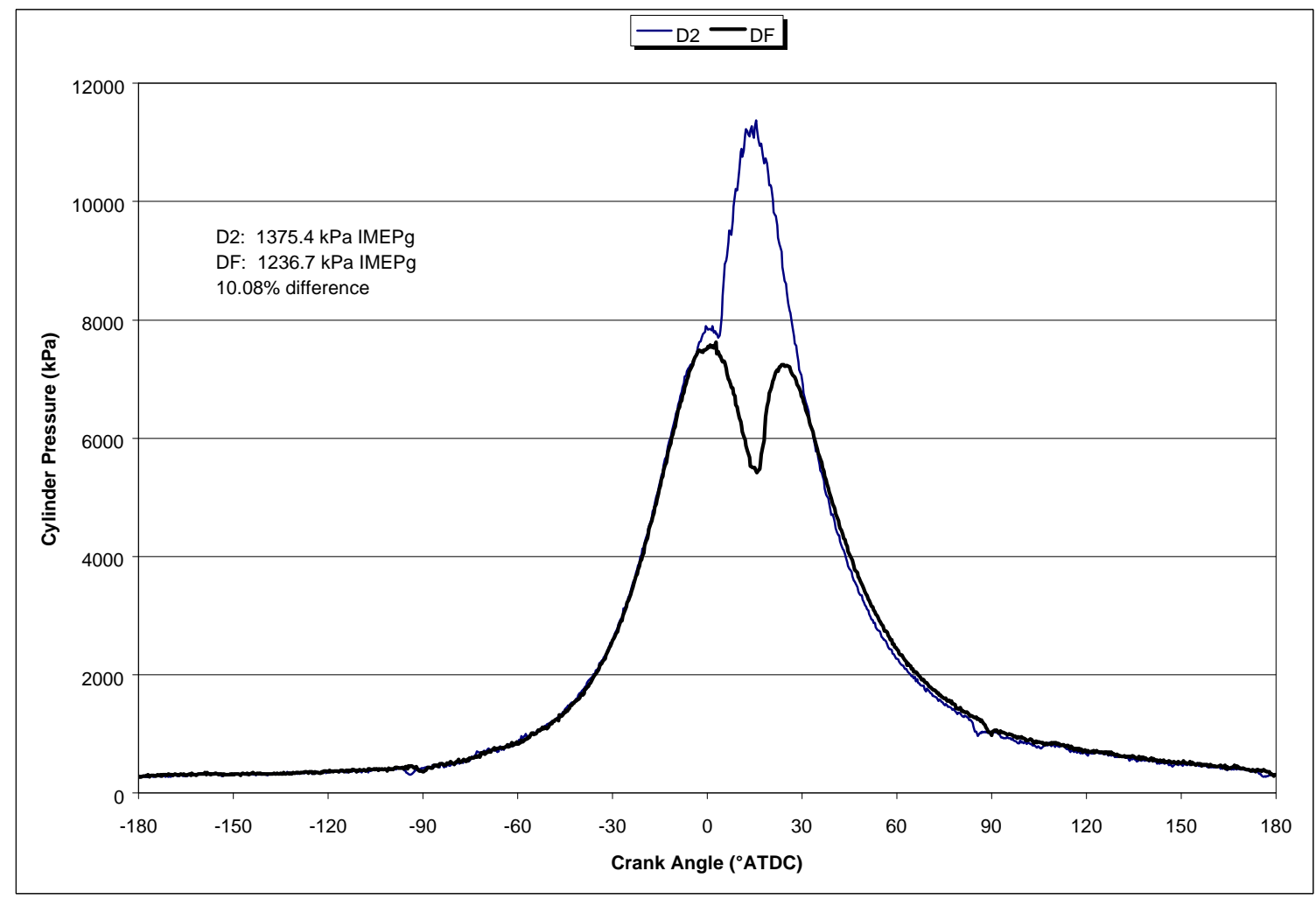

Figure 44: Dual fuel and diesel in-cylinder pressure and IMEPg comparison (1500 rpm; 580 N-m) 


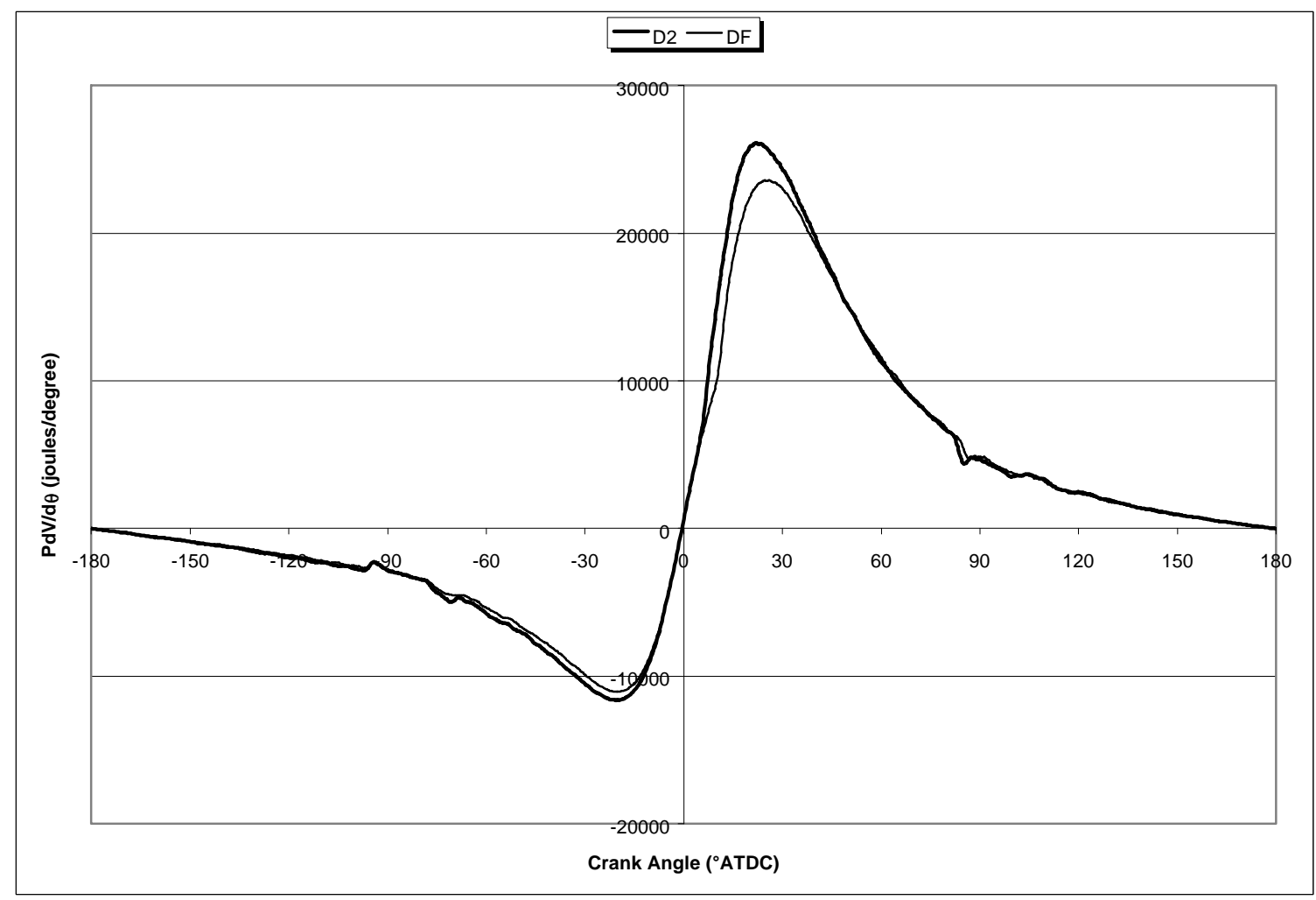

Figure 45: Dual fuel and diesel PdV/d $\theta$ comparison (1500 rpm; 335 N-m)

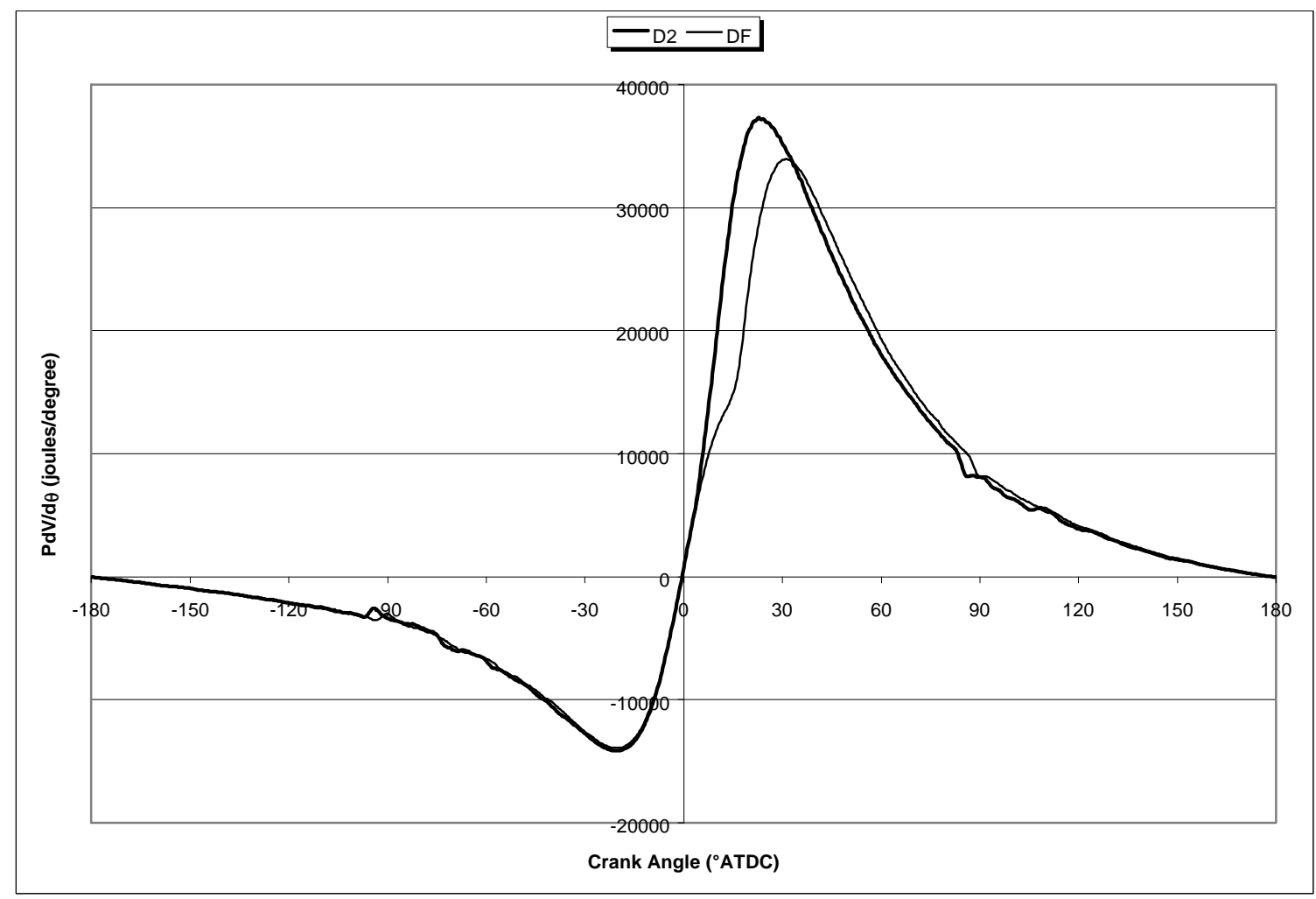

Figure 46: Dual fuel and diesel PdV/d $\theta$ comparison (1500 rpm; $580 \mathrm{~N}-\mathrm{m}$ ) 


\section{Conclusions \& Recommendations}

Over the course of this project, a direct injected diesel engine was converted to pilot-injected dual fuel operation with natural gas. However, many small intermediate steps were required to determine if any real emissions and efficiency benefits would be realized from this conversion. First, the engine had the be tested in its original configuration, and then a completely new engine control unit had to be designed, built, and fitted to perform extensive sweep testing of engine operation parameters including FIPW, ADV, ICP, and CNG flow, among others. Optimized dual fuel operation parameters were found using the information gathered from these sweeps. Finally, the engine was tested in optimized dual fuel mode to compare and confirm any emissions and efficiency improvements that resulted.

The comparative data presented in Chapter 4 shows that there were indeed significant improvements in emissions of $\mathrm{NO}_{\mathrm{x}}$ and $\mathrm{PM}$ for dual fuel operation. Even more noteworthy is the fact that reduction in $\mathrm{NO}_{\mathrm{x}}$ and $\mathrm{PM}$ come with a slight increase in thermal efficiency. These benefits appear with a dramatic decrease in diesel fuel usage compared to diesel-only operation. However, these benefits come with a price. Both THC and NMHC, as well as CO production, increased substantially over diesel-only levels. Although this is a concern, it should not cause alarm because $\mathrm{CO}$ and $\mathrm{HC}$ are easily reduced by exhaust after-treatment with an oxidation catalyst. This research also showed that the HEUI injection system is well suited for use in a dual fuel conversion since it allows for flexible fuel injection, critical for reducing the dual fuel emissions.

Admittedly, the scope of this research is limited as only two set points were investigated. However, it does prove that emissions and efficiency improvements over 
diesel-only operation can be obtained with a dual fuel conversion and provides the groundwork for more extensive research. Future work should focus on optimizing the engine for more speeds and loads with the final goal being a complete dual fuel control scheme with special attention to further reduction of pilot quantities. Once the engine is fully optimized for steady state dual fuel operation, then transient tests may be attempted.

Other methods of emissions reduction should also be researched. Some methods include exhaust gas recirculation which was named earlier as a means to reduce $\mathrm{HC}$ emissions at light load, turbocharger air bypass, and possibly an investigation of different pilot fuels such as dimethyl ether and Fischer-Tropsch fuels.

An attempt to further minimize diesel usage should also be made. Modified HEUI injectors capable of injecting micro pilot quantities of diesel fuel could be used. The use of a well matched set of micro pilot injectors would also alleviate the cylinderto-cylinder injection variations that caused the apparent IMEPg differences between dual fuel and diesel-only operation.

In general, it can be seen from this research that dual fuel engines are a viable way to use environmentally and economically appealing natural gas directly as a vehicular fuel. A dual fuel engine, when properly optimized, can produce lower emissions than a diesel engine with diesel-like thermal efficiency, while offering a significant reduction in diesel fuel usage and acceptable driveability. 


\section{References}

1. Weaver, C. S. and Turner, S. H., "Dual Fuel Natural Gas/Diesel Engines: Technology, Performance, and Emissions," SAE Paper 940548.

2. Varde, K. S., "Propane Fumigation in a Direct Injection Type Diesel Engine," SAE Paper 831354.

3. Daisho, Y., Takahashi, Y. I., Nakayama, S., Kihara, R., Saito, T., "Controlling Combustion and Exhaust Emissions in a Direct-Injection Diesel Engine Dual-Fueled with Natural Gas," SAE Paper 952436.

4. Brogan, T. R., Graboski, M. S., Macomber, J. R., Helmich, M. J., Schaub, F. S., "Operation of a Large Bore Medium Speed Turbosupercharged Dual Fuel Engine on Low BTU Wood Gas," ASME 1993 ICE-Vol. 20 pp. 51-66.

5. Aly, H.and Siemer, G., "Experimental Investigation of Gaseous Hydrogen Utilization in a Dual-Fuel Engine for Stationary Power Plants," ASME 1993 ICE-Vol. 20 pp. 6779.

6. Poonia, M. P., Ramesh, A., Gaur, R. R., "Effect of Intake Air Temperature and Pilot Fuel Quantity on the Combustion Characteristics of a LPG Dual Fuel Engine," SAE Paper 982455.

7. Dardalis, D., Matthews, R. D., Lewis, D., Davis, K., "The Texas Project, Part 5 Economic Analysis: CNG and LPG Conversions of Light-Duty Vehicle Fleets," SAE Paper 982447.

8. Liss, W. E., Thrasher, W. H., "Natural Gas as a Stationary and Vehicular Fuel," SAE Paper 912364.

9. Hupperich, P., Dürnhoiz, M., "Time-Controller Pilot Injection for Stationary and Heavy-Duty Gas Engines," SAE Paper 971713.

10. Karim, G. A., Liu, Z., Jones, W., "Exhaust Emissions from Dual Fuel Engines at Light Load," SAE Paper 932822.

11. Gebert, K., Beck, N. J., Barkhimer, R. L., Wong, H., "Strategies to Improve Combustion and Emission Characteristics of Dual Fuel Pilot Ignited Natural Gas Engines," SAE Paper 971712.

12. Karim, G. A., "An Examination of Some Measures for Improving the Performance of Gas Fuelled Diesel Engines at Light Load," SAE Paper 912366.

13. Liu, Z., Karim, G. A., "The Ignition Delay Period in Dual Fuel Engines," SAE Paper 950466. 
14. Li, X., Chippior, W. L., Gülder, O., L., "Effects of Cetane Enhancing Additives and Ignition Quality on Diesel Engine Emissions," SAE Paper 972968.

15. Gunea, C., Razavi M. R. M., Karim, G. A., "The Effects of Pilot Fuel Quality on Dual Fuel Engine Ignition Delay," SAE Paper 982453.

16. Gebert, K., Beck, N. J., Barkhimer, R. L., Wong, H., "Development of Pilot Fuel Injection System for CNG Engine," SAE Paper 961100.

17. Liu, Z., Karim, G. A., "A Predictive Model for the Combustion Process in Dual Fuel Engines," SAE Paper 952435.

18. Miyoshi, N., Matsumoto, S., Katoh, K., Tanaka, T., Harada, J., Takahashi, N., Yokota, K., Sugiura, M., Kasahara, K., "Development of a new Concept Three-Way Catalyst for Automotive Lean-Burn Engines," SAE Paper 950809.

19. Penetrante, B. M., Bruasaco, R. M., Merritt, B. T., Pitz, W. J., Vogtlin, G. E., Kung, M. C., Kung, H. H., Wan, C. Z., Voss, K. E., "Plasma Assisted Catalytic Reduction of $\mathrm{NO}_{\mathrm{x}}, "$ SAE Paper 982508.

20. Lancaster, D. R., Krieger, R. B., Lienesch, J. H., "Measurement and Analysis of Engine Pressure Data," SAE Paper 750026.

21. Heywood, J. B., Internal Combustion Engine Fundamentals, McGraw-Hill, New York, NY, 1988.

22. Matekunas, F. A., "Modes and Measures of Cyclic Combustion Variability," SAE Paper 830337.

23. Degobert, P., Automobiles and Pollution, SAE Publications, Warrendale, PA, 1995. 


\section{Appendix A: Natural gas analysis}

A sample of the natural gas used in testing was taken from the West Virginia University supply and sent to Gas Analytical Services, Inc., of Bridgeport, WV for analysis. The following analysis was used for all calculations involving natural gas.

\begin{tabular}{|c|c|c|c|}
\hline \multicolumn{4}{|c|}{ Natural gas fractional analysis } \\
\hline Component & MOL\% & $M$ & MOL\% ${ }^{*} M$ \\
\hline methane & 96.113 & 16.043 & 15.419409 \\
\hline ethane & 2.571 & 30.07 & 0.7730997 \\
\hline propane & 0.359 & 44.097 & 0.1583082 \\
\hline I-butane & 5 & 3.124 & 9062 \\
\hline N-butane & 0.09 & 58.124 & 0.0523116 \\
\hline I-pentane & 0.01 & 72.151 & 0.0072151 \\
\hline N-pentane & 0 & 72.151 & \\
\hline nitrogen & 0.598 & 28.016 & 5357 \\
\hline $\mathrm{CO} 2$ & 0.149 & 44.011 & 0.0655764 \\
\hline oxygen & 0 & 32 & \\
\hline hexanes & 0.06 & 86.178 & 0.0517068 \\
\hline \multicolumn{3}{|c|}{ Apparent Molecular Weight: } & 16.724224 \\
\hline
\end{tabular}

Table 17: Natural gas analysis 


\section{Appendix B: Natural gas control valve calibration}

The IMPCO natural gas control valve was supplied with the following calibration information. This information was used to generate a calibration equation which was used to convert the signal from the gas mass sensor to engineering units.

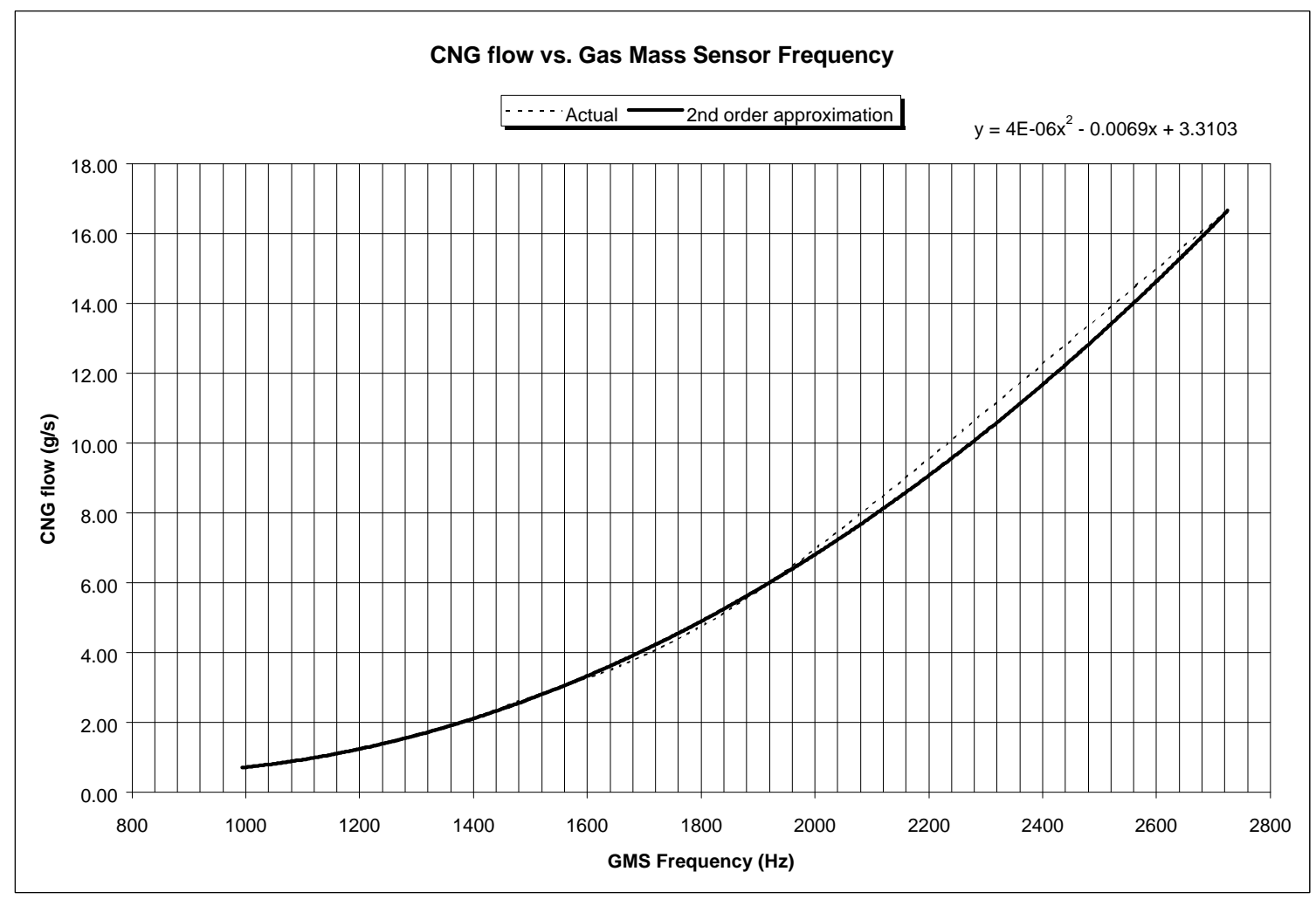

Figure 47: IMPCO gas mass sensor calibration 


\section{Appendix C: WVU-ECU Pinout diagram}

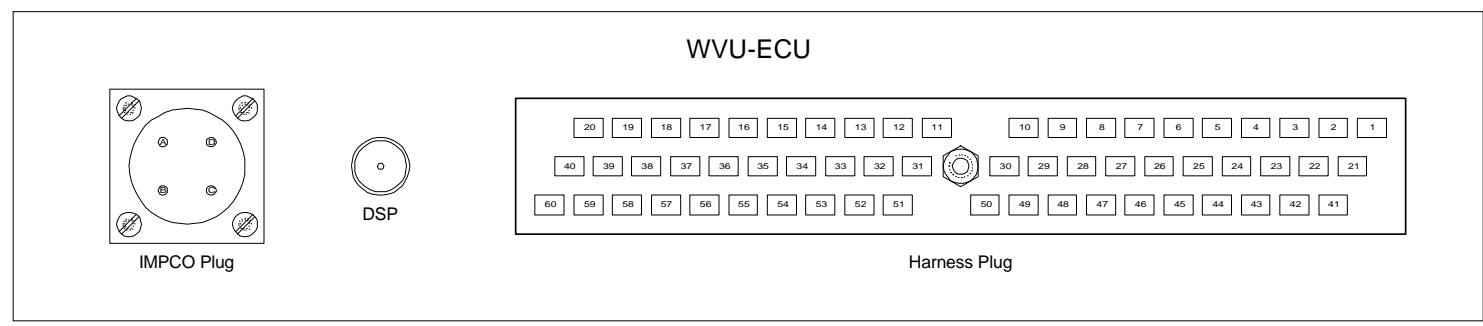

Figure 48: View of the interface end of the WVU-ECU

\begin{tabular}{|l|l|l|l|}
\hline \multicolumn{2}{|l|}{ IMPCO Plug } & \multicolumn{2}{l|}{ harness Plug } \\
\hline A & $+12 \mathrm{~V}$ & 7 & ECT \\
\hline B & GND & 14 & EOT \\
\hline C & MCV(desired) & 20 & GND \\
\hline D & GMS(measured) & 21 & ICPR \\
\hline & & 22 & FDCS \\
\hline & & 24 & IDM_F \\
\hline & & 26 & VREF(+5V) \\
\hline & & 27 & ICP \\
\hline & & 31 & CAMP GND \\
\hline & & 33 & IDM_EN \\
\hline & & 34 & FIS \\
\hline & & 37 & +12 V \\
\hline & & 40 & GND \\
\hline & & 45 & MAP \\
\hline & & 46 & SIGGND \\
\hline & & 47 & APS \\
\hline & & 50 & CNG Flow (MCV) \\
\hline & & 51 & CNG Flow (GMS) \\
\hline & & 56 & CAMP \\
\hline & & 57 & +12 V \\
\hline & & 60 & GND \\
\hline
\end{tabular}

Table 18: WVU-ECU Pinouts*

\footnotetext{
* The DSP (Digital Signal Processing) connection was an additional signal provided for another project and was not used in this research.
} 


\section{Appendix D: WVU-ECU Wiring diagrams}

The following pages contain the circuit diagrams for the WVU-ECU. 


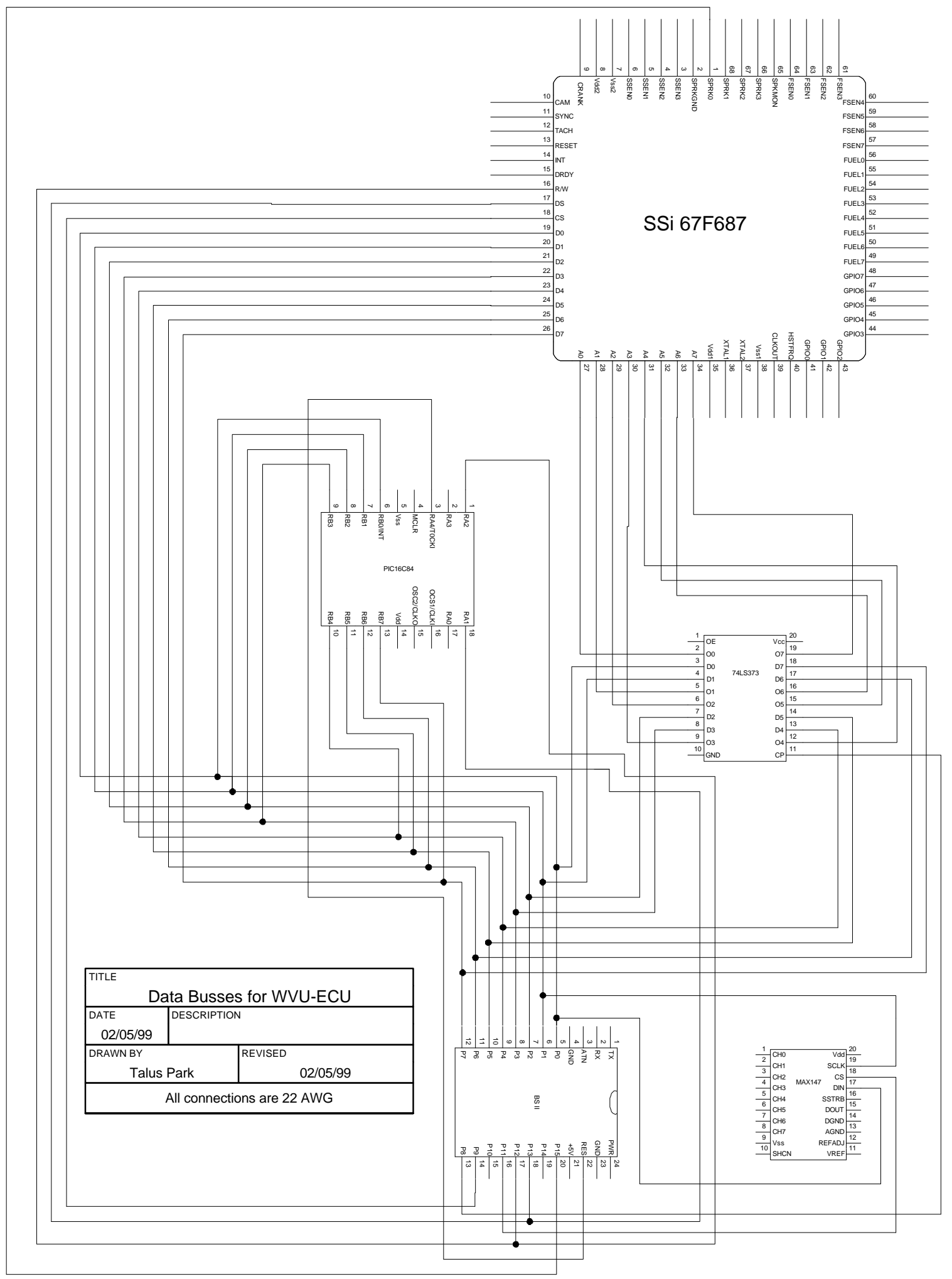




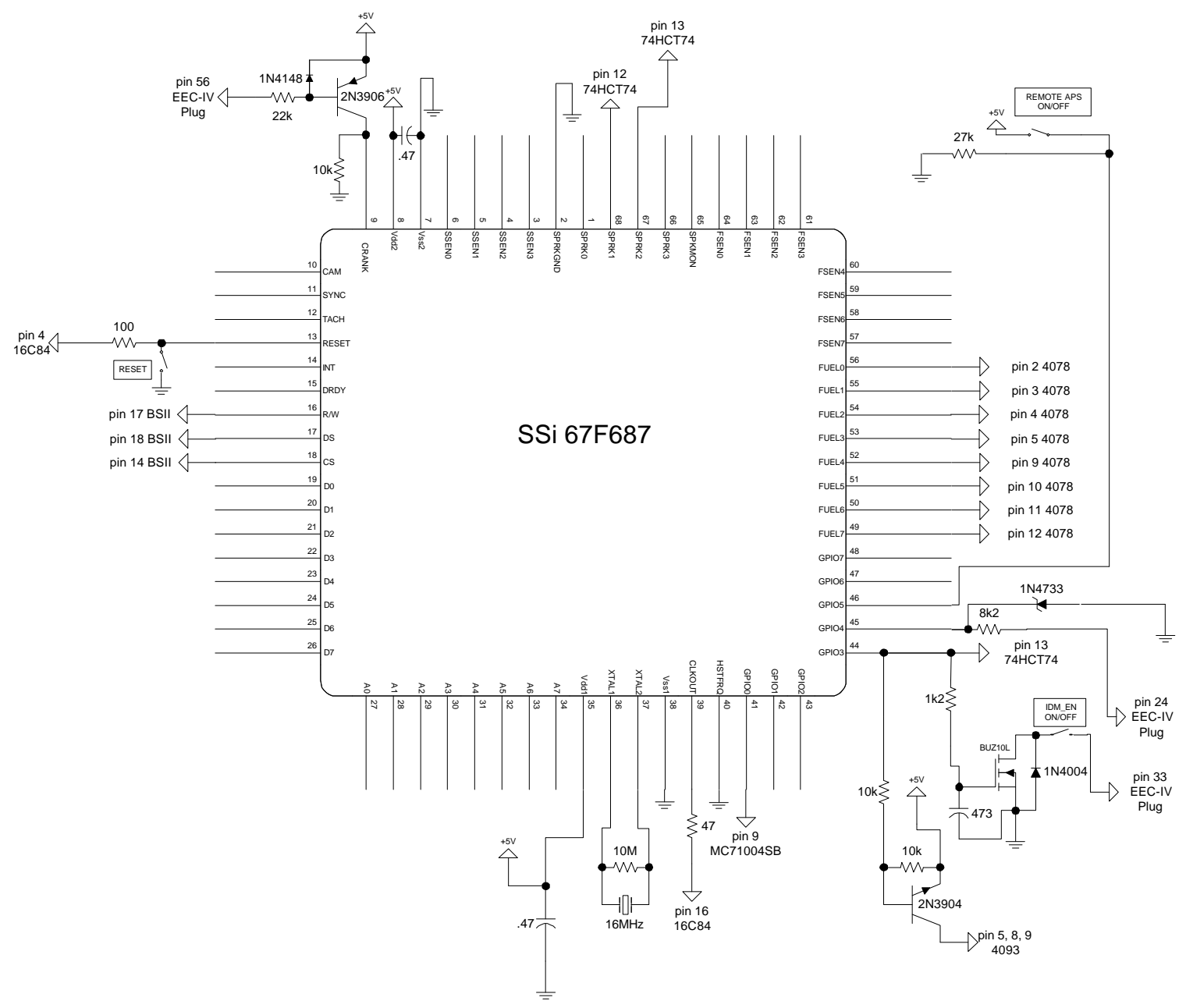

\begin{tabular}{|c|c|c|}
\hline \multicolumn{3}{|l|}{ TITLE } \\
\hline \multicolumn{3}{|c|}{ Engine Interface Peripheral } \\
\hline DATE & DESC & \\
\hline $2 / 10 / 99$ & \multicolumn{2}{|c|}{ All connections except data busses. } \\
\hline \multicolumn{2}{|l|}{ DRAWNBY } & REVISED \\
\hline Talu & s Park & $2 / 10 / 99$ \\
\hline \multicolumn{3}{|c|}{ All connections are $22 \mathrm{AWG}$} \\
\hline
\end{tabular}




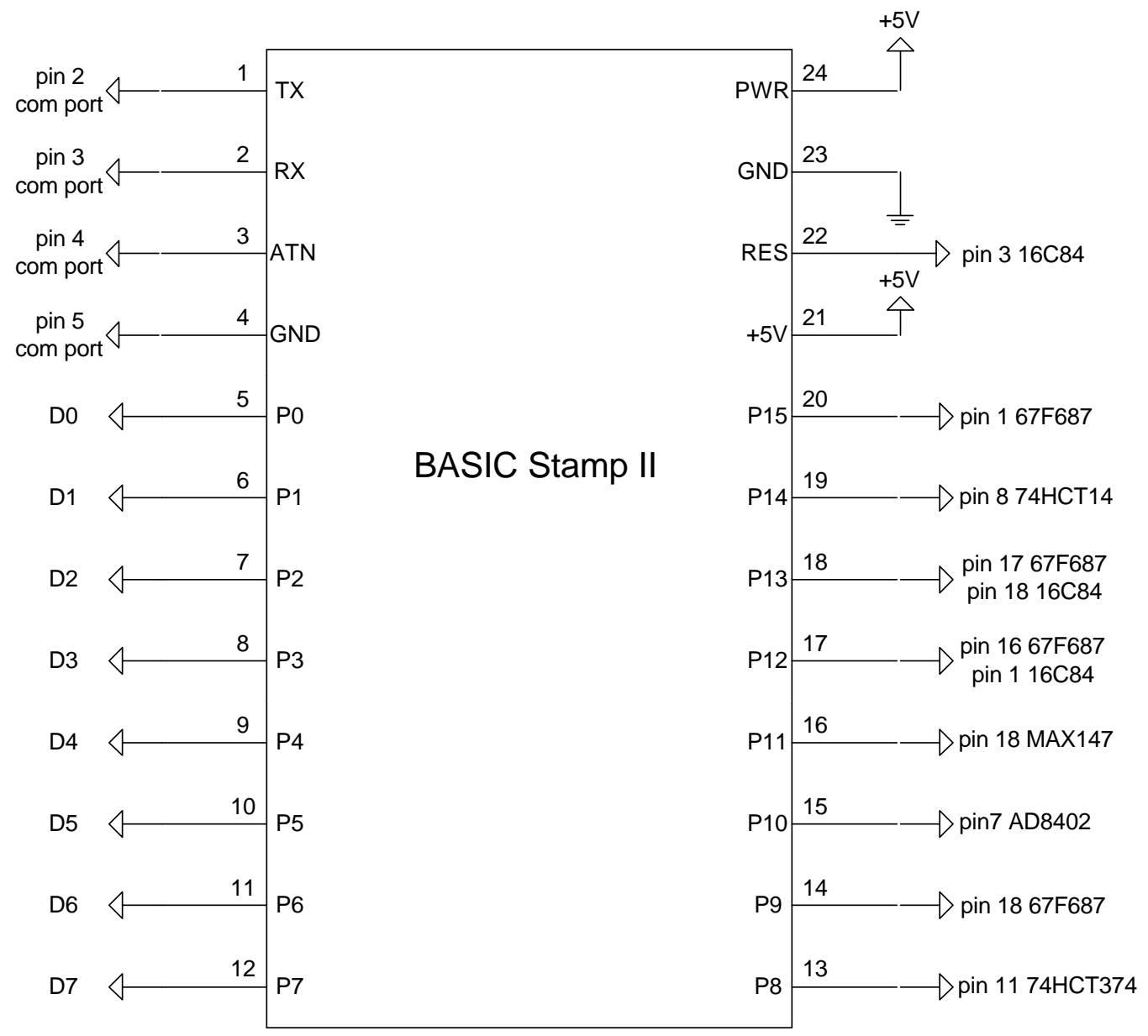

\begin{tabular}{|c|c|}
\hline \multicolumn{3}{|c|}{ RITLE } \\
\multicolumn{2}{|c|}{ Run-Time Microcontroller } \\
\hline DATE & DESCRIPTION \\
2/9/99 & All connections except data busses. \\
\hline $\begin{array}{c}\text { DRAWN BY } \\
\text { Talus Park }\end{array}$ & REVISED \\
\hline \multicolumn{2}{|c|}{ All connections are 22 AWG } \\
\hline
\end{tabular}




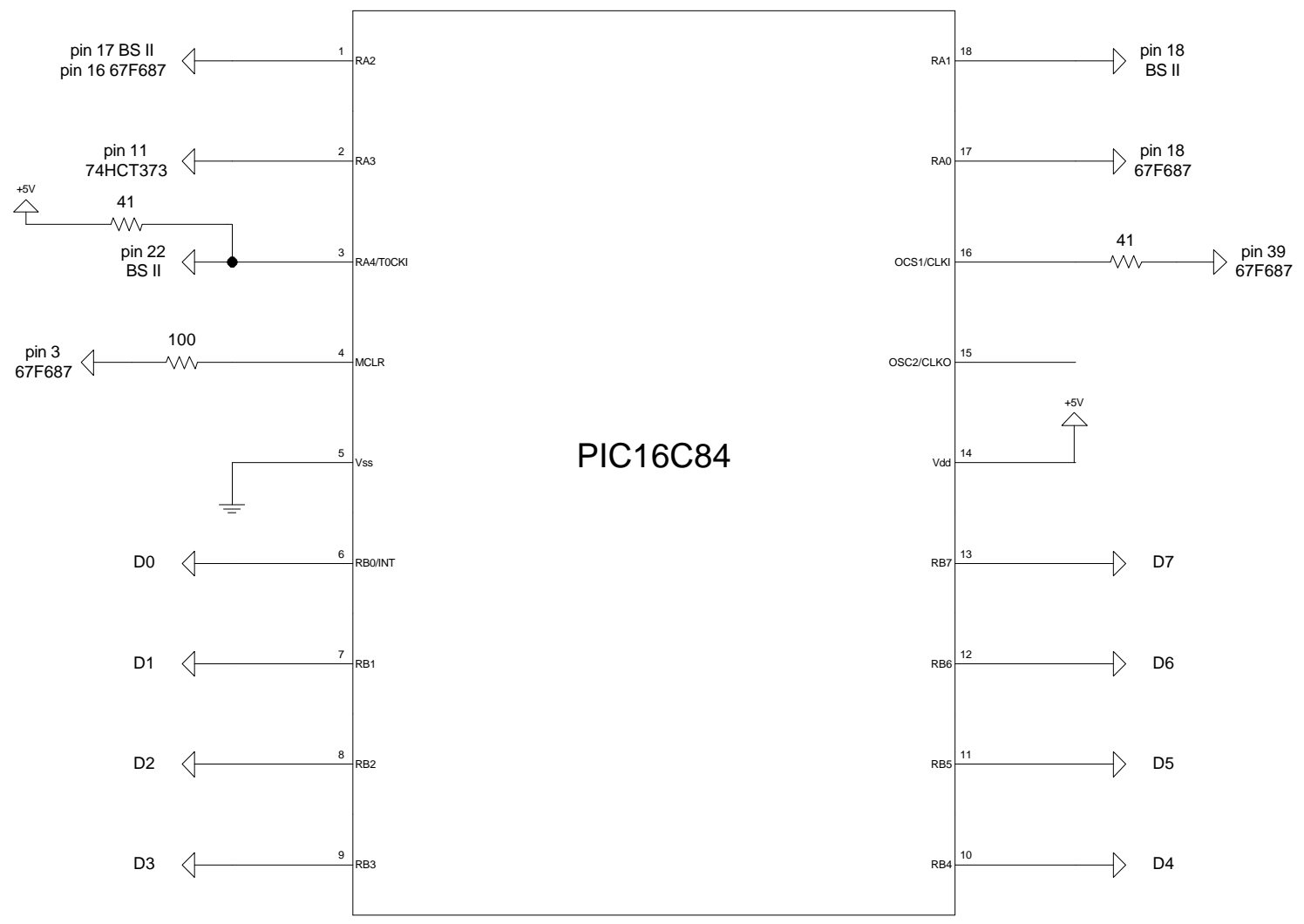

\begin{tabular}{|l|l|}
\hline \multicolumn{3}{|c|}{ IITLE } \\
\hline $\begin{array}{c}\text { DATE } \\
2 / 10 / 99\end{array}$ & $\begin{array}{c}\text { DESCRIPTION } \\
\text { All connections except data busses. }\end{array}$ \\
\hline $\begin{array}{c}\text { DRAWN BY } \\
\text { Talus Park }\end{array}$ & REVISED \\
\hline \multicolumn{2}{|c|}{ All connections are 22 AWG } \\
\hline
\end{tabular}




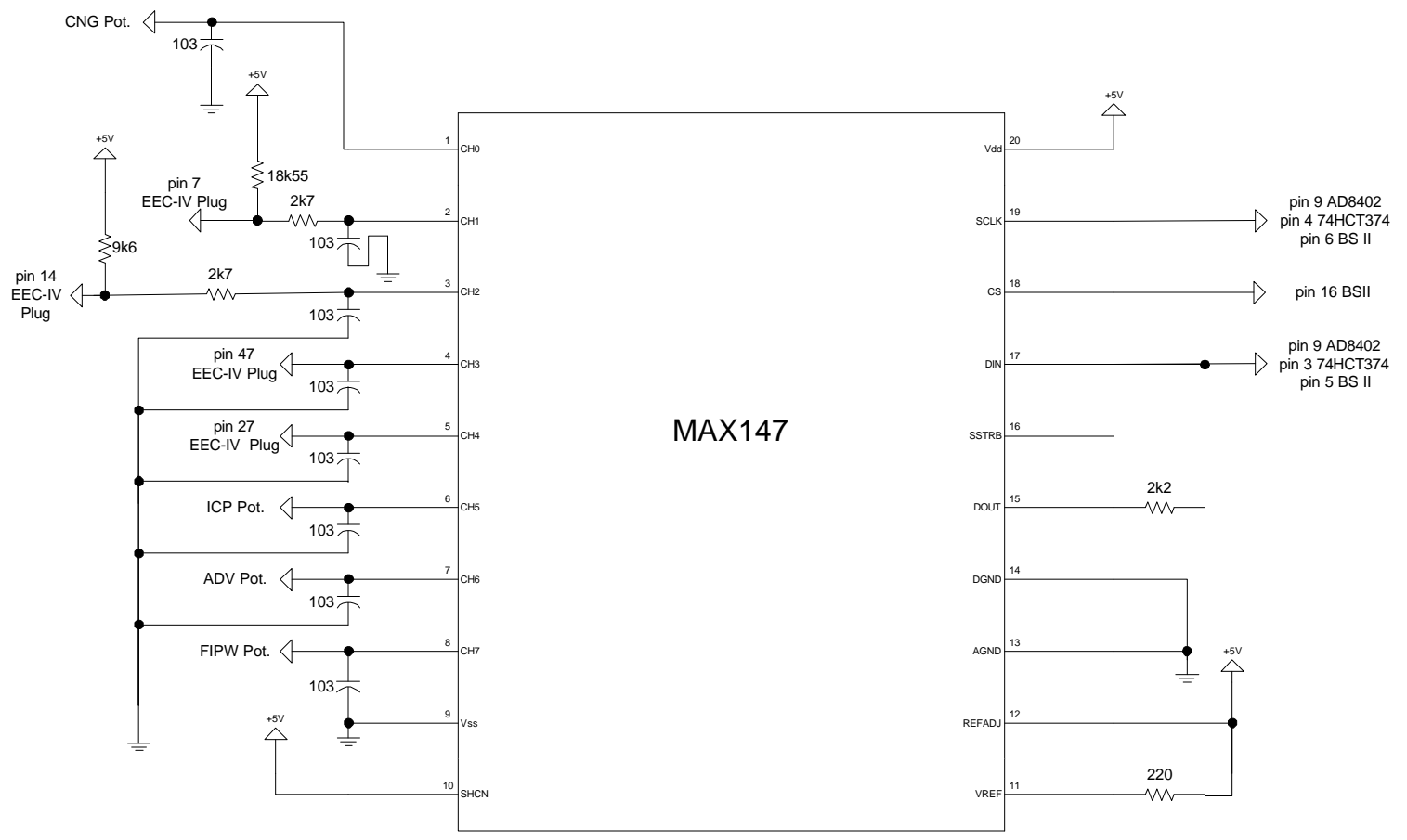

\begin{tabular}{|l|l|}
\hline \multicolumn{3}{|l|}{12 bit Analog to Digital Converter } \\
\hline $\begin{array}{c}\text { DATE } \\
2 / 7 / 99\end{array}$ & $\begin{array}{c}\text { DESCRIPTION } \\
\text { All connections except data busses. }\end{array}$ \\
\hline $\begin{array}{c}\text { DRAWN BY } \\
\text { Talus Park }\end{array}$ & REVISED \\
\hline \multicolumn{3}{|c|}{ All connections are 22 AWG } \\
\hline
\end{tabular}




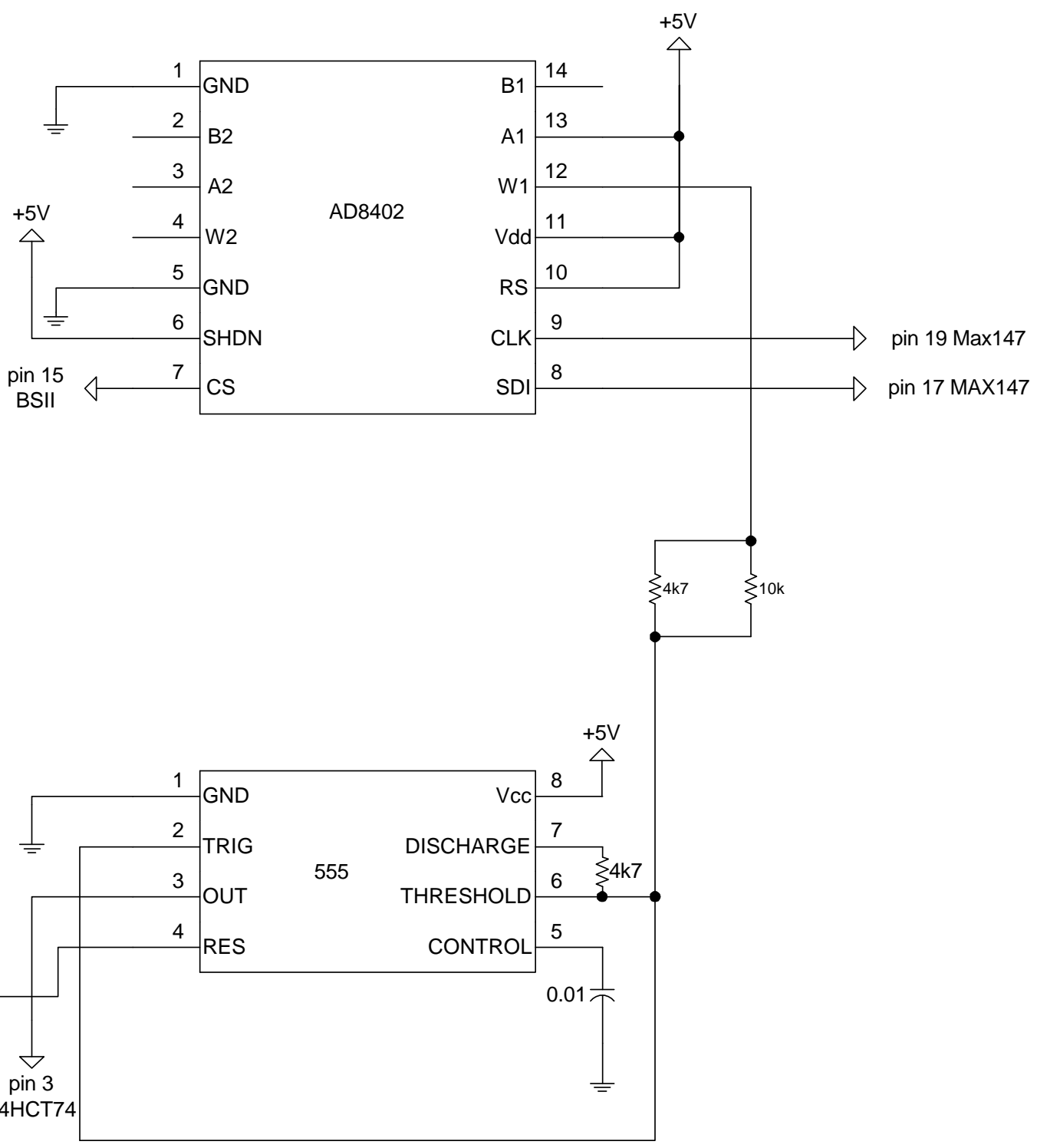

\begin{tabular}{|l|c|}
\hline \multicolumn{3}{|l|}{ VITLE } \\
\hline $\begin{array}{c}\text { VATE } \\
\text { 2/10/99 }\end{array}$ & $\begin{array}{c}\text { DESCRIPTION } \\
\text { All connections except data busses. }\end{array}$ \\
\hline $\begin{array}{c}\text { DRAWN BY } \\
\text { Talus Park }\end{array}$ & REVISED \\
\hline \multicolumn{2}{|c|}{ All connections are 22 AWG } \\
\hline
\end{tabular}




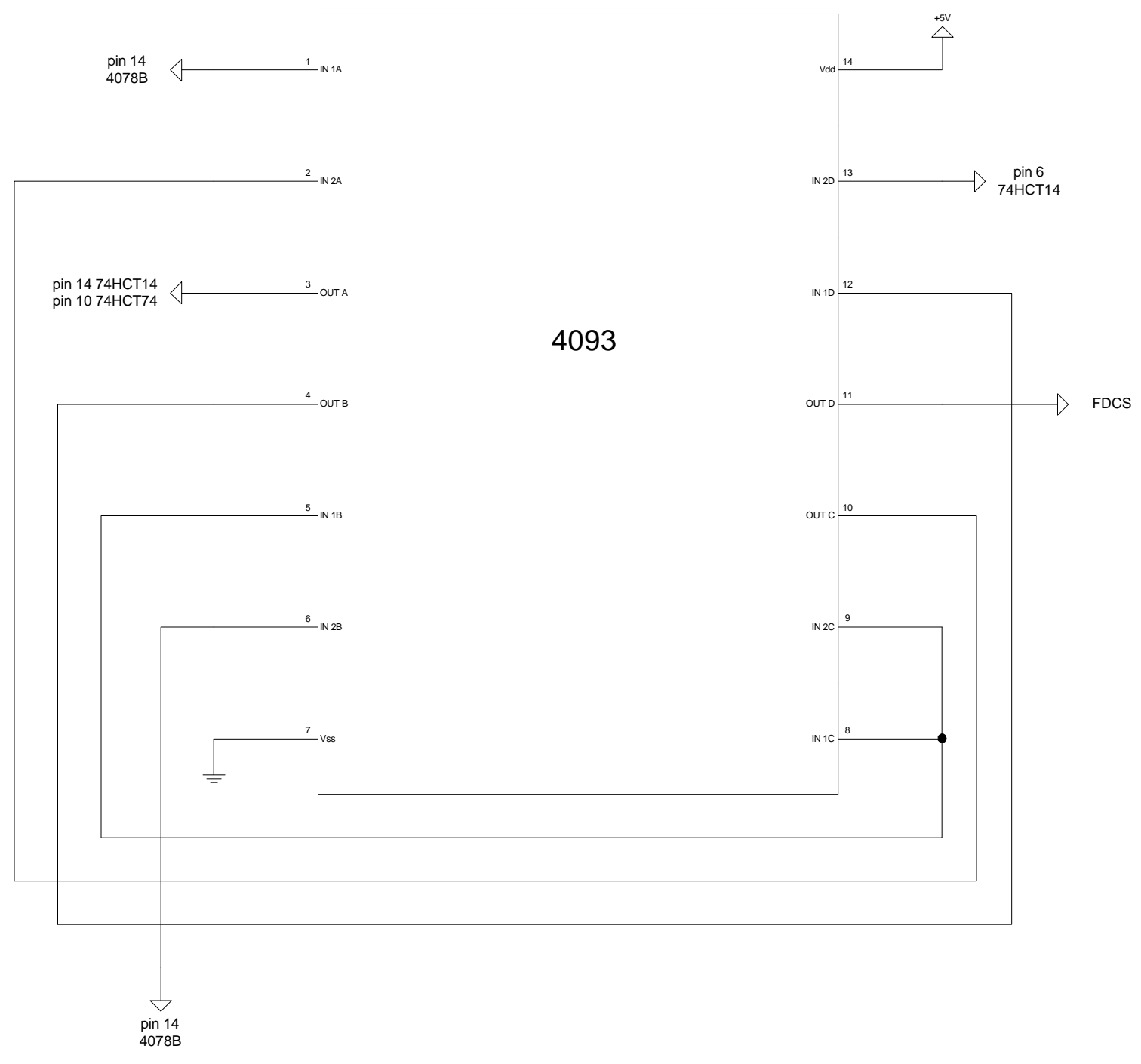

\begin{tabular}{|l|l|}
\hline \multicolumn{3}{|c|}{ EITLE } \\
\hline $\begin{array}{c}\text { DATE } \\
2 / 10 / 99\end{array}$ & DESCRIPTION \\
All connections except data busses. \\
\hline $\begin{array}{c}\text { DRAWN BY } \\
\text { Talus Park }\end{array}$ \\
\hline \multicolumn{2}{|c|}{ All connections are 22 AWG } \\
\hline
\end{tabular}




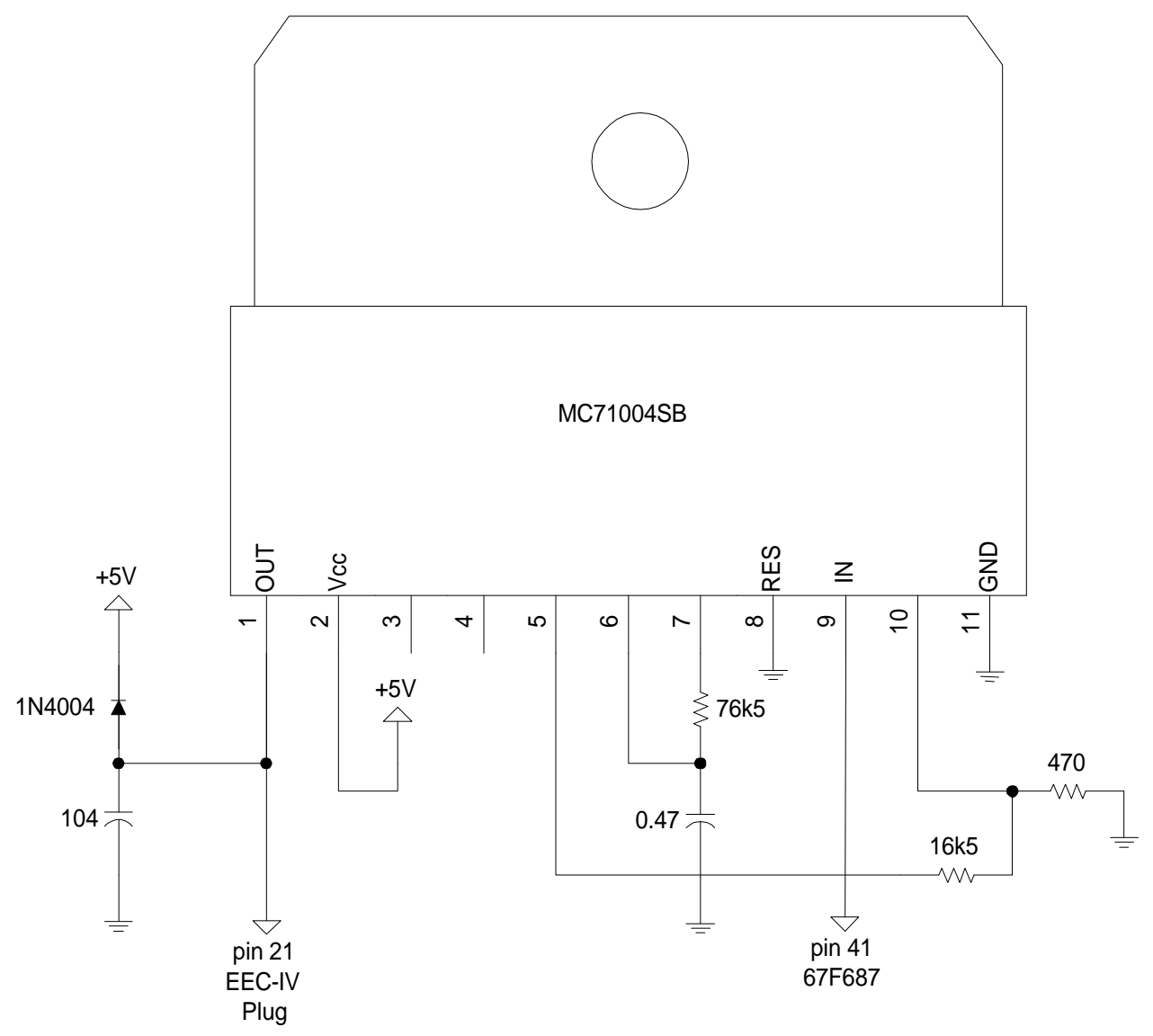

\begin{tabular}{|c|c|}
\hline \multicolumn{2}{|c|}{ IITLE } \\
\hline $\begin{array}{c}\text { DATE } \\
2 / 9 / 99\end{array}$ & $\begin{array}{r}\text { DESCRIPTION } \\
\text { All connections except data busses. }\end{array}$ \\
\hline $\begin{array}{c}\text { DRAWN BY } \\
\text { Talus Park }\end{array}$ & REVISED \\
\hline \multicolumn{2}{|c|}{ All connections are 22 AWG } \\
\hline
\end{tabular}




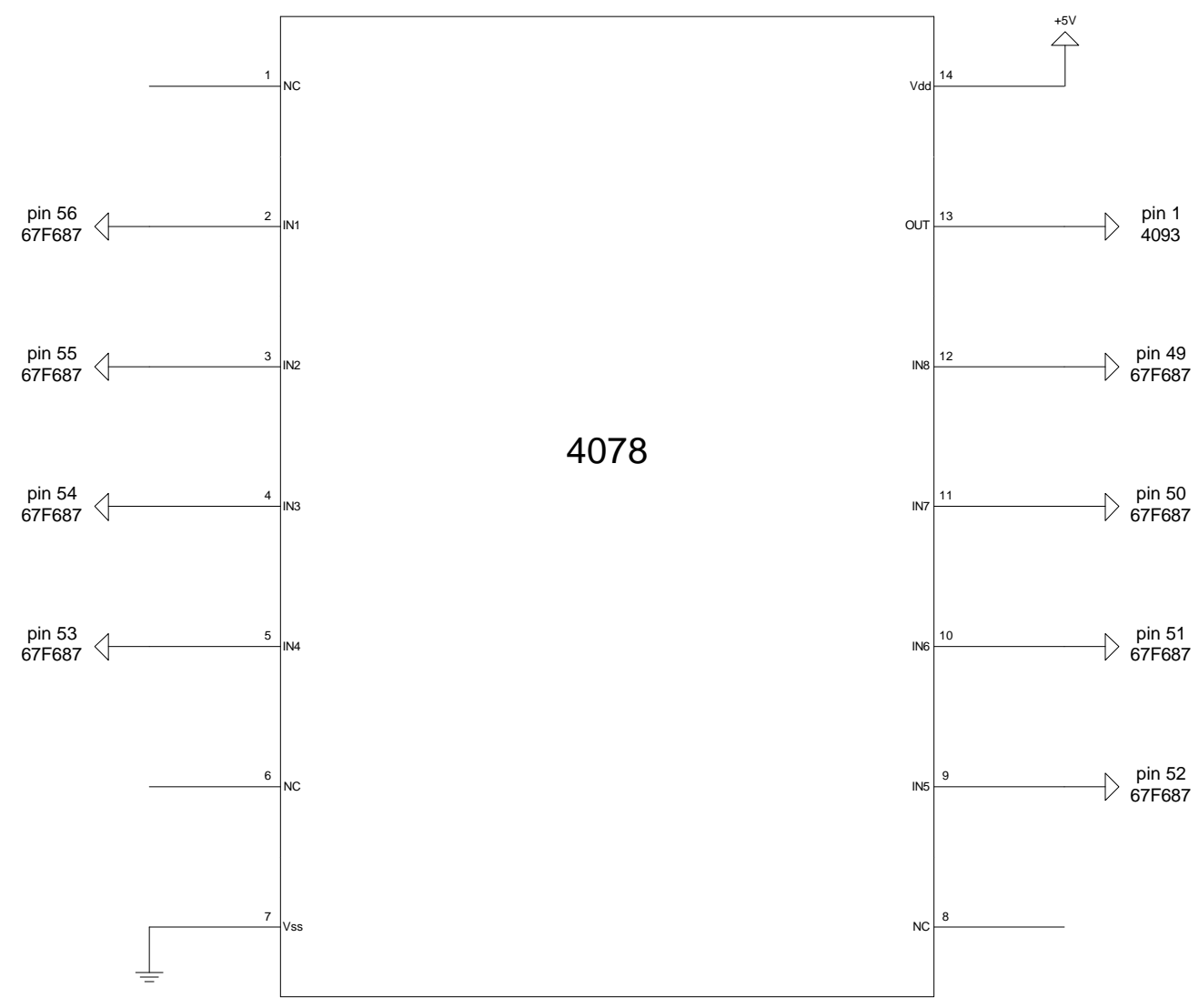

\begin{tabular}{|c|c|}
\hline \multicolumn{2}{|c|}{ TITLE } \\
\hline $\begin{array}{c}\text { DATE } \\
2 / 10 / 99\end{array}$ & $\begin{array}{c}\text { DESCRIPTION Combiner } \\
\text { All connections except data busses. }\end{array}$ \\
\hline $\begin{array}{c}\text { DRAWN BY } \\
\text { Talus Park }\end{array}$ & REVISED \\
\hline \multicolumn{2}{|c|}{ All connections are 22 AWG } \\
\hline
\end{tabular}




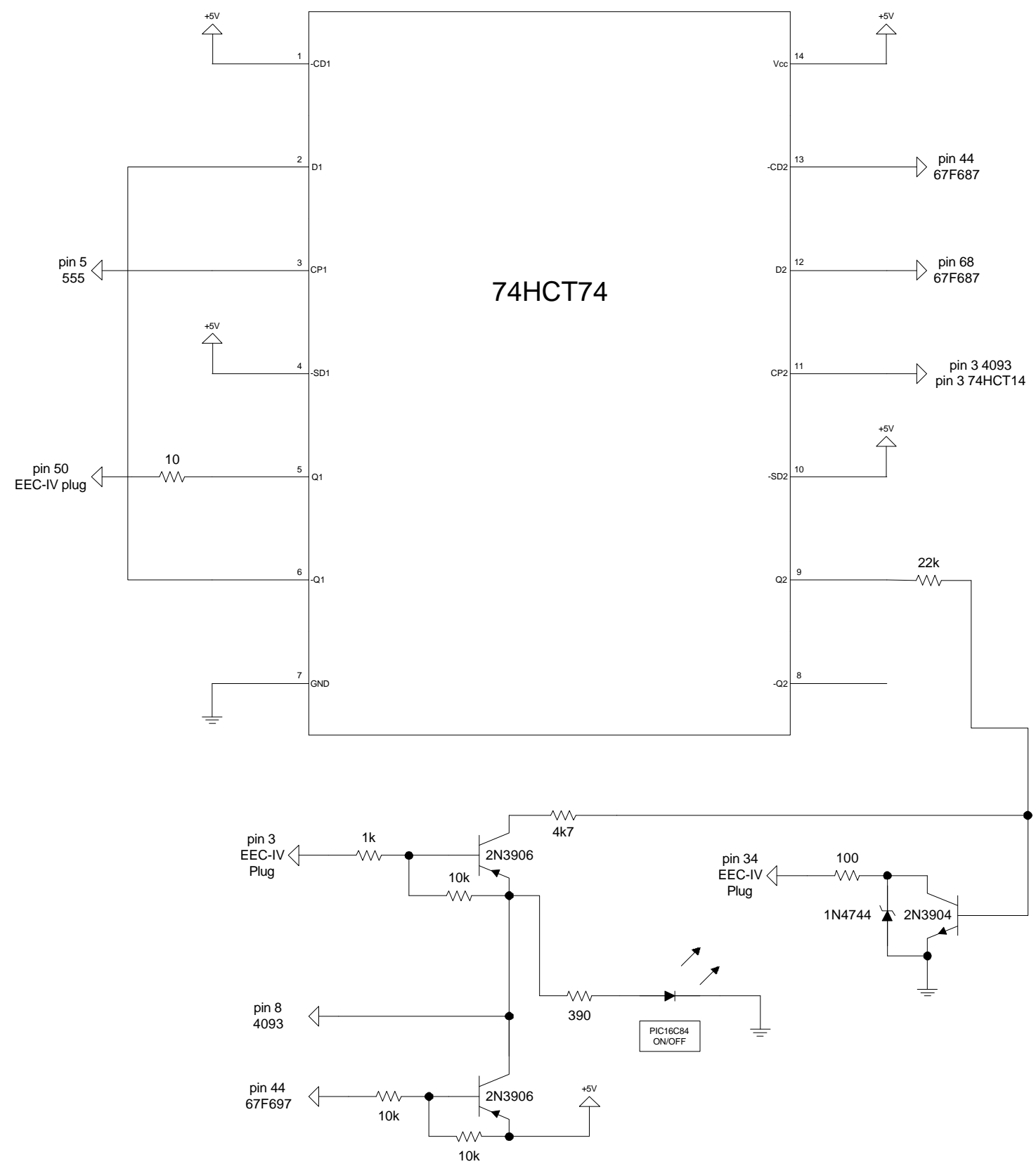

\begin{tabular}{|l|c|}
\hline \multicolumn{3}{|c|}{ IITLE } \\
\hline $\begin{array}{c}\text { DATE } \\
2 / 10 / 99\end{array}$ & $\begin{array}{c}\text { DESCRIPTION Coincedence Latch } \\
\text { All connections except data busses. }\end{array}$ \\
\hline $\begin{array}{c}\text { DRAWN BY } \\
\text { Talus Park }\end{array}$ & REVISED \\
\hline \multicolumn{2}{|c|}{ All connections are 22 AWG } \\
\hline
\end{tabular}

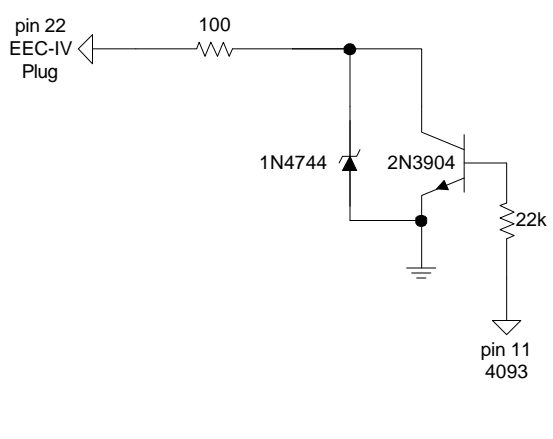




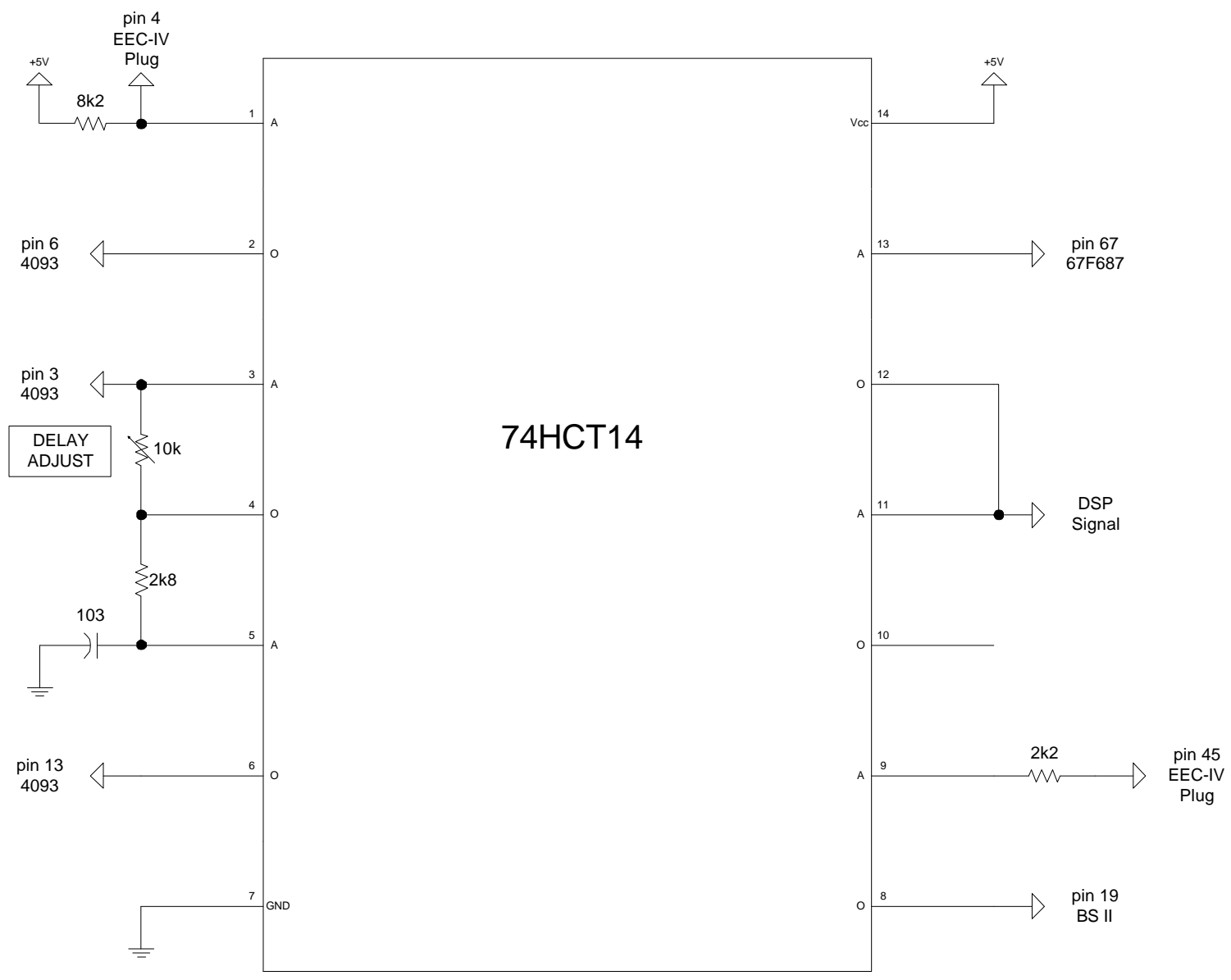

\begin{tabular}{|c|c|c|}
\hline \multicolumn{3}{|c|}{ Schmitt Trigger } \\
\hline DATE & DESC & \\
\hline 2/10/99 & \multicolumn{2}{|c|}{ All connections except data busses. } \\
\hline DRAWN BY & & REVISED \\
\hline \multicolumn{2}{|c|}{ Talus Park } & 2/10/99 \\
\hline
\end{tabular}




\section{Appendix E: PIC16C84 Code}

The Microchip PIC16C84 machine code listing for initializing the SSi67F687:

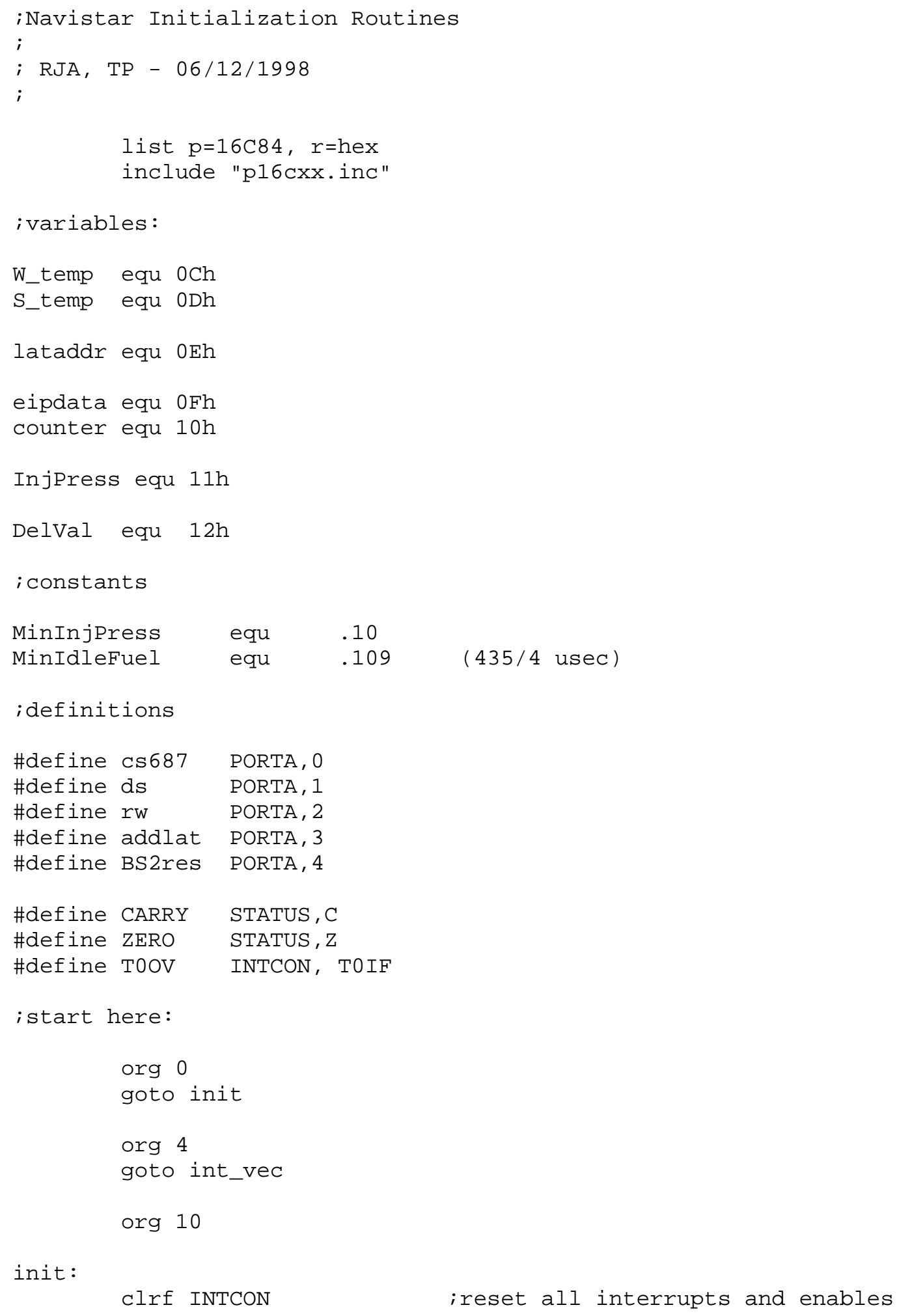




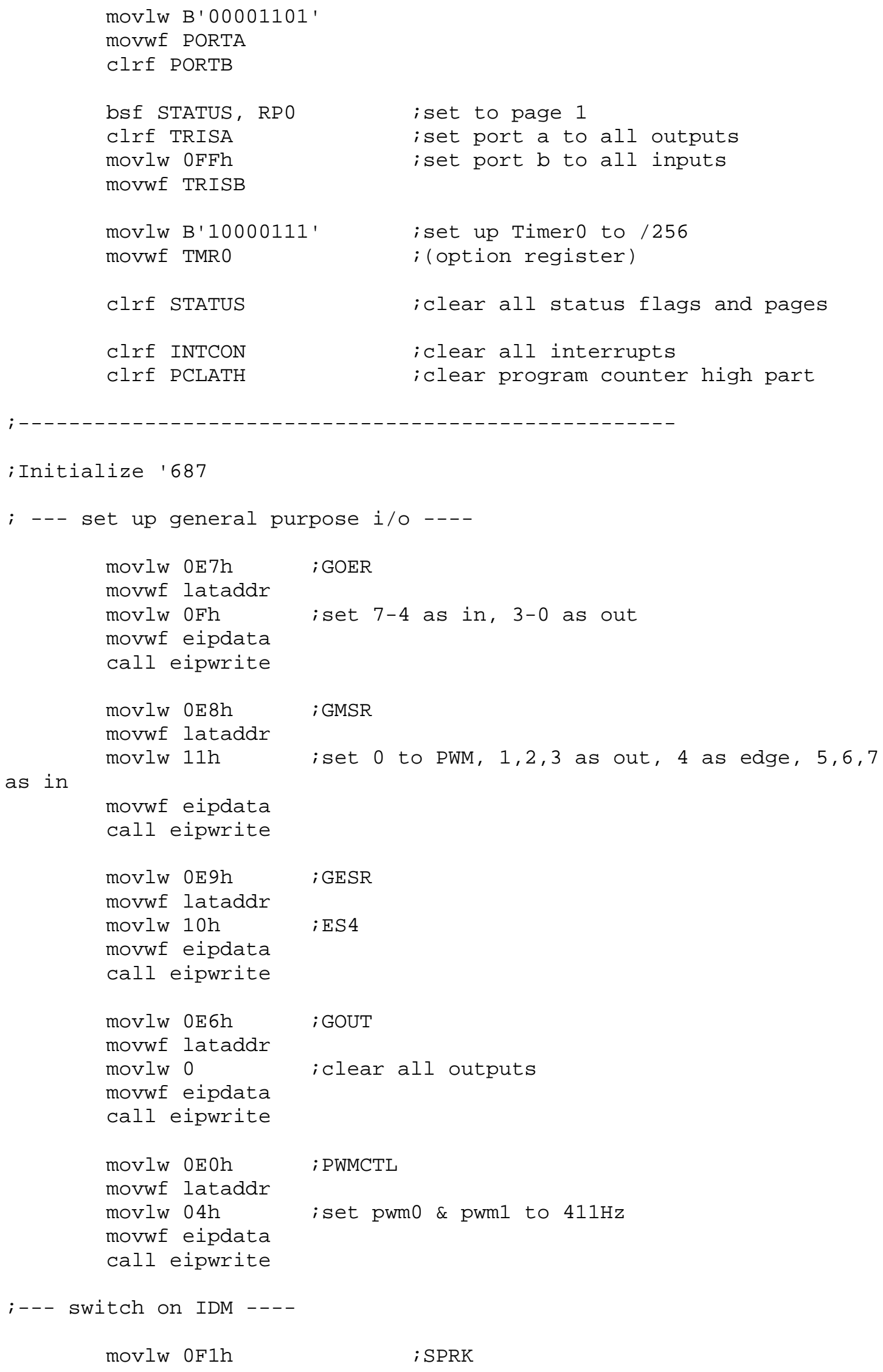




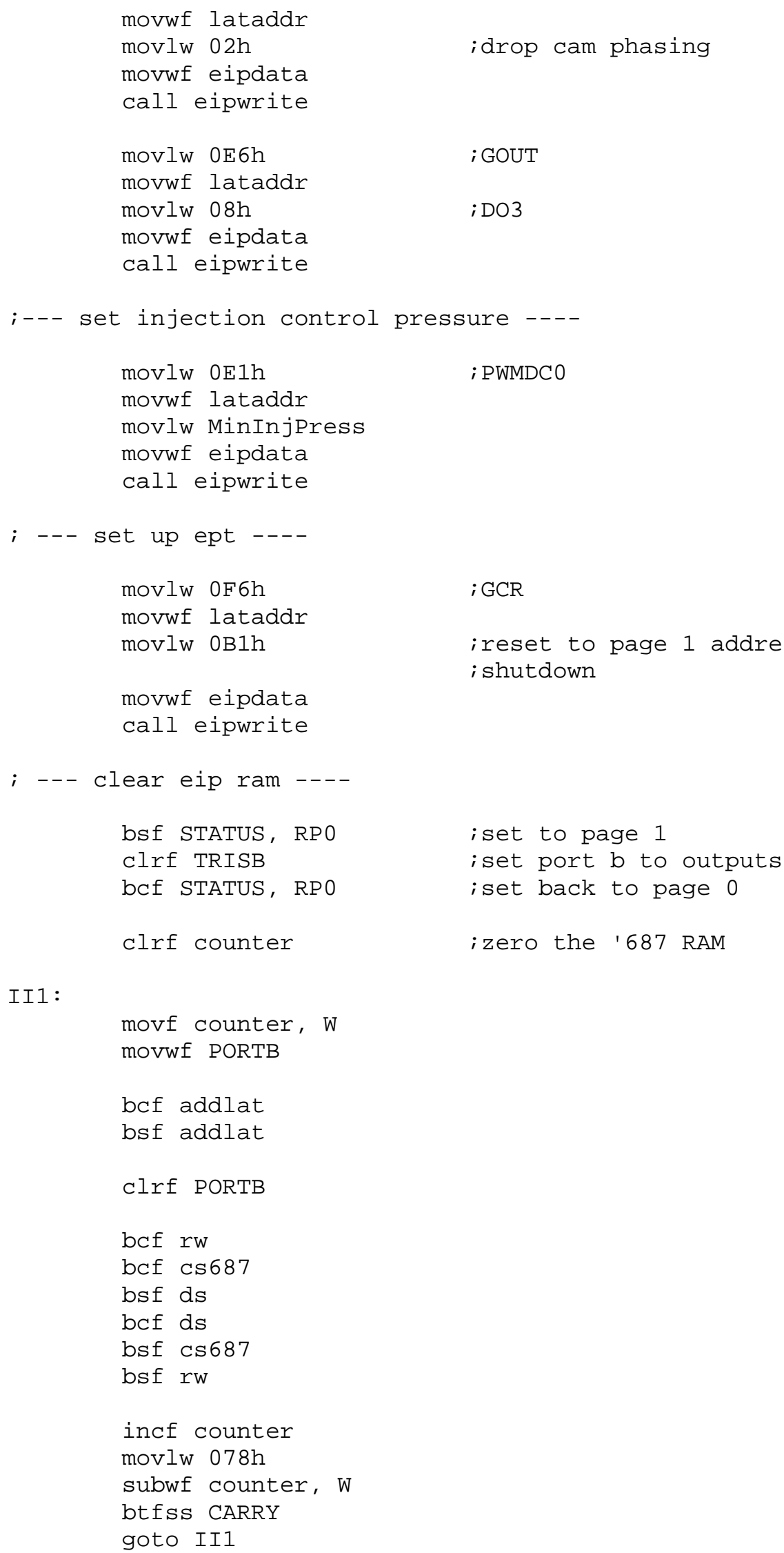


; --- load ept parameter table ----

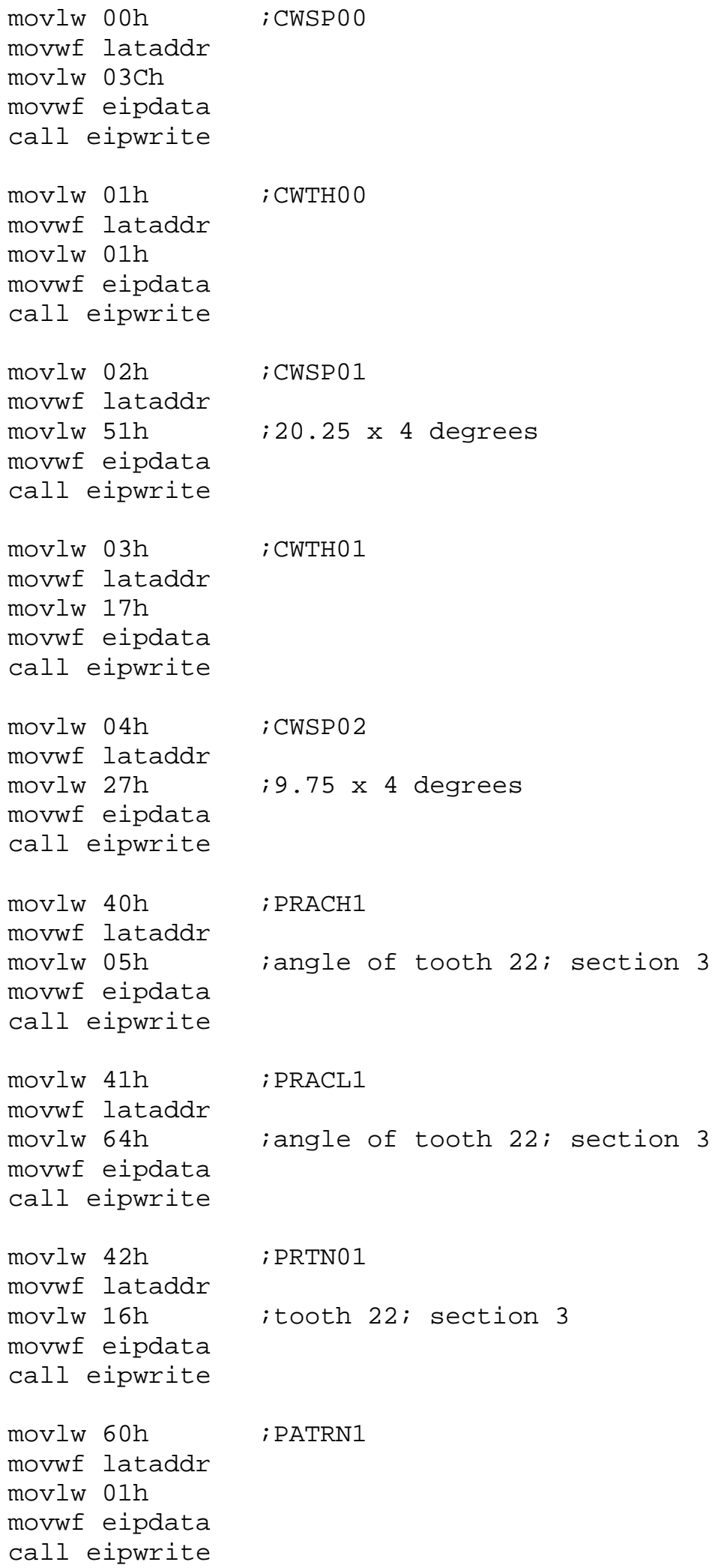




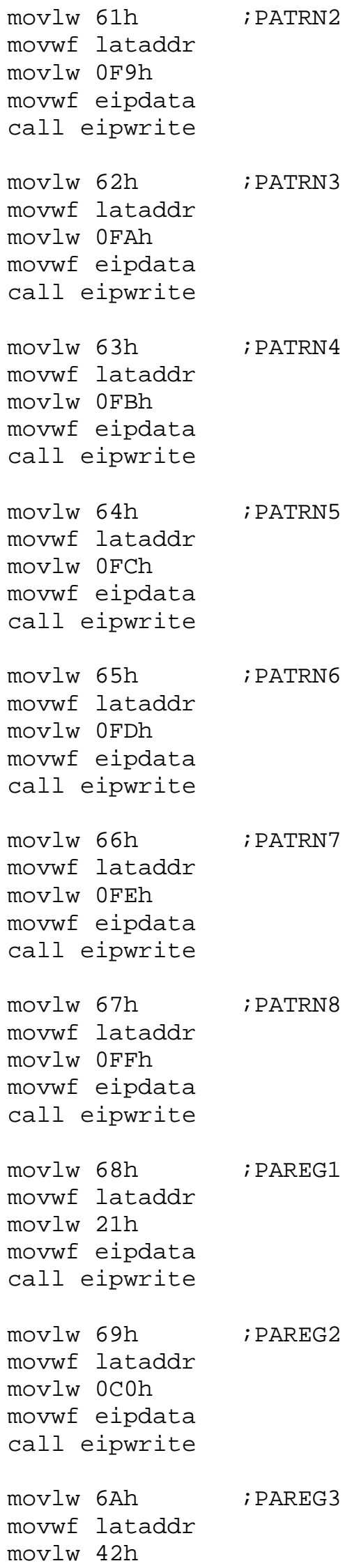




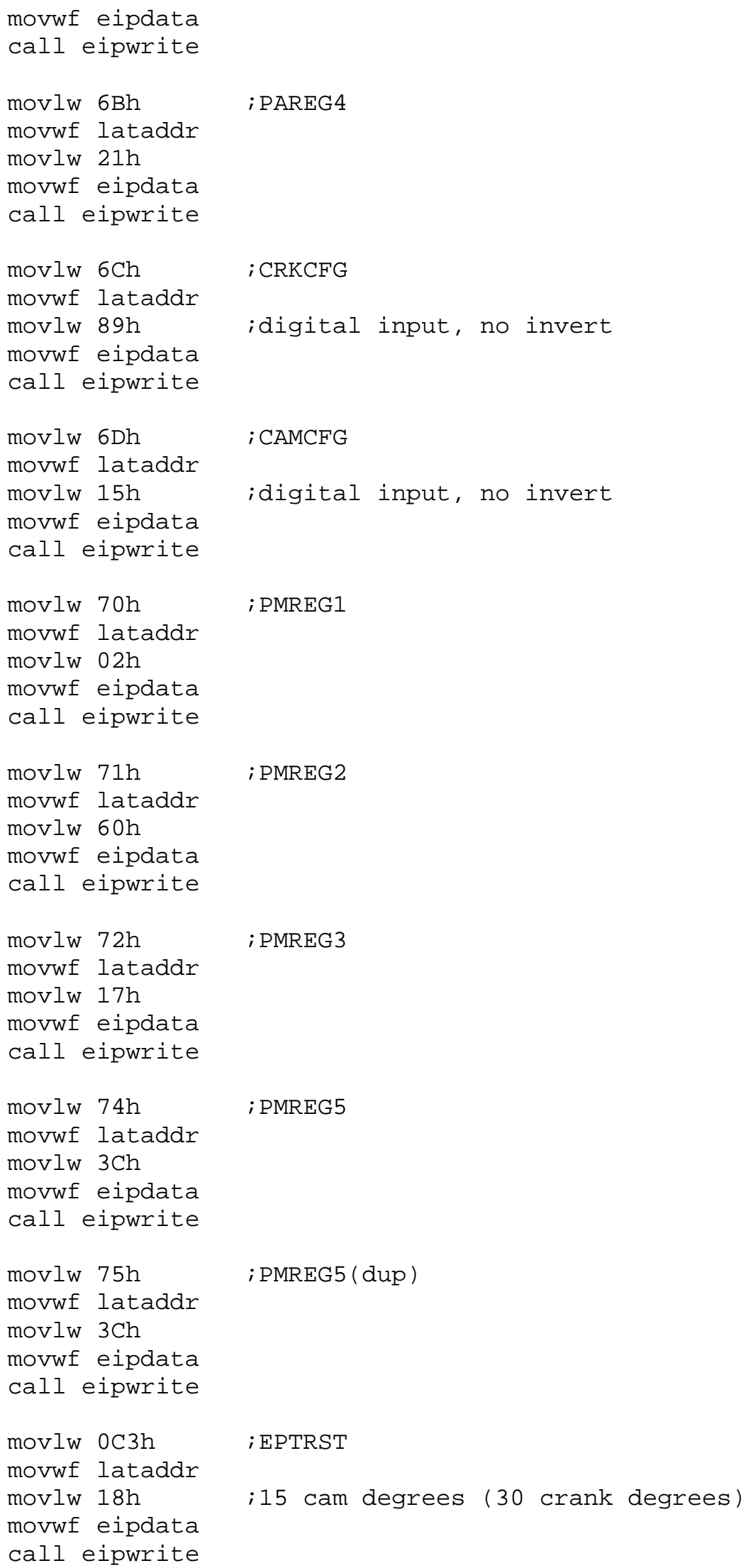




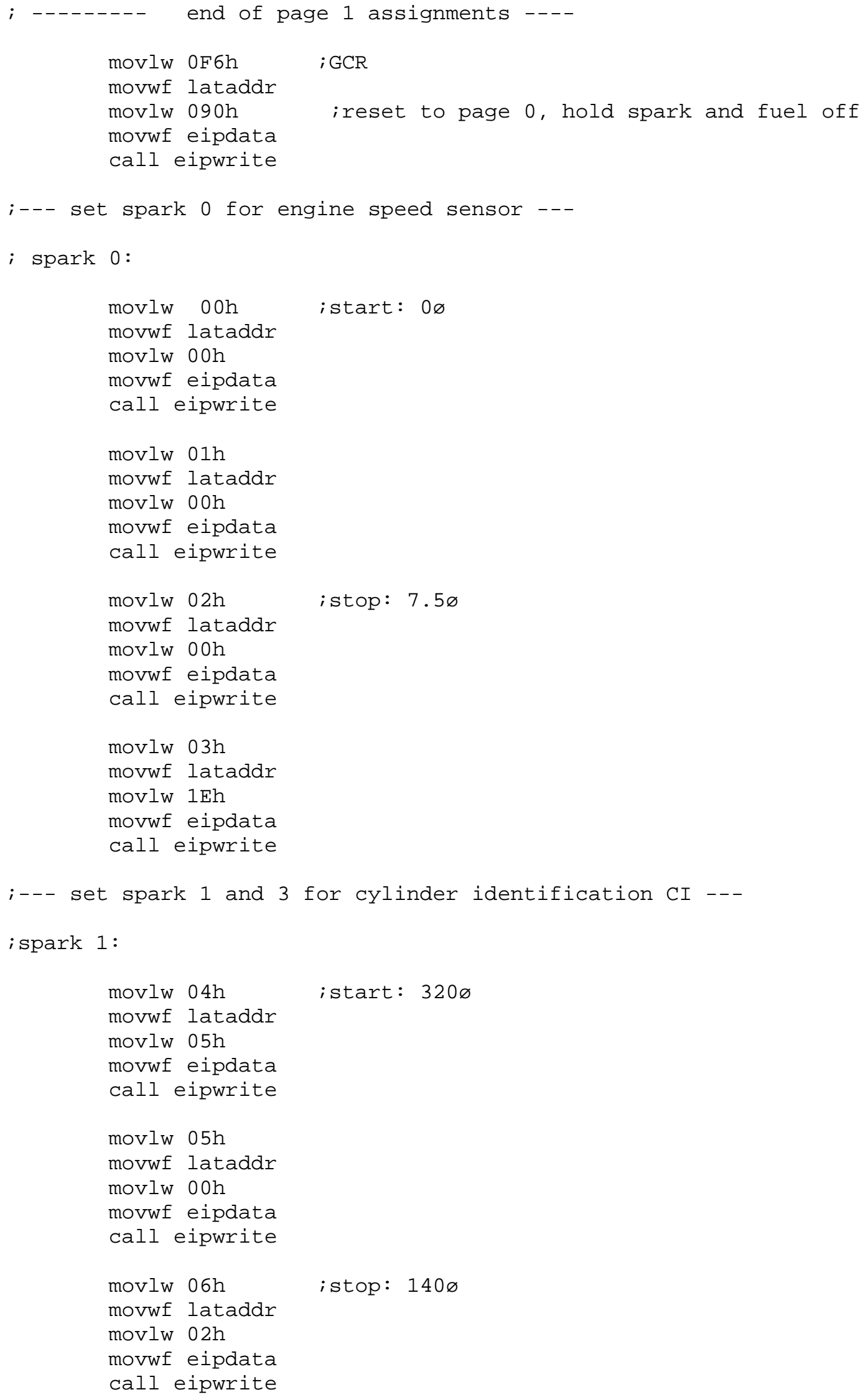




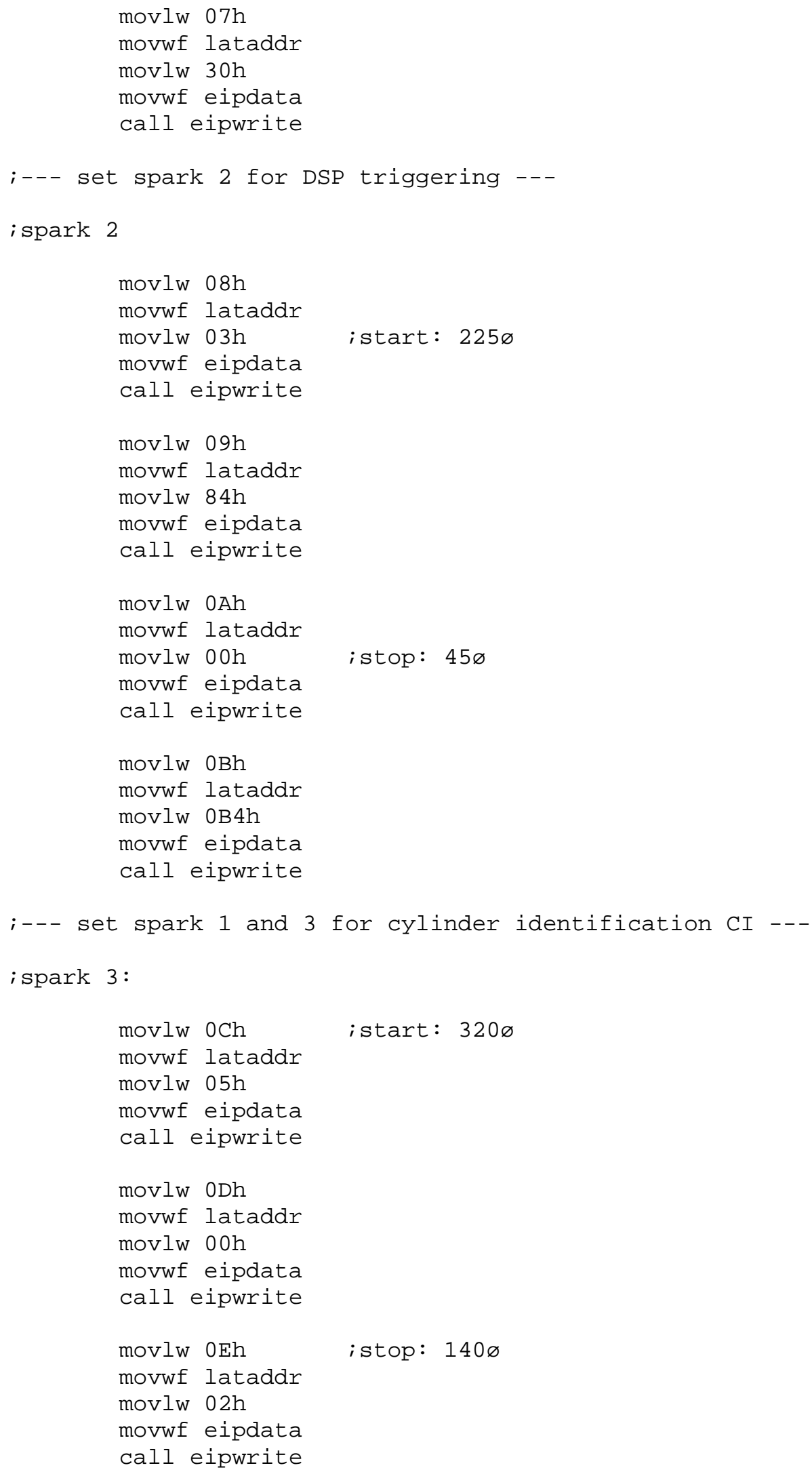




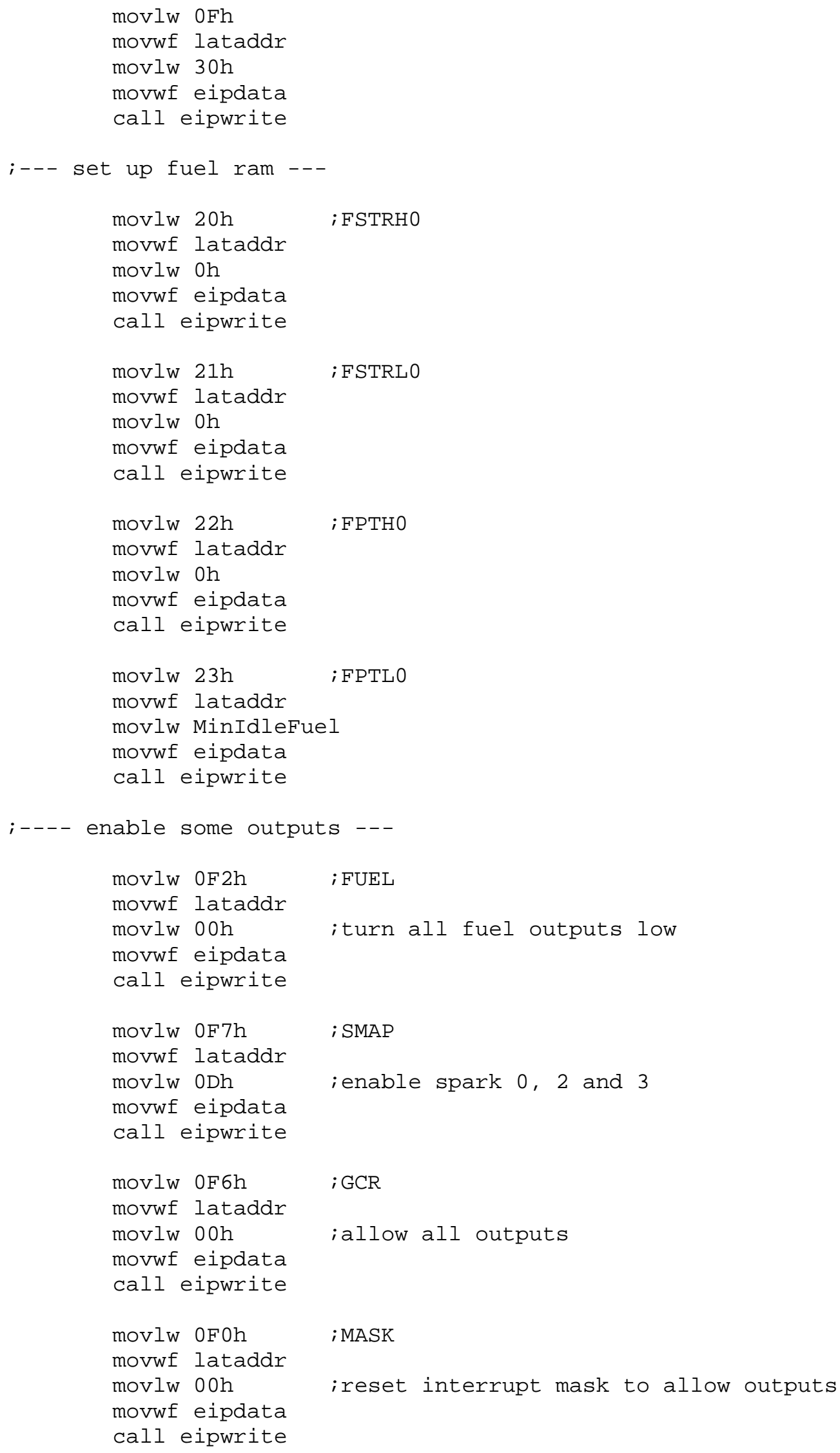


;--- hand control over to Basic Stamp...

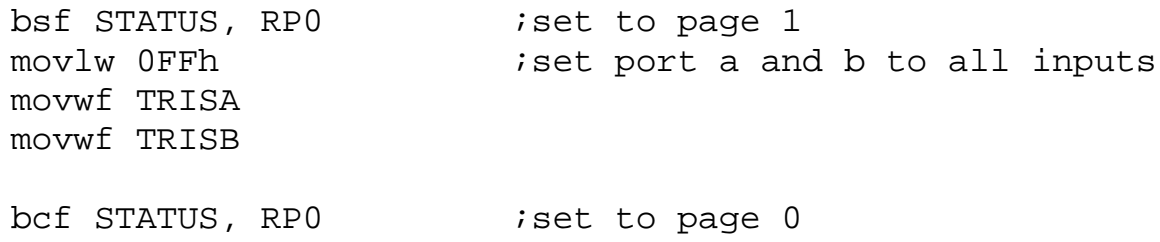


Ext_Int:

bcf INTCON, INTF

goto End_Int

T0_Int:

bcf INTCON, TOIF

End_Int :

pop :

swapf S_temp, W

movwf STATUS

swapf W_temp, 0

swapf W_temp, W

retfie

; -----------------------------

end
; clear the ext int flag

; clear the timero interrupt flag bit

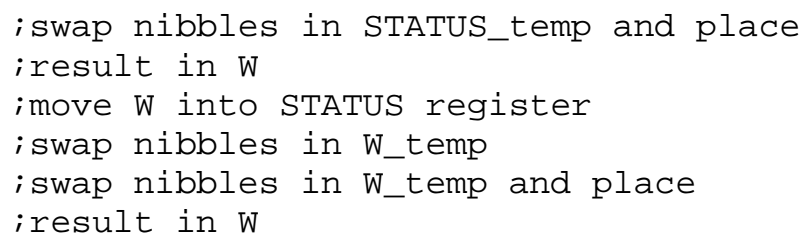




\section{Appendix F: BASIC Stamp II code}

The BASIC Stamp II PBASIC code used in the to execute the run-time operations:

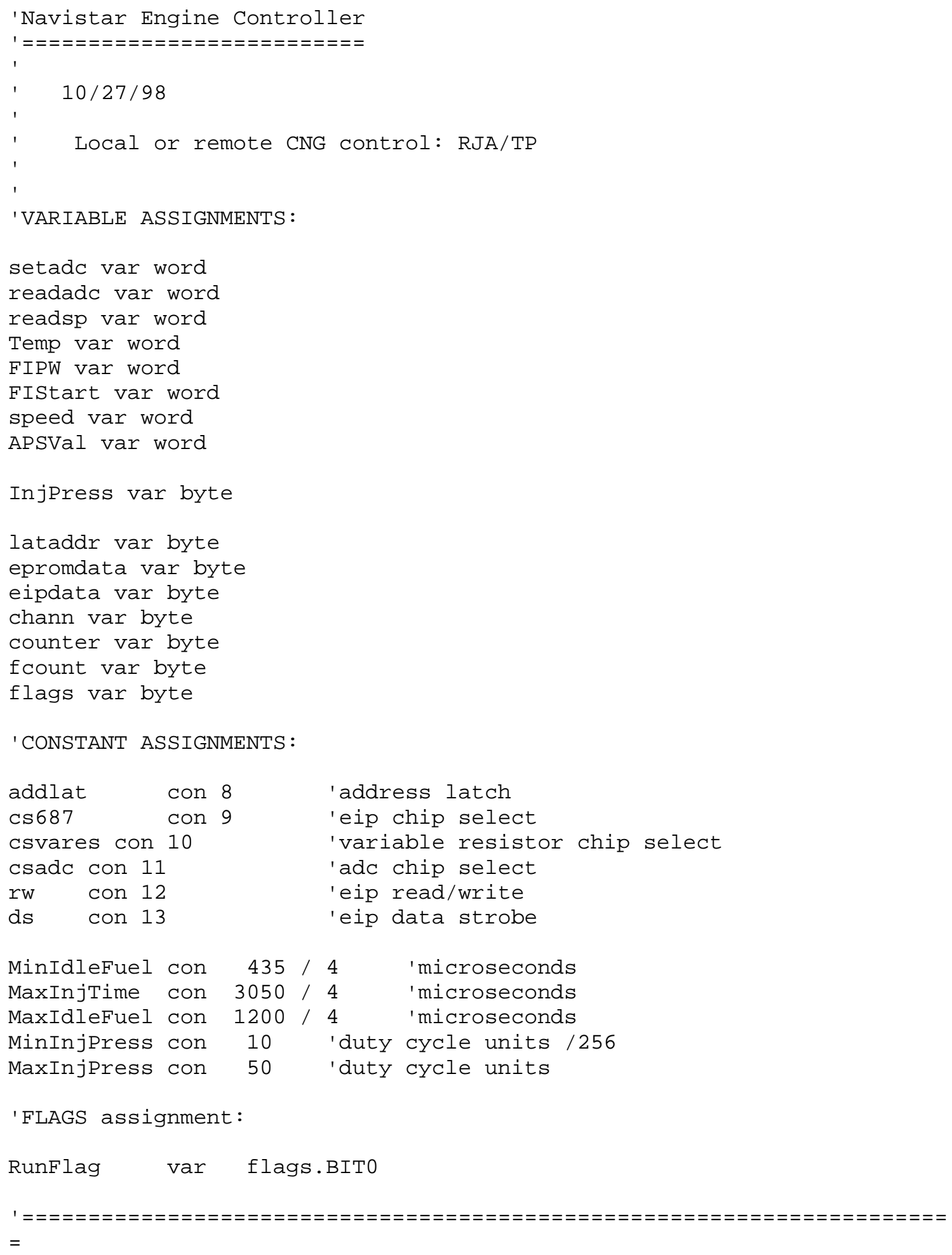


Initialization:

RunFlag $=0$ 'engine not running

outc $=\$ 0 F \quad$ 'deselect all peripherals

dirh $=\$ 3 F$ 'set lower six bits of upper byte to out

dirl $=\$ F F$ 'set whole of lower byte to out

'

$$
\text { counter }=20 \quad \text { 'initialize counters }
$$

'set start-up fuel injection pulse width

FIPW $=$ MinIdleFuel

gosub SetFIPW

' set fuel injection start angle

FIStart $=(358 \star 4)-1$

gosub SetInjStart

' set injection control pressure

InjPress $=$ MinInjPress

gosub setInjPress

' Engine starting

WaitForStart: pulsin 15,1, readadc
debug dec 5 readadc $\quad$ Read $15 \varnothing$ pulse width

if readadc $=0$ then WaitForstart

'else engine is running

'resume normal service

'turn off EEC interface

lataddr $=\$ 0 \mathrm{E} 6 \quad$ 'GOUT

eipdata $=\$ 08$

gosub eipwrite

'allow cam phasing output

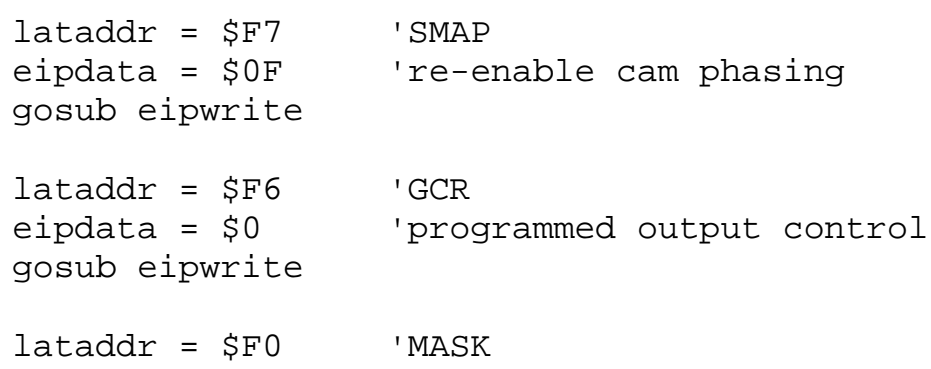




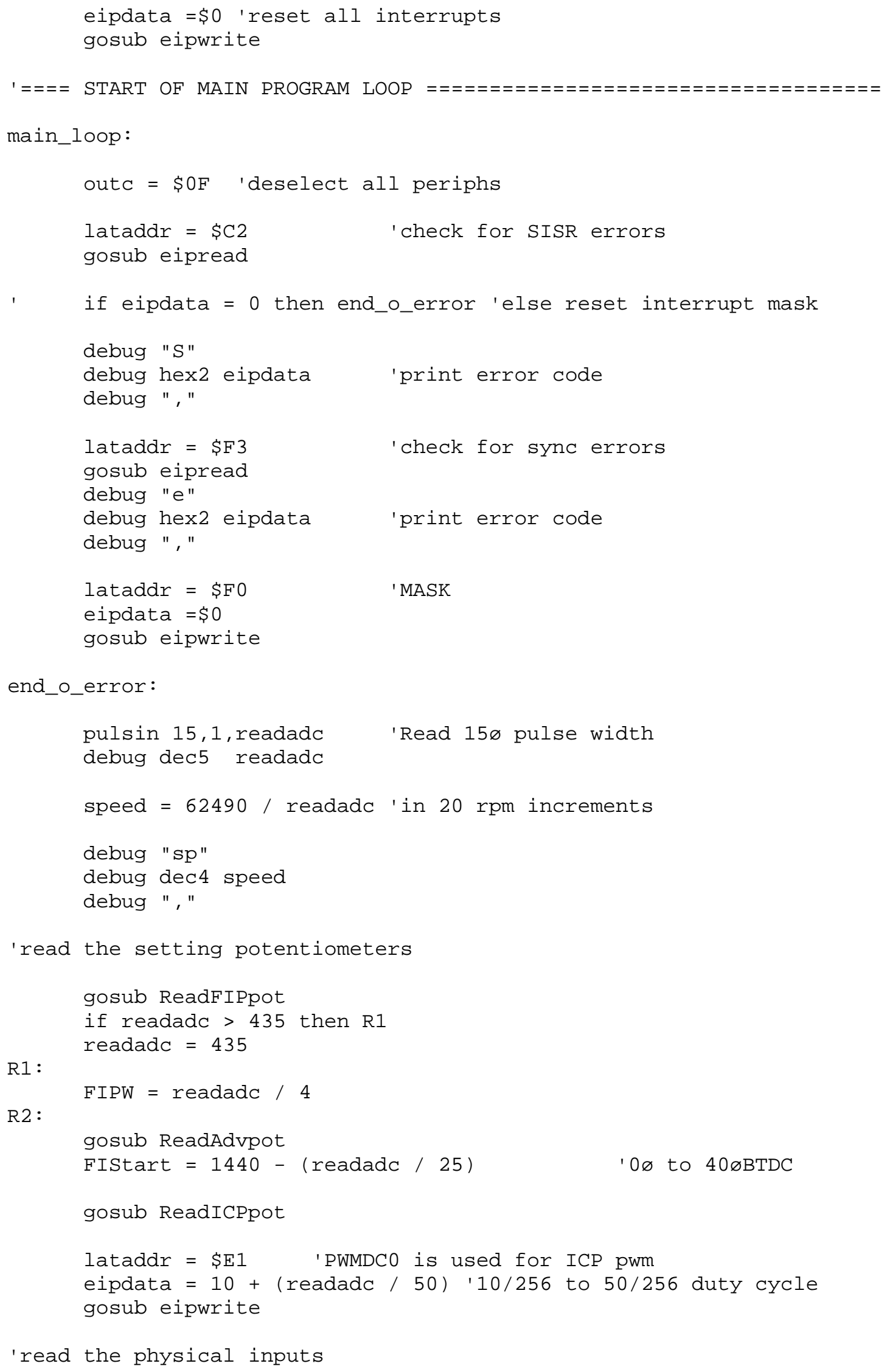




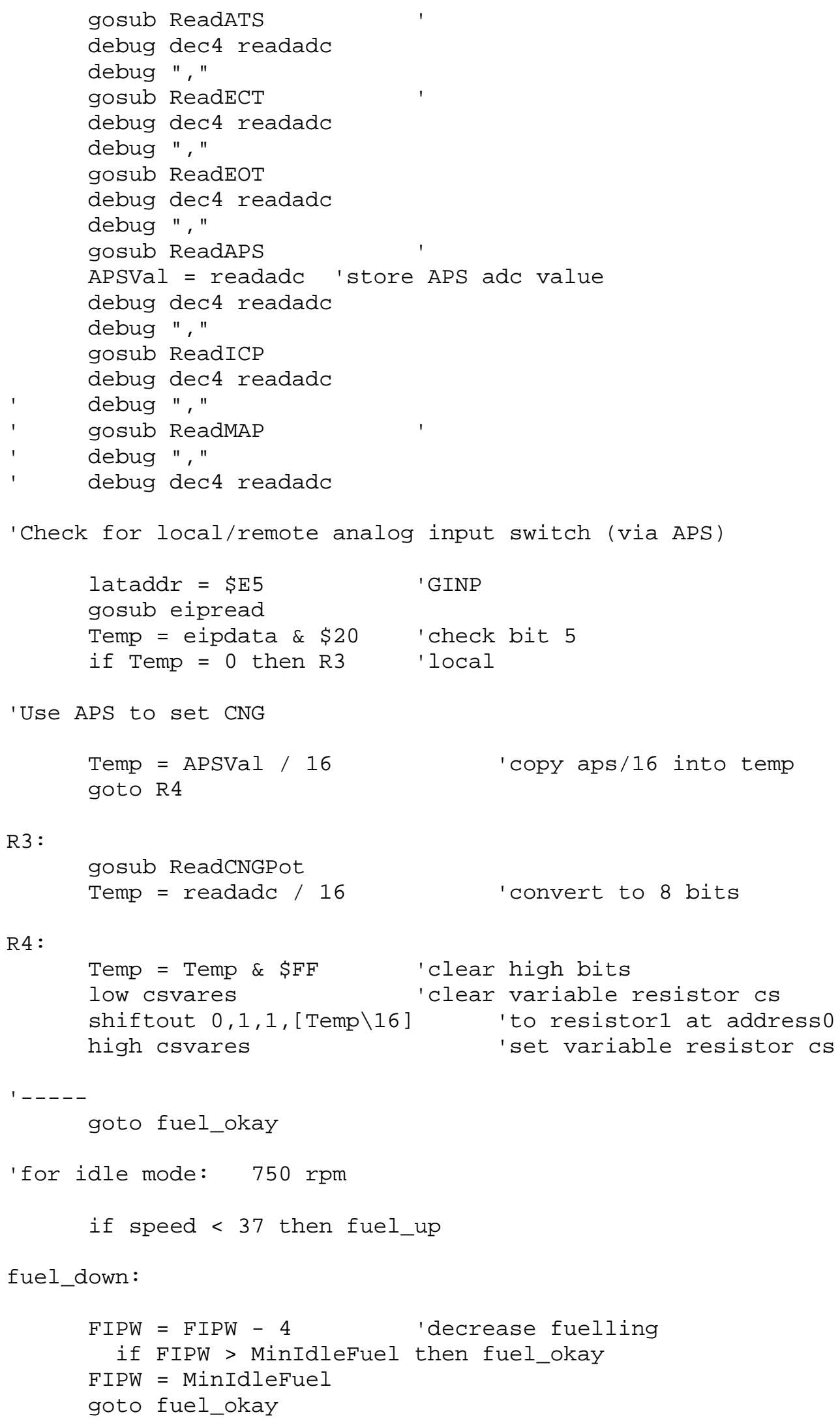

R4 : 


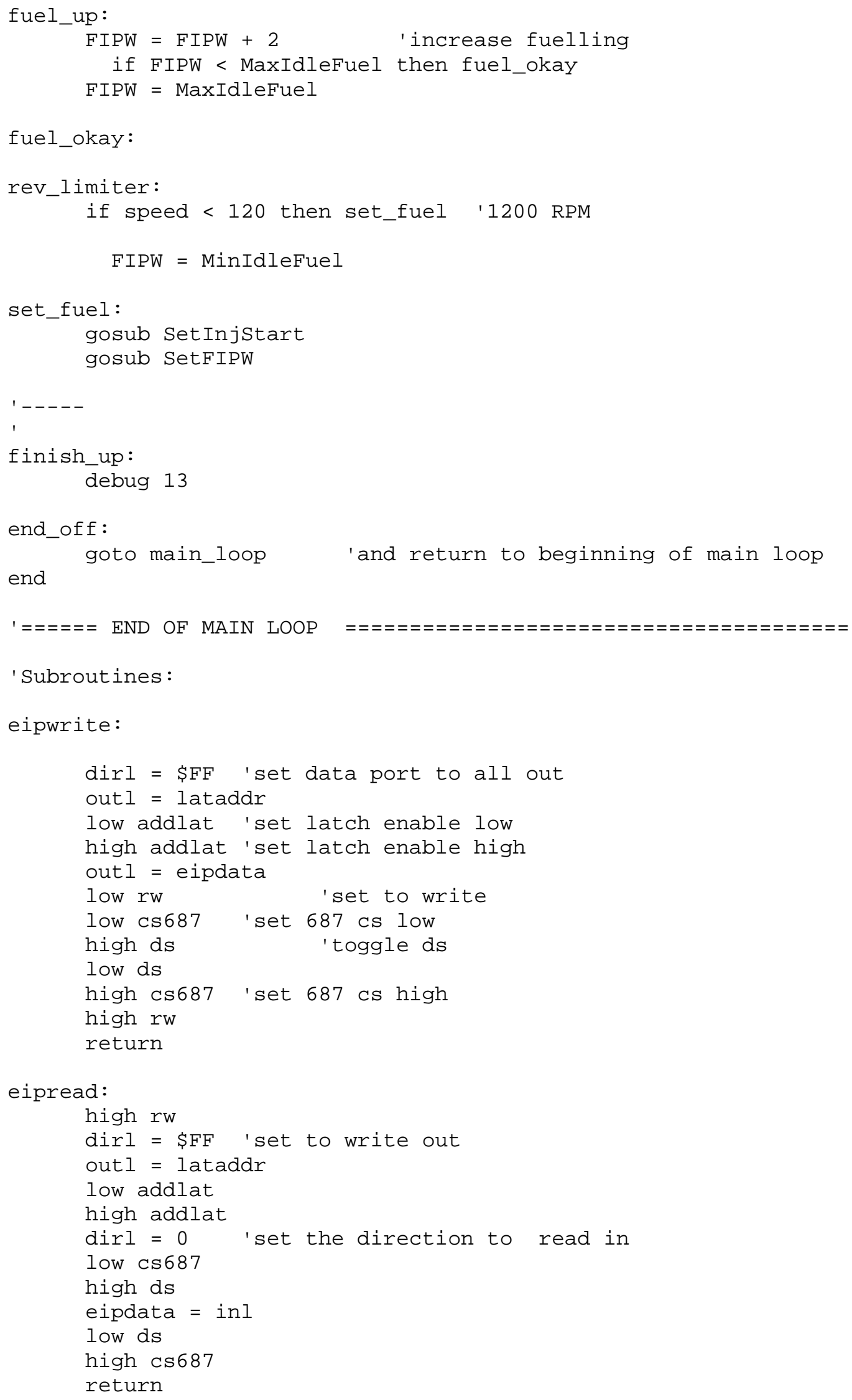




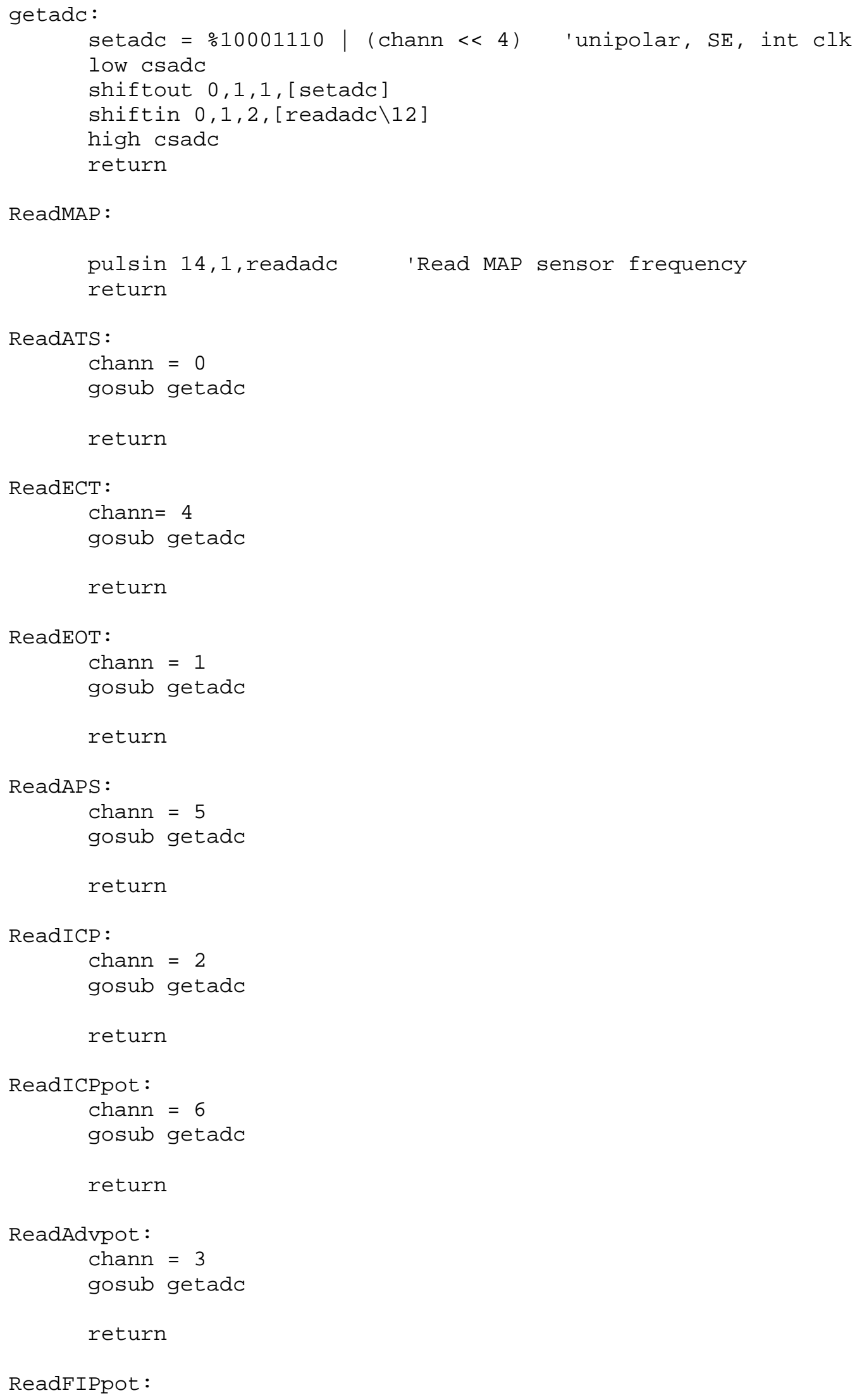




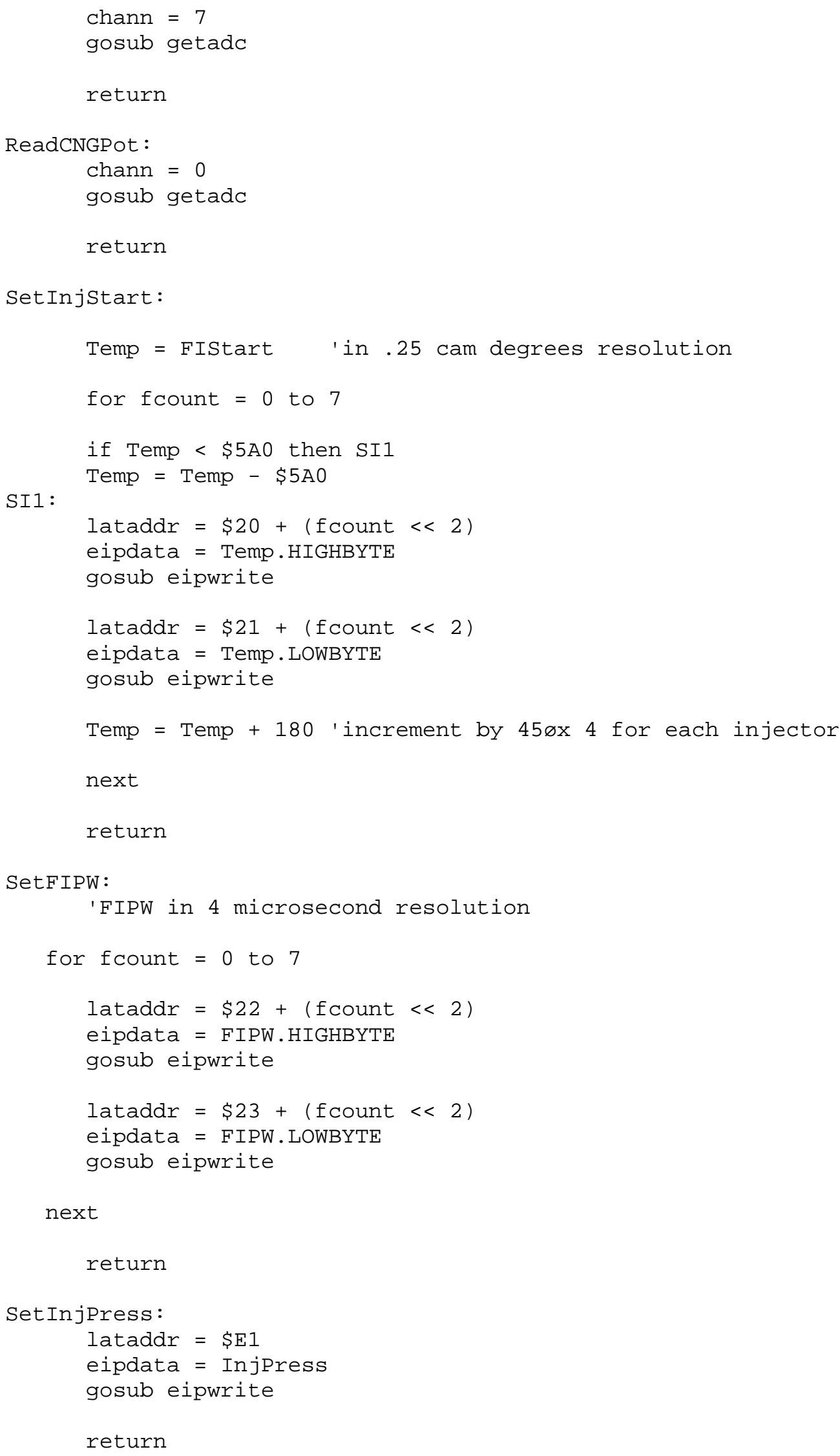

